\title{
The Baloch Movement: a Study of Ethno-nationalist Conflict
}

\author{
by
}

\section{Ali Qasim Khaliq Kareemi}

A thesis submitted to the Faculty of Graduate and Postdoctoral Affairs in partial fulfillment of the requirements for the degree of

Master of Arts

in

Political Economy

Carleton University

Ottawa, Ontario

(C) 2018, Ali Qasim Khaliq Kareemi 


\begin{abstract}
The Baloch movement is a diffuse and splintered ethno-nationalist movement oriented against the Pakistani state and broadly aimed at attaining political autonomy for Baloch peoples. This project traces the history of the Baloch movement, assessing how key variables have played out at local, state and international levels and affected the movement's evolution. A complex Baloch ethnicity built on a fractious tribal social base, a fluctuating supply of resources, broader state and international politics and actors, and a colonial legacy that manifests through a power-centralizing Pakistani state are all key factors that have affected the evolution of the Baloch movement. This project contributes to literature on ethno-nationalist conflict by emphasizing how these factors must be dynamically assessed together at local, state, and international levels in order to explain how ethno-nationalist movements evolve.
\end{abstract}




\section{Acknowledgements}

This project owes much to my thesis supervisor Professor Gopika Solanki.

Professor Solanki’s insightful guidance and unwavering support have been fundamental to this project's success.

I would also like to thank Donna Coghill, Administrator of the Institute of Political Economy, for keeping myself and so many of us students on track. Donna's care and concern for the students in the Institute of Political Economy and her warm demeanour made the institute a wonderful place to learn.

I would also like to thank Professor Cristina Rojas, Professor Jeremy Paltiel, and Professor Richard Mann for their contributions to my education and as members of my thesis committee.

I thank my parents Mani and Fauzia Kareemi, and my partner Ellen Hrinivich (and my pup Zelda) for their unending encouragement as well as their patience and caring support. I also owe thanks to my extended family and my friends who never hesitate to help when they can.

Finally I wish to acknowledge the important role played by my grandparents who played active roles in the birth of Pakistan. Their open discussions of and work in Pakistani politics and society opened my mind to a world of politics at a very young age. That interest has guided me in so many of the directions I have taken in my own life including this project.

Thank you,

Qasim Kareemi 


\section{Table of Contents}

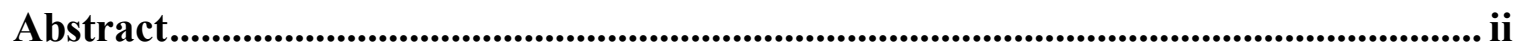

Acknowledgements .............................................................................................................................iii

Table of Contents ........................................................................................................... iv

List of Tables .............................................................................................................................. vi

List of Appendices......................................................................................................................... vii

1 Chapter: Introduction ........................................................................................................... 1

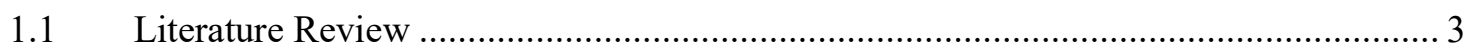

2 Chapter: Analytical Framework ............................................................................ 33

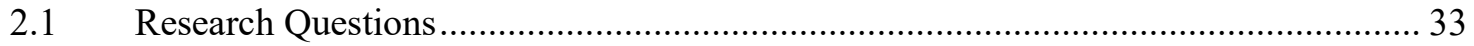

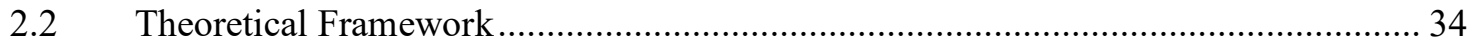

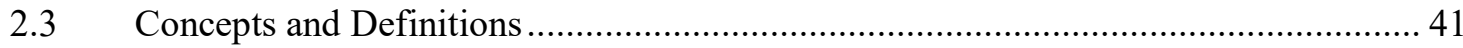

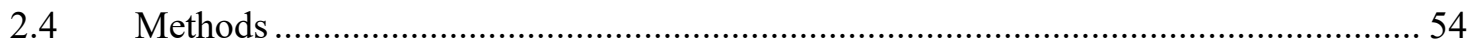

3 Chapter: An Overview of Balochistan ....................................................................... 61

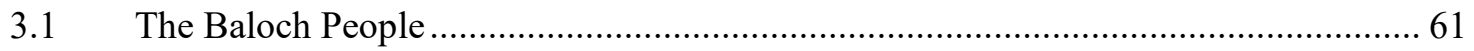

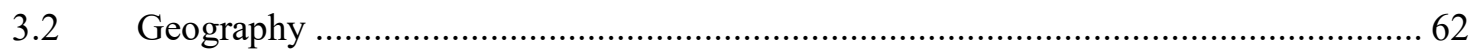

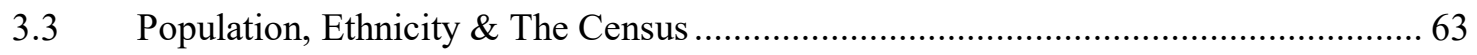

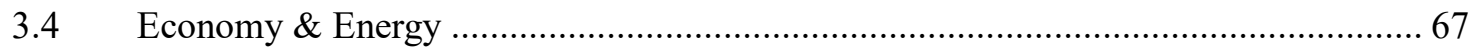

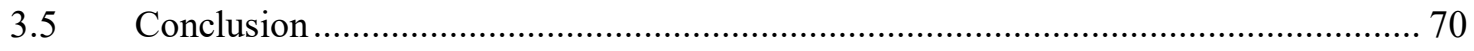

4 Chapter: A History of Conflict ....................................................................... 71

4.1 The Birth of Balochistan: The Khanate of Kalat ...................................................... 71

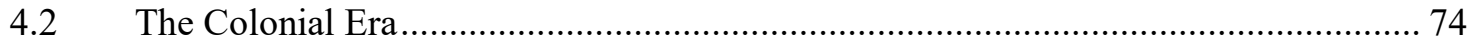

4.3 Pre-Partition Era: The Foundations of Modern Baloch Nationalism .......................... 77

4.4 Accession to Pakistan: The Birth of Pakistan-Baloch conflict .................................. 79 


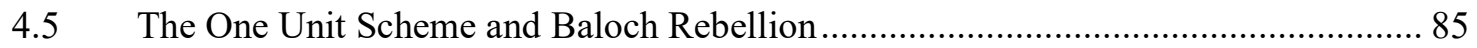

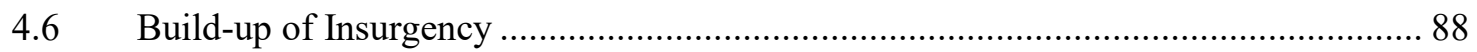

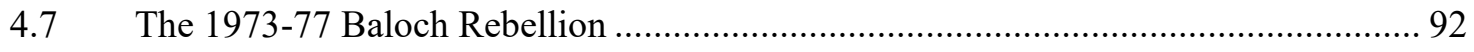

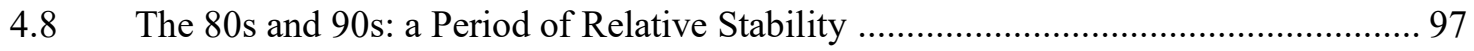

5 Chapter: The Recent Conflict......................................................................... 103

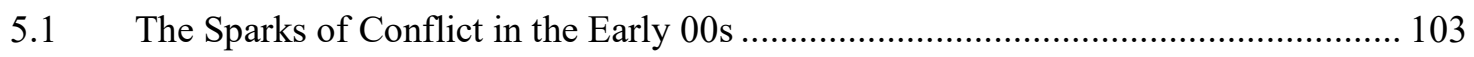

5.2 The Death of Nawab Akbar Bugti: Moderate turned Martyr ................................. 107

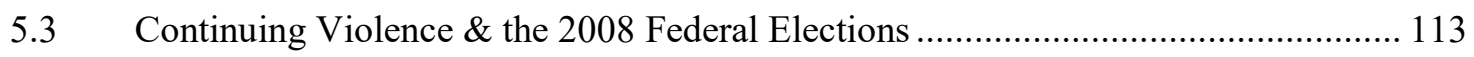

5.4 Federal Government Changes but the Pattern Continues ...................................... 119

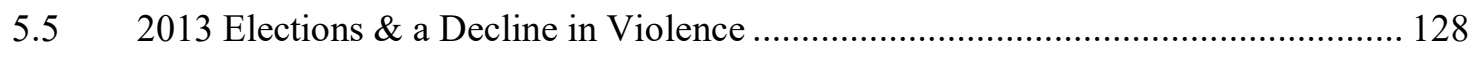

5.6 Revenue-Sharing, Energy Crisis \& the Pak-Iran Pipeline ........................................ 134

5.7 Gwadar Port \& the China-Pakistan Economic Corridor.......................................... 138

5.8 India: A Phantom Menace or an Easy Scapegoat? ............................................. 144

5.9 2018 Elections: Prolonged Civilian Rule and a Prolonged Conflict ......................... 148

6 Chapter: Conclusion ................................................................................................ 152

6.1 Policies \& Prospects: A Separate State or a Seat at the Table ................................. 152

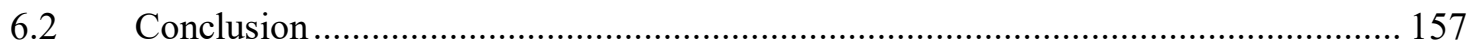

Appendices................................................................................................................................. 162

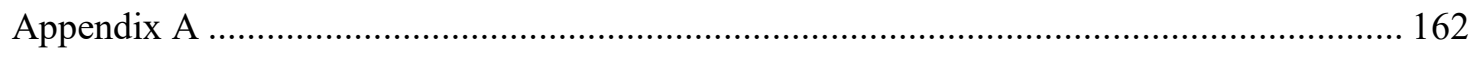

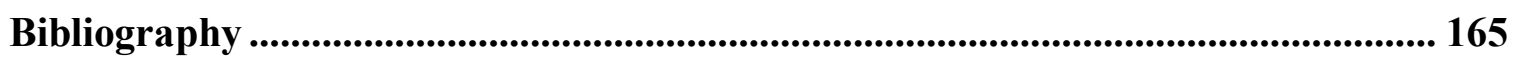




\section{List of Tables}

Table 1: Pakistan versus Balochistan Population (PBS 1998, and PBS 2017)................. 64

Table 2: Percentage of Households by Language Spoken and Areas: 1981 (PBS 1998,

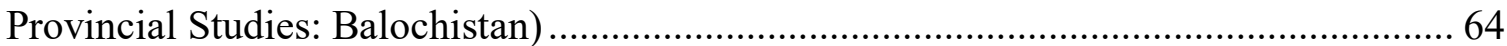




\section{List of Appendices}

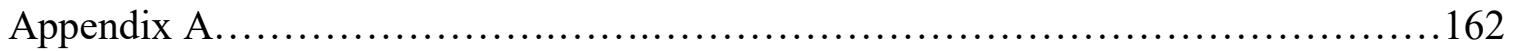




\section{Chapter: Introduction}

The Baloch ethno-nationalist movement can be understood to be a broad and splintered ethno-nationalist movement, made up of many Baloch tribes who often have different aims and methods ranging from active political participation in the federalist Pakistani system to armed guerilla warfare aimed at securing an autonomous and independent state. The movement is broadly built on an idea of Baloch ethnicity, but it is far from a homogeneous movement. A diverse and factious feudal tribal social base, a fluctuating supply of resources, broader state and international politics and actors, and a colonial legacy that manifests through a power-centralizing Pakistani state are all key factors that have affected the evolution of the Baloch movement. The various ways these factors have exercised influence on the Baloch movement can be understood by tracing over the history of conflict in Balochistan.

When assessing these factors on local, state, and international levels, it becomes apparent that the movement has been stronger when there is a wealth of local level support, with Baloch tribal and political leaders pooling resources and coordinating their actions in opposition to the Pakistani state. The centralizing tendencies of Pakistan's federal government have kept it steadily in opposition to the broad Baloch movement, but various tactics by state leaders with short reigns has resulted in an ever-changing nexus of tactics and responses on both sides.

When the British colonial empire gave way to the Pakistani state, colonial practices which put non-Baloch into positions of power in the region continued. As Baloch peoples were pushed out of seats of power in their own region, resentment against 
the state grew. Thus when the Pakistani state acts on a broad agenda against Baloch peoples, it unifies key actors and tribes while furthering the mythos of an ancient Baloch ethnicity being targeted by the state.

The Pakistani state is not homogenous, nor has it featured a history of stable political direction. Accordingly some Pakistani officials and leaders cater to some Baloch by supplying certain tribes with political power or resources. When this happens the Baloch movement splinters internally as those in favour with the state are deemed to have "switched sides".

At the same time the Baloch peoples have widely varying end goals. Many Baloch are happy to be part of the broad federalist project that is Pakistan. Others wish for greater provincial autonomy for Balochistan. On the far end of the spectrum are those who see a separate state as the only guarantee of enduring Baloch livelihood and progress. The disparately populated and varied tribal cultures of the Baloch people undermine prospects for a cohesive movement. Coupled with a scarcity of resources, this makes the possibility of a successful and acute conflict unlikely. It also adds to the complexity of the Pakistani state settling grievances with Baloch peoples.

Support from international actors is key for a steady flow of resources and to exert political pressure on the state. Conversely international support and funding for the Pakistani state, and in particular its military, have bolstered the ability of the state to respond to a steady guerilla bombing campaign, targeting key infrastructure such as gas pipelines and the Gwadar Port Project.

Considering these factors in tandem and assessing them across local, state and international levels, this project finds that the Baloch ethno-nationalist movement has 
never truly dissipated, nor has it ever come close to realizing an autonomous political state controlled by Baloch people. Without significant change both amongst the Baloch and within the Pakistani federal government, a long-standing end to the conflict remains unlikely.

This thesis begins with a literature review to assess the value of relevant theoretical work as well as the field of study concerning Balochistan. Chapter 2 outlines the theoretical framework for this project as well as key concepts and the methodology. The major portion of this thesis consists of three chapters. Chapter 3 provides an overview of Balochistan to set the backdrop of the narrative and analysis of conflict. Chapter 4 broadly outlines the history of Balochistan, focusing particularly on how Baloch tribal leaders have interacted with the British colonial government and the Pakistani federal government that followed. Chapter 5 hones in on the recent conflict, laying out the timeline of the conflict between the Baloch movement and the state as well as the conflict and divisions within the Baloch movement. Chapter 5 concludes with an assessment of how the variables have played out in the context of key economic projects in order to assess how international actors are influencing the region. Chapter 6 concludes the project by offering key policy recommendations to resolve the long-standing conflict.

\subsection{Literature Review}

The literature on Balochistan, such as works by Jalal (1995 \& 2014), Jaffrelot (2014), Siddiqi (2012), and Malik (2013), tends to focus on elites and their decisions in order to explain how and why the Baloch nationalist movements have manifested. 
Authors like Jalal (1995 \& 2014) and Jaffrelot (2014) tend to orient their analyses around the Pakistani state, whereas Siddiqi (2012) and Malik (2013) focus on the movement itself. All of these authors orient their analyses on the historical context of the BalochPakistan relationship. Authors more focused on the ethno-nationalist movement itself group the Baloch as either within the movement or opposed to it. There is little attention or importance given to the complex inter-tribal structures at play amongst the Baloch people. While there is a consistent narrative that posits that the heavy-handed actions by a Pakistani state with power-centralizing tendencies has spurred much of the retaliation by nationalist movements, there is a distinct gap of in-depth analysis into the tribal politics at play. The dearth of historical information on intra-ethnic conflicts in Balochistan and the structure of tribal relations outside of the most powerful few tribes is evidently a gap that will not be able to be filled by the present project.

This thesis begins to fill in gaps in this neglected area of study, focusing analysis on contemporary inter-tribal politics amongst broader national and international politics. This project also assesses the increasing influence of international actors, whose interest in Balochistan is often tied to its wealth of natural resources or its key geopolitical location. This project contributes to literature on Balochistan by focusing on the evolution of the ethno-nationalist movement in tandem with key factors. By assessing these factors at local, state and international levels, the project ties together disparate narratives to give a fuller picture of how the Baloch ethno-nationalist movement has been prevalent in some eras while remaining under the surface at other times.

Literature on ethno-nationalist conflict, such as works by Gurr (2017), Byman (1998), and Brubaker and Laitin (1998), focus on moments where ethno-nationalist 
movements reach their most impactful or violent peaks. Such analyses overlook how the presence of certain factors that led to a movement's surge in popularity or efficacy are also important in explaining the weakening of an ethno-nationalist movement. Other authors, such as Casperson (2008) and Staniland (2012) place more importance on understanding the social, economic, and power dynamics within an ethnic group to understand how a movement evolves. This project contributes to the literature on ethnonationalist conflict by bridging the gaps between these approaches to understanding ethno-nationalist conflict and emphasizing the importance of assessing local level dynamics in tandem with state and international politics in order to explain how an ethnonationalist movement functions.

At its core, this project applies contemporary theories on nationalist and ethnic movements to the most recent conflict in Balochistan. While the available literature sets a well-established historical narrative before a complex and rich theoretical backdrop, much of this project relies on novel research for constructing a narrative to the present conflict due to gaps in the literature.

\subsubsection{Theories of Ethno-Nationalist Conflict}

A core aim for this project is to explain 'ethno-nationalist movements'. Accordingly this literature review begins by assessing the literature on ethno-nationalist conflict. Various theories outline different ways of understanding similar concepts such as 'ethno-political conflict', 'ethno-nationalist movements, 'inter/intra-ethnic conflict', and so on. Although the slightly different terminology may hold significance in other 
cases, here the focus is on explaining these movements' evolution insofar as they are both violent or non-violent.

Gurr's work (2017) on the Minorities at Risk Project has expanded the field of study of ethno-political conflicts and serves as an excellent starting point. Gurr (2017) provides insight about how to define ethno-political conflict and specifies the importance of precisely defining 'ethnicity' in different social contexts. For Gurr (2017) ethnicity is a construct and understanding how that construct appeals to a communal identity is key to understanding how ethnicity is mobilized. His work allows the present project to situate itself within a broader field dedicated to understanding how ethno-political movements function and evolve.

Brubaker and Laitin (1998) use a similar approach to Gurr (2017) by working to integrate theories and studies on ethno-nationalist conflict and political violence. At the time of their writing, those fields were only beginning to integrate and realize their overlaps at an academic level. Brubaker and Laitin provide a particularly useful definition of ethno-nationalist violence by exploring how conflicts "driven by struggles for power between challengers and incumbents are newly ethnicized, newly framed in ethnic terms" (Brubaker and Laitin 1998, 425, 428). The authors survey different works on violence and ethnic violence identifying ways in ethnic violence is fostered. Like Gurr (2017), their work covers a broad scope of theory and identifies useful tools for the present project, particularly the need for a diverse theoretical perspective for a good explanation of specific cultural violence.

Fearon and Laitin's work (2003) builds on these approaches by focusing on civil war. They attempt to determine the factors that cause insurgency by analyzing the factors 
present where civil wars break out. Fearon and Laitin (2003) undermine the common, often assumed, belief that civil wars emerge as a buildup of ethno-nationalist or broad political grievances. They find that conditions that favour insurgency are the main factors determining the prevalence of civil wars during the period 1945 to 1999 (Fearon and Laitin 2003, 75). The authors define insurgency as "a technology of military conflict characterized by small lightly armed bands practicing guerrilla warfare from rural base areas" (Fearon and Laitin 2003, 75). Like Gurr (2017), Fearon and Laitin find that insurgents are usually weak relative to the governments they oppose (2003, 79-80).

Fearon and Laitin (2003) undertake an extensive analysis of civil wars to determine how insurgency is successfully able to gather support and resources from often diverse and disparate populations. Particularly important for an insurgency are "the government's police and military capabilities and the reach of government institutions into rural areas" (Fearon and Laitin 2003, 80). Insurgents prosper when the governments they oppose are weak, specifically "badly financed, organizationally inept, corrupt, politically divided, and poorly informed about goings-on at the local level" (Fearon and Laitin 2003, 80). The authors assert that members of ethnic insurgencies are not necessarily of one mind in terms of either their ultimate ends or the means to achieve those ends. Instead insurgencies may be more focused on short term concerns about outmaneuvering the government as their primary opposition, choosing to use local resources as they are available (Fearon and Laitin 2003, 80). Fearon and Laitin's work (2003) is of major import to this project's theoretical framework as it provides explanations for why insurgencies splinter and why ethnic grievances do not necessarily give rise to organized anti-state movements. 
Byman (1998) explores how ethnic terrorists, as distinct from other types of terrorists, foster communal identity and target moderates in order to draw support for their cause. Byman (1998) focuses on how the dynamics of ethnic terrorists evolve in tandem with state counter-terrorist measures. Byman importantly identifies how state actions can both undermine or bolster radicalism $(1998,160)$. Another important focus of Byman's work is the exploration of identity creation by terrorists as a means to "first create a nation, and from there to attain a state" $(1998,154)$.

Byman's work (1998) is of particular importance for its analysis on the development and tactics of ethnic terrorists. Byman's analysis is particularly focused on the tactics of the insurgents and terrorists. It provides less analysis than Gurr (2017) and Brubaker and Laitin (1998) on broader social and political considerations beyond their effect on the insurgents. Byman's focus on the insurgent perspective is important as it provides insight into why certain courses of action are followed and why some actions trigger support for an insurgent group where others undermine it.

Kydd and Walter (2002) also analyze terrorism, but focus on explaining how terrorist violence undermines the effectiveness of peace negotiations without any particular discussion of ethnicity. Kydd and Walter (2002) develop a game theory model to analyze terrorist violence as a problem of mistrust between moderates and extremists on one side with governments on the other. For the authors, peace processes are disrupted when the violence fosters mistrust between moderate groups (Kydd and Walter 2002, 264). Their rational choice model, although insightful within its context, assumes governments to be open rather deceitful and peaceful rather than warmongering. This an assumption this project does not make (Kydd and Walter 2002, 266). The assumed 
homogeneity of actors on either side of Kydd and Walter's (2002) game theory model does not reflect actors involved on either side of the Baloch ethno-nationalist movement. Moreover their approach fails to explain the broader contexts around the conflicts that lead to peace negotiations, or to address the motivations of terrorists.

A markedly different approach from the above authors comes from Kaufman (2006). Kaufman (2006) reviews theories of ethno-nationalist conflict, testing social psychological theories against rational choice theories. Kaufman (2006) is critical of rational choice theories as being satisfactory for explaining how ethno-nationalist movements and conflict both arise and unfold. In a study of Sudan and Rwanda, Kaufman finds that powerfully hostile mass attitudes "created a context for leaders in which predatory policy was more popular than moderate policy; and the hostile narratives provided a symbolic vocabulary that the leaders used as tools to mobilize support" (2006, 48). For Kaufman, a symbolist model holds more explanatory power for understanding why individuals participated in ethno-nationalist movements or ethno-nationalist conflict (2006, 50-1). The predictable loss of power for elites and often deadly consequences for individuals involved undermine rational choice explanations. Instead Kaufman finds that "group fears and myths" play an important factor in mobilizing individuals as members of the ethnic group $(2006,48)$.

Kaufman's work (2006) is particularly useful for its symbolist model of ethnic war and genocide. Balancing the symbolist approach with rational choice theories allows Kaufman to deepen the analytical scope into ethnic conflicts by looking at variables such as group fears and myths. These variables are often overlooked in rational choice models. 
Kaufman (2006) helps balance the theoretical model of the present project by offering powerful explanations of the symbolic nature of ethnicity and ethno-nationalist conflict.

The approaches of the above authors vary to a significant degree, but they inform case analyses of ethno-nationalism by providing rich theoretical elaborations on ethnicity and conflict. In the context of Pakistan, these approaches inform narratives that pit the state in opposition to regional ethnicities.

\subsubsection{Federalism and Nationalism in the Pakistani Context}

Literature informed by the above theories commonly assesses Pakistan as a splintered nation, comprised by many ethnic groups who are vying for a share of power in a fractious federalist system. Authors such as Jalal (1995 and 2014) and Jaffrelot (2014) model their state-centric analyses around a concept of a "Pakistani" nation, drawing from contemporary theories of ethno-nationalism to explain how ethnonationalist conflict continues to plague Pakistan.

Jalal's work The Struggle for Pakistan (2014) and Democracy and Authoritarianism in South Asia (1995) assess the evolution of Pakistan. Jalal's works assess the project of nation-building in Pakistan predominantly at the state level. Democracy and Authoritarianism in South Asia (Jalal 2014) compares Pakistan, Bangladesh and India's development to assess how democratic politics and authoritarianism have shaped these countries in different ways despite a shared colonial past. Jalal distinguishes between formal and substantive democracies, arguing that covert authoritarianism disrupts democratic processes that would truly empower the people 
(Jalal 1995, 3). Jalal's work looks at domestic, regional and international factors, however only really assessing their impact at a state level.

An important contribution Jalal (1995) makes is her analysis of the colonial legacy and state construction. For Jalal "the post-independence adaptations of the colonial concept of the centre, both in its institutional and ideological manifestations" explain how state construction resulted in a functioning parliamentary democracy in India and an almost absent one in Pakistan (Jalal 1995, 6). Jalal points to the dominance of certain social groups and their takeover of a formerly colonial administration to explain how these structures were bolstered by the new state. When these state structures interact with the diverse ethnicities across Pakistan, Jalal argued that overly coercive use of power was used to mask a weak central state (Jalal 1995, 157). For Jalal the volatility of ethnic divisions in Pakistan have been shifted and refashioned in response to the central state structures and political economies (Jalal 1995, 183).

Jalal's work (1995) seems largely informed by the above authors on ethnonationalism. Jalal's (1995) argument essentially places the onus on the Pakistani state, arguing that ethnicity alone is not enough to create conflict. What is further necessary is a state with certain tendencies that allow those within an ethnic group to unify around their alienation. Jalal's (1995) work orients itself around explaining the failures Pakistani federalism, so it focuses on state-level elites, often neglecting to emphasize the role of elites or culture amongst the ethnic groups.

In The Struggle for Pakistan Jalal (2014) focuses directly on Pakistani federalism. This book also examines some dynamics within the ethno-nationalist movements more explicitly than Democracy and Authoritarianism in South Asia, but never particularly 
extensively. For Jalal (2014) the focus is on explaining a weak Pakistani democracy rather than investigating the movements themselves. As such her analysis of, for example, the Baloch movement is limited and oriented around explaining how the movement responded to and disrupted Pakistani federalism.

Jalal's work (2014) stands as valuable and insightful research on Pakistan's complex evolution, but its focus on state level analysis narrows its scope significantly. That is understandably normal in the literature on Pakistan. For a country with many cultural and ethnic groups within it, assessing Pakistan's federalism and associated nationalism invariably asks authors to eschew in-depth analyses of those ethnic groups.

Jaffrelot's extensive work The Pakistan Paradox: Instability and Resilience (Jaffrelot 2014) delves into the question of Pakistan's nationalist identity and its paradoxical oscillations between instability and progress. Situating his work as at least in part a continuation of the work of Hamza Alavi and Paul Brass before him, Jaffrelot notes that his work is "less Marxist than Alavi's reading and less instrumentalist than Brass' interpretation for the simple reason that it emphasizes the weight of the cultural and societal parameters that defined the mentality of the Muslim elite during the Raj" (2014, 10). There is a lot of Jalal's approach in Jaffrelot (2014), with a focus on state level analysis to explain an ailing federation.

Jaffrelot's underlying thesis is that three "sets of tensions" and paradoxes have held the greatest impact on Pakistan's historical trajectory $(2014,10)$. The first is that Pakistan's national identity could be simply summed by reference to Islam and Urdu. For Jaffrelot the elites who birthed Pakistan tried to give it a national identity in a way that undermined the inherent linguistic, cultural and spiritual diversity in the region (Jaffrelot 
2014, 15). The second tension ties into the exercise of power by the civilian and military branches of government. The early institutional relationship between the Pakistani military and the federal civilian government for Jaffrelot undermined the few wellintentioned efforts at democratic reform, resulting in a history of military coups and short-lived elected governments $(2014,16)$. The third tension pertains to the religious identity inherent in Pakistan's creation. Jaffrelot reads Jinnah's understanding of Islam in Pakistan as a culture that needed protection from an Indian Hindu majority $(2014,16)$. This understanding sits in opposition to the fundamentalist views that Pakistan is a country for Muslims where all other practices are to be prohibited or at least suppressed. At the core of these tensions and paradoxes is an identity born out of a split from its Hindu (Indian) counterpart. Jaffrelot's work (2014) investigates these tensions by recounting the history and pointing out key decisions that have perpetuated these tensions rather than resolving them.

While the Pakistan Paradox is thoughtful and presents a great deal of contextual support for many of its determinations, Jaffrelot (2014) may overemphasize the role of the elites in perpetuating Pakistan's problems. He gives due credence to cultural and religious differences but does not focus on how those differences may be inherently at odds with each other in a way that could stack the odds against a unified identity in Pakistan. Nor does he thoroughly analyze the structural impediments to a balanced federalism in Pakistan. His inclination to refer back to a diffuse cultural makeup for the country is sometimes at odds with his analysis which centers on the main wheels of the political establishment, focusing more on the decisions of key players rather than the broader cultural context that may inform them. However, his work is an exercise in 
historical analysis of Pakistan's entire history. As such it focuses on the big moments and the key factors to the decisions in those moments, overlooking extensive analysis of any particular moment for a broader narrative.

For the purposes of the present work, Jaffrelot (2014) and Jalal (1995 and 2014) provide broad contextual insights into the history between Pakistan's federal government and Balochistan. They identify key moments and decisions in that relationship. Their analyses favour discussing those big moments as they developed Pakistan's central government rather than how they were influenced by grassroots movements in Balochistan. As such Jalal (1995 \& 2014) and Jaffrelot (2014) provide well-researched historical narratives on Pakistani federalism, but cultural and underlying causes or events in regional politics take a back seat to the broader narratives that sit at the core of their work.

\subsubsection{Ethnicity in the Pakistani Context}

Where authors such as Jaffrelot (2014) and Jalal (1995 \& 2014) focus on the impacts of ethnicity and nationalism on the Pakistani state as a whole, Akhtar (2011) Siddiqi (2012) and Khan (2005) focus their analysis on the ethno-nationalist movements themselves. Akhtar (2011), Siddiqi (2012) and Khan (2005) also put the Pakistani state in opposition to the ethno-nationalist movements, but their analyses focus on how ethnonationalist movements have adapted and responded to a Pakistani state that aims to centralize power.

Nasreen Akhtar (2011) moves through the history of Baloch nationalism as it has evolved in tandem with Pakistani state actions. Akhtar (2011) argues that the key issue is 
a lack of integration of Baloch ethnicity into the national power structures. The central government's unwillingness to give up "any measure of cultural and political autonomy have now turned against the Pakistani state" (Akhtar 2011, 126). Akhtar sees the centralising tendencies of the modern Pakistani state as a continuation of the colonial legacy left behind by the British $(2011,127)$.

Akhtar (2011) traces over the major conflicts raised by Baloch nationalists, emphasizing how control over resource extraction and development in the region has continued to bolster nationalist sentiment. Akhtar (2011) also introduces the "Balochistan Package" and the proposed $18^{\text {th }}$ Amendment to the 1973 Constitution as efforts by the Pakistani state to transition to a more balanced model of federalism that better integrates regional and ethnic differences.

Akhtar (2011) approaches Baloch nationalism from a perspective aimed at finding stability and security in Pakistan generally. Where Akhtar (2011) lacks deep investigation into the Baloch nationalist movements themselves, it brings information about the broader issues of federalism that plague Pakistan's history. As such Akhtar does well to note how "external forces also play a major role in promoting separatist ethnic identity in multi-ethnic and multinational states" (2011, 132). As such Akhtar (2011) serves as a useful resource that balances a multitude of perspectives and provides good insight into the major external factors that are at play in regards to Baloch nationalism.

Khan (2005) follows a similar approach to Akhtar (2011), by focusing on how the Pakistani state has operated in tandem with ethno-nationalist movements. For Khan, "the interventionist nature of the modern state and its penetration of almost every aspect of individual life make it a focal point of all struggles" (Khan 2005, 29). Khan thus begins 
by exploring how the modern Pakistani state came to be and how that state exercises power. From there Khan goes on to explore Pashtun, Baloch, Sindhi and Muhajir ethnic movements individually.

Khan's view of the modern governmental state is sourced from Foucault's theories on governmentality $(2005,26)$. This informs his critical perspective of the modern state as an actor that centralizes power and "prefers to have one language, one culture and one nation, and every citizen is included for the attainment of homogeneity and unity of the nation" (Khan 2005, 36). Similarly, Khan (2005) sources his own perspective on ethnicity and nationalism in the works of modern nationalist scholars Benedict Anderson and Ernest Gellner. Khan identifies two key types of nationalism, state nationalism and ethnic nationalism, which work against each other in contemporary Pakistan $(2005,38)$. The social foundations of ethnic nationalism and its reactionary responsiveness to oppression by state nationalism serves as the underlying dynamic Khan explores through his work.

Khan's work (2005) is important for this project both for his critical elaborations on theories about the modern state and nationalism, as well as his thoughtfully constructed narrative on Baloch nationalism. Khan's (2005) exploration of the fragmented federalism that has typified Pakistan's history in the early chapters of the book is fundamental to his analysis of the Baloch nationalist movements. For Khan, "nationalism is always either about share in the existing state power structure, or, if that is not possible, about creating its own state" $(2005,109)$. Thus Khan (2005) surveys the pre-partition history of Baloch nationalism, honing in on the British colonial administration's efforts to play tribal chiefs in the region against each other in order to 
maintain power. For Khan the post-partition Pakistani state continued colonial era tactics causing Baloch nationalism to further develop as a response to the intervention of the state $(2005,114)$. He traces the history of conflict between Baloch nationalists and Pakistan's federal government focusing on the reactionary nature of the nationalists. At times he references the tribal and ethnic segmentation within the Baloch movements, but often eschews a deeper analysis of these issues in favour of a broader focus on the conflict between the Pakistani state and Balochis.

Khan's work was published in 2005 meaning his analysis foregoes any application of his theories to the latest conflict between Balochistan and the Pakistani state. Furthermore his analysis of the Baloch nationalist movements is cursory and while it provides a solid application of his theoretical framework, it lacks extensive explanatory power and insight into the internal dynamics of the Baloch nationalist movements themselves. As such Khan's insightful book (2015) is of particular use for its elaborations on relevant theories of ethnicity, nationalism and the modern postcolonial state as well as its concise historical analysis of Baloch nationalism.

Farhan Siddiqi's The Politics of Ethnicity in Pakistan: The Baloch, Sindhi and Muhajir ethnic movements (Siddiqi 2012) undertakes an analysis of ethnic politics in Pakistan, focusing on Balochi, Sindhi and Muhajir ethnic movements. Siddiqi's work (2012) focuses on theories of ethnicity, nationalism and the state in order to explain the evolution of these ethno-nationalist movements. The first substantive chapter assesses the nature of these theories, their weaknesses and their strengths in order to build a conversation about the theories. The theories' explanatory power is elaborated on further 
in subsequent chapters which focus on Pakistan's history broadly and then on each ethnonationalist movement.

In regards to the Baloch ethno-nationalist movements, Siddiqi (2012) traces the historic roots of Baloch nationalism to the Khanate of Kalat and assesses the evolution of the movement from there. While his analysis does not extend to the most recent Baloch conflict, it serves as an excellent application of his theory to the early Baloch movements in Pakistan's history. A unique contribution from Siddiqi (2012) is his emphasis on the importance of intra-ethnic conflict within Baloch nationalist movements.

Siddiqi's work (2012) is particularly important for this project for its theoretical contributions to the field. His handling of modern theories on nationalism in a postcolonial context illustrates that some of the key variables identified in those theories do not serve to adequately explain how ethno-nationalist movements in Pakistan have manifested. An important lesson Siddiqi draws from the work of Fearon and Laitin (2003) is that "the mere presence of ethnic heterogeneity does not in essence produce ethnic conflict between dominant and non-dominant ethnic communities" (Siddiqi 2012, 4). This assertion is fundamental to the theoretical grounding of the present work which aims to explore nationality and ethnicity not as inherently in conflict but as something which can be used, by elites generally, to foment or quell conflict depending on the socio-political context.

Siddiqi's work (2012) is in essence a broad investigation into these ethnonationalist movements but the period of analysis, especially in regards to the Baloch movement, is peculiarly dated. As such the great strength of the theoretical framework he builds is weakened by a narrow historical exploration for each movement. In bringing his 
work into the more contemporary analysis of the current project, fine-tuning of his theory helps expand on the explanatory power of his framework.

An important example of this is in Siddiqi's (2012) emphasis that intra-ethnic conflict can be as present and conflict ridden as inter-ethnic conflict. Where the Baloch movement has at moments found great unity, any one specific movement generally has not garnered unified support from the entire populace that might be considered Balochi. Moreover, the inability of any one Baloch leader to maintain their position at the head of the calls for either a separate Balochistan or a more autonomous Baloch province suggests that there are powerful dynamics at play within the Baloch ethnic group.

Siddiqi’s work (2012) provides a nuanced and insightful discussion of relevant theories which greatly aids the framework established in this project. In large part the present project's focus on the contemporary Baloch movement requires re-evaluation of the effectiveness of Siddiqi's theoretical analysis in order to expand on the timeframe within which it is applied. Siddiqi’s (2012) emphasis on the impact of intra-ethnic conflict on ethno-nationalist movements is shared by authors such as Casperson (2008), Staniland (2012), and Cunningham (2011).

\subsubsection{Theories of Ethno-nationalist Movements as Heterogenous}

Analyses of ethno-nationalist conflict, such as Brubaker and Laitin (1998), Jalal

(2014) and Jaffrelot (2014), often homogenize the ethnic group in question, overlooking their internal dynamics and representing their motivations predominantly by the actions of movement leaders. Instead, Casperson's work (2008) focuses directly on intraethnic rivalry and conflict within nationalist or ethnic movements. Although Casperson's (2008) 
selection of cases differ significantly from the case of the Baluch movements, the analysis of the internal dynamic of ethno-nationalist movements is of acute importance to the present project.

Understanding how movements splinter, unify, adapt and evolve internally is fundamental to assessing how they evolve in tandem with state and international factors. Casperson (2008) explains how elites rival each other for leadership within groups, how in-group ethnic audiences may support different leaders for various reasons and how these rivalries affect movements. For Casperson (2008) these intraethnic rivalries affect resource-sharing arrangements, and the supply and prevalence of resources, whether monetary or military, is fundamental to the evolution of the broader ethno-nationalist movement. Casperson argues that the central forces "driving intraethnic rivalry, and hence influencing the positions adopted by ethnic leaders, can be analysed in terms of resources and the audiences to which the rivaling elites appeal" $(2008,242)$.

From Casperson we can understand that analysing intraethnic divisions allows us to assess elite interests and elite politics in tandem with popular attitudes, "without having to rely on overly simplified, static categories" $(2008,242)$. Although there is a dearth of adequate information and data about in-group dynamics in Baluchistan, Casperson's work provides valuable tools and insight that can draw explanatory power out of what data there is.

Staniland (2012) adds another perspective on the significance of resources and internal social and political dynamics to ethno-nationalist movements. Staniland (2012) assesses how resource flows affect organizational form and behaviour in insurgent groups alongside social foundations. Staniland (2012) develops a social-institutional theory, 
arguing that the foundational social base of a group is built upon and reconfigured by insurgent networks. Staniland finds that "the structure of pre-existing social networks upon which an armed group is built determines the organizational integration or fragmentation of the group. Social ties establish how and when robust institutions can be built" $(2012,142)$.

Staniland (2012) explains how organizational structure determines the impact that resource endowments have on discipline and behaviour, as opposed to economic and resource support being determinative of a networks ability to function effectively. Staniland finds that in the short term a wealth of resources can help to hold together an otherwise loose coalition, but "over time they can exacerbate pre-existing conflicts over control and distribution that lead to unrest and indiscipline within the group" $(2012,151)$. Staniland's work (2012) also contributes a useful case study on Kashmir and offers guiding insight for the present project through its assessment of insurgent networks and resource management.

Similar to Staniland (2012), Cunningham (2011) focuses on internal divisions within an ethnic group, however Cunningham's focus is on self-determination networks rather than insurgent networks and resource flows. Cunningham (2011) looks at internal divisions within self-determination movements from a state perspective, assessing how states from a randomized sample group respond to separatist movements. Cunningham finds that, in regards to what she terms 'self-determination movements', that only $36 \%$ of these movements "remain unified during most of their interaction with the state" (Cunningham 2011, 280). For Cunningham (2011), internally divided movements are more likely to get state concessions than more unitary movements. Importantly 
Cunningham (2011) notes that the state can externally influence these internal dynamics by offering concessions to certain groups or to segments of the group in order to divide them.

Cunningham's work (2011) is useful for its assessment of state responses and their effect on separatist movements. In this way Cunningham (2011) helps push a more dynamic understanding of the state-separatist relationship across local and state levels, explaining how state actions are affected by a movement's internal structure and how those actions in turn affect that structure.

Kalyvas (2003) further bridges the gaps between the local, state, and international level by emphasizing the complexity of analyzing conflict by looking at "microfoundations of cleavage" based on the interplay between identity and actions at the center and the periphery of ethno-nationalist movements. For Kalyvas (2003) the complexity of kinship on the local level can undermine what seems from afar to be clear class or ethnic distinctions. These local cleavages are not determinative but they affect the overall movement. Kalyvas finds that conflict arising from the complexities of kinship ties and cleavages at the local level are often mistaken as part of the broader pattern of conflict (Kalyvas 2003).

In a study focusing on civil wars, Kalyvas finds a "disjunction between identities and actions at the central or elite level, on the one hand, and the local or mass level, on the other" $(2003,475)$. The civil war context is generally a broader context of violence in terms of actors, movements, and scale than a single ethno-nationalist movement, but Kalyvas' finding on the relationship between identity and action are still useful for understanding a general relationship between local level cleavages, identity and conflict 
(2003). Kalyvas (2003) thus provides insight into why assessing cleavages at the local

level is fundamental to understanding how ethno-nationalist movements are affected by factors at state and international levels.

Contrasted with the theoretical approaches of Staniland (2012), Casperson (2008) and Kalyvas (2003), it is evident the approaches taken by Khan (2005), Jaffrelot (2014) and Jalal (1995 and 2014) can benefit from a deeper look into the splits within any broadly termed Baloch ethno-nationalist movement. Explaining the evolution of an ethno-nationalist movement without analysis into the ethnic group's internal social cleavages, politics and resources leaves unsatisfactory explanations about why the movements have grown or diminished. Besides Siddiqi (2012), there are some studies that have successfully employed a more detailed look into the internal workings of the Baloch ethno-nationalist movement.

\subsubsection{Heterogeneity within the Baloch Ethno-nationalist Movement}

Generally literature that is successful at illuminating cleavages within Baloch peoples focus on Balochistan, rather than centering the analysis around Pakistani federalism. The focus on Balochistan gives insight into the resource and political issues at play within the region that shape its broader interactions on the state and international levels.

Conflict and Insecurity in Balochistan is a report by the Pak Institute for Peace Studies (PIPS 2012). As opposed to being theoretically grounded or motivated to assert a specific position, the report is oriented around identifying sources of conflict and 
insecurity within Balochistan. It largely glosses over the history of the region and focuses more on providing a well-rounded overview of the contemporary conflict.

PIPS (2012) assesses key factors of conflict by identifying geographical, political, economic, social and security issues and then delving into an analysis of major actors in the ongoing conflicts. These include nationalist insurgents, sectarian groups, political parties as well as some smaller actors throughout Balochistan. Where PIPS (2012) assesses conflict between Baloch and Pakistani actors, it tries to balance its assessment by exploring how various factors and actors intersect and diverge.

By situating the conflict at a more local level within broader conflicts at the state level, PIPS (2012) gives a balanced and insightful picture of contemporary Balochistan. It is also notable that the report (PIPS 2012) is largely critical of the elites in both the federal and provincial governments in an offhand manner that situates itself well in the context of most academic studies on the region.

PIPS (2012) fills a large information gap in much of the existing literature which largely focuses on the historical aspects of Baloch nationalism. As it is well-sourced the report has proved a useful reference resource for further research as well as particularly informative in and of itself. The report (PIPS 2012) does not make any explicit reference to theories that emphasize the importance of internal cleavages or social bases, however it does focus on some key actors at the provincial level and within some of the more prominent Baloch tribes. This stands in contrast to many sources, including news sources, which blur or ignore the lines between these actors in favour of larger overarching narratives. 
Maria Malik's book Baluchistan Conundrum: The Real Perspective (2013) similarly benefits from a dedicated focus on Balochistan as a region. Like Jaffrelot (2014) and Khan (2005), Malik (2013) draws lessons from historical conflicts between Balochistan and the central government of Pakistan in order to assess routes for better conflict resolution in relation to the contemporary movements for autonomy and independence in the region. Malik's (2013) analysis includes more in-depth looks at the cleavages within Baloch ethno-nationalist movements, giving more insight into the dynamics below the surface of past conflicts.

Malik grounds her work in modern theories of nationalism that look at how ethnicity and territorial borders help define nationality for a given group $(2013,39)$. She couples this with an emphasis on theories of insurgency and conflict in order to assess how social and political inequalities tie in with feelings of ethnicity and nationalism in order to create an environment of protracted conflict (Malik 2013, 49).

Looking into the history of Balochistan, Malik (2013) identifies moments where modern Baloch nationalist sentiment is often sourced while also identifying how the relationships between Baloch tribes, their ruling elites, and larger regional powers evolved in tandem with nationalist movements. Malik (2013) finds that the history of Baloch conflict in Pakistan tells a tale of resurgent and unresolved conflicts. "The use of brute military force to crush the uprisings made the Baloch nationalists stop for a while but they came back with more strength in number and organization every time" (Malik 2013, 102). For Malik (2013) the unresolved nature of the previous conflicts lays a foundation of unrest upon which the contemporary conflicts are built. 
Malik (2013) sources the contemporary conflict in Balochistan in the early 2000s. Malik (2013) argues that federal action against Baloch elites sparked insurgency. Heavyhanded responses by the central federal government of Pakistan led to further violence. Meanwhile continuing socio-economic regional disparities, especially in regards to the extraction of natural gas from Balochistan and the Gwadar Port, fueled civil unrest. Malik (2013) puts an emphasis on federal government actions that could quell nationalist sentiments by giving Balochistan greater political and provincial autonomy especially in regards to controlling the resources which make the region particularly valuable to foreign interests and the rest of Pakistan.

Malik's chapter (2013) on the recent conflict is of particular importance for this research project. Malik (2013) identifies key political leaders while pinpointing key issues felt by the Baloch populace. She balances a discussion of elite politics with inquiries into what ongoing socio-economic and cultural factors motivate the nationalist movements in Balochistan. Malik's (2013) layout and theoretical grounding is also similar to that of this project and it should be considered that much of the novel research in the present project aims to compound, verify and update much of the original research in Malik's text in regards to the contemporary conflict between Balochistan and Pakistan's federal government.

Malik's work (2013) stands as an excellent discussion of the continuing conflict between Balochistan and the rest of Pakistan. While areas of the text suffer from ambiguity as to her theoretical background, Malik's (2013) tempered investigation into the key sources of conflict make the text a valuable resource for the current project. Her focus on the more recent conflict makes her work more relevant than many other 
investigations into the issue which focus heavily on the historic roots of the conflict (Malik 2013).

Surendra (2009) builds on the grievance-based approached used by authors like Casperson (2008), drawing in an important theoretical perspective into the literature on Balochistan via a useful case study comparing Balochistan to Azad Kashmir. Arguing against predominantly grievance-based explanations of social mobilization, Surendra (2009) advocates opportunity-based explanations for why certain ethnic or nationalist groups mobilize. Surendra (2009) traces the histories of both regions before pinpointing specific opportunities that spurred social mobilization in Balochistan as opposed to Azad Kashmir, despite strong similarities in their relationships with the Pakistani state.

It is important to acknowledge that Surendra (2009) does not see opportunitybased explanations as a solely explanatory. For Surendra (2009) what is key is that grievance-based explanations do little to articulate why Azad Kashmir has not seen the same kind of social and ethno-nationalist mobilization and conflict between the Pakistani state and Balochistan. In particular Surendra's (2009) exploration draws in a particularly useful explanation of why there was a nearly thirty-year gap in violent conflict between Baloch nationalists and the Pakistani state.

Assessing the cleavages within the Baloch movement is key to explaining how the movement has evolved. By building on the approaches of authors like Surendra (2009) and Malik (2013), this project aims to delve deeper into local level dynamics within the Baloch ethno-nationalist movement to explain its evolution. 


\subsubsection{International Actors and Perspectives}

The literature referenced above illustrates how studies of the Baloch movement tend to focus on state and local level actors and variables. However, in an increasingly globalized world, assessing the Baloch ethno-nationalist movement requires understanding how international factors and actors affect the movement. This relates to the security and conflict, resource extraction, and geopolitical location. One dimension of this is taken up by authors, like Chadda (2009) and Jaffrelot (2014), who focus on understanding the security concerns of major actors like the US, who have been a longstanding key supporter of Pakistan's military.

Chadda (2009) gives a broad picture of Sindhi, Muhajir, Baloch and Pashtun ethno-nationalist movements and related conflict in Pakistan from an international perspective. Chadda (2009) focuses on how a stable Pakistan that will quell US and international security concerns will have to do more than simply focus on strengthening democratic institutions. Chadda (2009) argues that the federalist foundations of the original constitution have been undermined by power hungry elites and the constant disruption of civilian rule by military coups. For Chadda the core issue for stability in Pakistan is balancing the concerns of the ethnic and regional actors within the country via a revitalized federal mandate $(2009,249)$.

Chadda's (2009) very brief exploration of Baloch politics is particularly reflective of international insights into Pakistani stability which are invariably forced to gloss over the specifics of the otherwise complex ethno-nationalist movements within Pakistan. While there is an acknowledgement of some internal complexity to the situation, the lesson is that the federal government of Pakistan is the primary actor that must change its 
own inner workings in order to quell ethnic unrest. While this may not serve to elucidate much on the specific conflicts within Balochistan, Chadda's article (2009) presents a distinctly US and security focused perspective that reflects the external perspective that domestic actors within Pakistan are accustomed too.

Chadda (2009) explains why the US and the international community will continue to support a federalist Pakistani state rather than support separatist or nationalist movements. While this project hones in on one nationalist movement in particular, it is imperative not to forget the international context within which any such movement operates. The pressure for a federalist Pakistani state that can ensure stability within all its regions illustrates why Baloch nationalists will not be able to look far beyond the borders of their region for support for their movements. Chadda (2009) also helps us to understand how authors like Jaffrelot (2014) and Jalal (2014) contextualize Pakistani politics in relation to the US.

Jaffrelot (2014) builds a strong narrative about Pakistan's clientelistic relationship with the US through his book. In particular Jaffrelot is critical of the Pakistan-US relationship because it has spared the state from having to implement sound economic and fiscal policies and because it has eroded Pakistani sovereignty $(2014,641)$. Jalal is similarly critical of US military policy which has often overtaken domestic Pakistani concerns in the interest of furthering US policy $(2014,386)$. Both authors find that continuing instability in Pakistan internal state-regional relations has been exacerbated by a federal government that has continued to rely on funding from the US. Malik also reinforces these perspectives, arguing that the dominance of US security policy in Pakistan further alienated the Baloch, and in particular Baloch moderates $(2013,153)$. 
Malik found that some Baloch believe that the US purposely destabilized economically valuable Balochistan in order to undermine a growing economic rivalry with China (2013, 154). Historical literature on Pakistan invariably includes elaborations on US relations, but the contemporary narratives by authors such as Jalal (2014), Jaffrelot (2014), and Malik (2013) suggest that the clientelist Pakistan-US relationship is steadily being replaced by a clientelist Pakistan-China relationship.

Writing in 2014 and in the context of the prolonged US withdrawal from Afghanistan and the War on Terror, Jaffrelot notes that Saudi Arabia and China are the most likely actors to take on the vacant clientelist role that the US held for so long (2014, 642). Jalal argues that from the late 1990 s onwards India began to see China as its major rival and threat $(2014,299)$. Malik also finds that as India and China's rivalry emerged in recent decades, Pakistan and China's economic and political cooperation grew, most visibly through the Gwadar Port Project (2013, 150-2). Notably the emphasis on the relationship with China is a recent development in the literature, and in particular is focused on a growing economic relationship and China's move geopolitical tactics to upstage India.

Every account of Pakistan's history or politics includes some reference to India. Jalal (2014) and Jaffrelot (2014) both note that India is the perpetual boogeyman as far as the Pakistani state is concerned, and they are not unique in this observation. Jalal finds that a fear of Indian intervention in conflict ridden regions like Balochistan continues to inform Pakistan's "ruthless suppression of political dissent" $(2014,384)$. Jaffrelot argues that Pakistan's government continues to point at India and Hinduism as enemies of Pakistan as a Muslim homeland in order to bolster calls for Pakistani nationalism as an 
alternative to acknowledging Pakistan's internal ethnic diversity (2014, 636-8). With a more direct focus on Balochistan, Malik argues that the Baloch ethno-nationalist movement has a potential ally in India that is hard to deny, despite any clear evidence of Indian support $(2013,150)$. In the context of the Baloch ethno-nationalist movement, the literature suggests that an India-Balochistan relationship is mutually beneficial against a growing Pakistan-China relationship.

More complicated is the relationship between Pakistan, Balochistan and Iran. Malik explains that Iran holds some traditional Baloch territory which a strong Baloch movement could lay claim too, thus suggesting that Iran and Balochistan's relationship would be antagonistic $(2013,154)$. However Iran's has a much broader antagonistic relationship with the US and Pakistan, which suggests that Iran would be unlikely to help Pakistan quash the movement outright (Malik 2013, 156). Jalal notes that as the PakistanUS relationship unravels, a closer economic and political relationship between Pakistan and Iran has emerged $(2014,387)$. While authors like Khan (2005) and Siddiqi (2012) elaborate on Iran's support for Pakistan during the 1973 Baloch rebellion, they fail to explore the more recent developments in Iran's role in Pakistan and Balochistan. Much of the literature gives cursory overviews of Iran's role, likely due to Iran's own complex interests and relationships with other actors in the region.

In understanding the evolution of the Baloch ethno-nationalist movement it has become increasingly important to assess the role and interests of international actors. As global rivalries shift, the literature notes that diverse economic interests in a volatile region become ever more important. 


\subsubsection{Conclusion}

The available literature gives the present work an ample bedrock of theory and history. Where the literature has generally lacked is in tackling the nature of the present conflict, with articles published after the start of the present conflict eschewing extensive analysis of the conflict in favour of narrower theoretical elaborations. Further available literature generally focuses on either the local, state or international level on its own, often failing to assess how the growing scale of Balochistan's importance has increasingly tied the Baloch ethno-nationalist movement to international interests.

The task before this project is how to balance these various analyses by bringing these divided approaches together by analyzing the state, local and international levels simultaneously. This project aims to contribute to literature on ethno-nationalism through a dynamic analysis of variables at local, state and international that better explains how ethno-nationalist movements evolve. With regard to the literature on the Baloch ethnonationalist movement, this project aims to fill the narrative gap on the recent conflict in Balochistan and explore how contemporary theories on ethno-nationalism can be applied to Balochistan's history to explain and draw insight into the nature of Balochistan's current conflict with the Pakistani state. 


\section{Chapter: Analytical Framework}

\subsection{Research Questions}

Though much has been written on the history of this conflict, much of it simply traces over the history with a broad brush, highlighting a few key actors and moments. The literature tends to focus solely on either the state or the ethno-nationalist movement, eschewing an in-depth analysis of how the movement evolved in tandem with the state. This project aims to understand ethnic separatist movements in Balochistan with greater depth of focus on the movement itself and the mechanics and variables that have affected and will continue to affect its evolution.

At its core, this project asks: What factors can explain the emergence and expansion of ethno-nationalist movements in Balochistan? In answering this question it is important to balance an exploration of the movements' internal dynamics with an understanding of the other factors at play. Of particular importance is the relationship between the Baloch movements and the Pakistani state. Accordingly a second central question asks: How has the Pakistani state responded to ethnic mobilization and insurgency? Beyond the state, external factors invariably affect ethno-nationalist movements. Thus this project also asks: What role do regional and international security and trade issues play in the evolution of the movement?

Answering these questions will require a varied approach, employing multiple theoretical considerations through an account of the movements history. Ultimately the aim is to understand and perhaps even predict how the movement will continue to evolve. 


\subsection{Theoretical Framework}

This project aims to contribute to the literature on Balochistan by bringing the narratives that assess Baloch politics at either the local, state or international level into a nuanced single narrative. It proceeds by focusing on five key factors: Baloch identity, resources, politics, the postcolonial state, and international actors. These factors intersect on local, state and international levels, affecting how the Baloch ethno-nationalist movement has evolved. These factors serve as the independent variables that are expected to affect this study's dependent variable: the Baloch ethno-nationalist movement.

In the context of contemporary literature on ethno-nationalist movements and ethno-nationalist conflict, this project argues for a broader and more dynamic approach to variable selection and scope of analysis. Ethno-nationalist movements seek to access, control or form a state, requiring investigation of local and state level actors. From the perspective of building historical narratives, increased globalization necessitates increased assessment of external and international factors and actors to give a fuller account of an ethno-nationalist movement's evolution. More significantly, narrow analytical frameworks have offered little insight into why ethno-nationalist movements seem to be curtailed only to flare into violent conflict again decades later. Assessing key variables at multiple levels prevents this project from overstating the significance of a few elites and allows it to assess how the group of individuals that make up an ethnic group are mobilized on such a large scale. The key contribution is that assessing an ethno-nationalist movement by focusing on only state or local levels fails to explain why an ethno-nationalist movement evolves as it has. Understanding how key variables 
intersect across a broad scope offers a fuller explanation of why an ethno-nationalist movement has evolved exactly as it has.

An ethno-nationalist movement for the purposes of this project incorporates a broad array of conceptions of ethno-nationalist conflict which are discussed more thoroughly below. For this project, an ethno-nationalist movement involves a community that identifies within itself some kind of ethnic homogeneity or fraternity through a mythsymbol complex, to potentially varying extents, and seeks to promote, protect, or improve the group's status by seeking access or control of the state, or by forming a separate state. This ethno-nationalist group's movement is directed at other outside groups, be they state or non-state actors. However, ethno-nationalist movements are not homogenous bodies. They can be understood to be made up of sub-ethnic groups such as tribes. These tribes can be further divided until we arrive at the individual: the smallest unit of analysis in this study of ethno-nationalist conflict.

Underlying social differences within an ethnic group are manipulated by elites vying for power within the broader movement as much as those same differences are used by the state to divide the ethno-nationalist movement. This project balances an approach that looks at elite's actions with an approach that respects the ongoing influence of social divisions, many of which are beyond any single elite's ability to manipulate.

Alongside this balance this project explores how resources flow from various sources and can both bolster and undermine a movement at the same time. Resources such as natural gas and mineral deposits are key to stakeholders at all three levels of analysis. Internal conflicts within the movement arise from the pre-existing social cleavages. Disputes over who controls the larger share of resources, regardless of whether 
those resources are supplied by internal or external actors, affect the cohesiveness of the broader ethno-nationalist movement. Precarious resource supplies hamper the ability of the ethno-nationalist movement to operate, but motivate broader cooperation to maximize the movements effectiveness. Thus resources heavily impact an ethno-nationalist movements ability to carry out a sustained armed conflict alongside a political campaign against its designated opposition.

Natural resources, such as gas and minerals, are also particularly important for their economic value as well as their symbolic value. When natural resources are extracted from the region tied to the ethno-nationalist group's history, an inability to benefit from that resource extraction becomes a major grievance for an ethno-nationalist group. At the same time state's desperately seek to control natural resources for their economic and political value, while international actors seek to make deals with whoever holds control over them. While existing physically at a local level, natural resources are of major concern to local, state and international actors.

Politics also invariably occur and impact at all three levels. In Pakistan and Balochistan, politics are tempered through the nature of the postcolonial state and the colonial legacy that informs relationships between the federal government of Pakistan, local Baloch authorities and actors, and external or international influences. Local social foundations, such as Baloch tribal structures, have historically affected political alliances at local and state levels. However, given the ability of contemporary elites to affect local conflict even from foreign locations, local social foundations increasingly take on international significance. Political differences within an ethnic base can then exacerbate violence without effectively bolstering the movement in a broad sense. 
Ethno-nationalist movements require cohesion to be impactful. The more that the an ethno-nationalist movement can forge a broadly cohesive 'myth-symbol' complex alongside collective fears and grievances, the more likely it will be to exert pressure and successfully attain concessions or win power from the state. Cohesion within the ethnonationalist group is not wholly determinative, but it does give an ethno-nationalist movement its particular regional and demographic shape.

In the case of Balochistan the way that ethnicity is constructed and the way that the various tribes band together has a continuous influence on how the movement develops. At the individual level identity is a particularly important factor. Baloch identity is tied heavily into conceptions of a historical tribal ethnicity and the longstanding feudal tribal social structures that persist in contemporary Balochistan. Individual Baloch peoples are often associated with or explicitly belong to a specific tribal group with their own chieftain, often referred to as the "Sardar". These Sardars have the most impact at the local level, with many struggling to find a similar share of power at the state level. These Sardars compete with other individuals vying for power within their own tribal group and with other Sardars in order to retain power across multiple tribal groups. Sardars also compete with other Baloch leaders who take other paths to power, for example through bureaucratic positions in Pakistan's federal and provincial governments. Baloch leaders and elites then compete and integrate at the state level against or with state actors. The way that the state responds to the movement leaders and the way that the movement's internal dynamics operate then temper the progress of any broad movement. 
A state's ability to respond to an ethno-nationalist movement will be affected not only by the broader politics at play at the state level, but also tempered by international pressures through actors who can also directly come into contact with actors at the local level. In this way international actors are expected to affect the movement, in particular through their influence on state and local level resources and politics.

International actors can support a movement and bolster it while undermining the state's ability to respond. International actors can also support the state in combatting the ethno-nationalist movement. An international actor may be motivated by its own selfinterest, for example for economic or political gain, or by a genuine stake in the conflict. As with state and local level actors, international actors are not always impactful, but powerful international influences do have serious consequences on an ethno-nationalist movement's ability to operate.

Assessing the convergence of local, state, and international factors is fundamental to this projects analysis. An ethno-nationalist movement can only be properly understood by assessing how key variables at international and state levels affect it in tandem with local and internal dynamics. Local level factors are fundamental to understanding the internal makeup and dynamics of an ethno-nationalist movement. State level factors work closely in tandem with those local level factors, usually impacting directly and significantly. Often overlooked in other studies on ethno-nationalist movements, a major emphasis in this project is to understand what international factors are affecting the ethno-nationalist movement. International actors may be particularly powerful, or contribute to state efforts to repress the movement or to the movement itself. Where international have particular interests in a given outcome or in supporting a particular 
actor in the conflict, these factors can directly impact the ethno-nationalist movement. Assessing the impact of an international actor can only be done after understanding factors at the local and state levels. Therefore it is pertinent to explore factors at these three levels and analyze how they converge, intersect, and overlap to influence the evolution of an ethno-nationalist movement.

Overall this project finds that the continuous yet varied progression of the Baloch ethno-nationalist movement(s) is associated with the confluence of these various actors and factors. Although ideas of Baloch ethnicity have existed since before the British colonial rule over South Asia, the modern Baloch ethno-nationalist movement was born at the same time as Pakistan and India. The creation and accession of the province of Balochistan solidified the idea of a modern Baloch peoples, but more significantly placed them in opposition to the new Pakistan government. The identity that might have been watered down by a broader anti-British sentiment in the colonial era was suddenly narrowed against the new state, controlled by non-Baloch actors. Local tribal structures became a symbol of historical ethnicity that impacted the state level imposition of Western federal democratic institutions. As a power-centralizing federal government emerged, so too did various ethno-nationalist movements.

With an established foundation of Baloch ethnicity, the Baloch ethno-nationalist movement is significantly dependent on support in terms of resource supply, politics and internal social dynamics. Grievances with the state and the dismal development within Balochistan motivated Baloch actors across the political to vie for power to achieve some kind of economic or political gains for Baloch peoples. Multiple military coups, and violent instability at the state level made moderates within the Baloch ethno-nationalist 
movement almost entirely ineffectual. The most significant historical peak of the movement notably came on the heels of Bangladesh' independence in 1971. Opportunity to achieve progress for the Baloch seemed non-existent within the federation and the weakened yet power-hungry Pakistani state was a unifying enemy. However, Iran's support for Pakistan undermined the movement, dealing a decisive blow that saw the movement beaten in a military resource battle.

Subsequently the Pakistani state took on a less antagonistic approach and created more room for opportunity for Baloch elites within the federal structure. While this did not resolve long-standing grievances, it split the movement, with various leaders and groups no longer able to agree on how best to proceed. A lack of ethnic and political cohesion, an almost complete lack of control over resources, and the importance of US geopolitical interests during the 1980s and 1990s undermined the ethno-nationalist movement.

The death of well-respected Baloch moderate turned militant catalyzed the movement in the early 2000s. Increasing presence of international actors such as China and Iran as well as the continuing displacement of Baloch by Pashtun and Punjabi migrants further unified the Baloch. As Pakistan's government became decidedly more antagonistic and militant in its response to Baloch ethno-nationalist insurgents, so too did the Baloch ethno-nationalist movement gain more momentum in the region. In recent years external pressures through international actors and the colonial legacy that persists in the Pakistani state structures have been particularly determinative of how the ethnonationalist movement evolved. 
By assessing Baloch identity, politics, resources, the postcolonial state, and international actors across local, state and international levels of analysis, this project explains why the recent conflict sparked after so many years of relative peace and how the Baloch ethno-nationalist movement has evolved.

\subsection{Concepts and Definitions}

At the outset it is important to explore some of the central terms and concepts in this project and where they are drawn from. This project prioritizes dynamic approaches that identify key variables yet allow for a fluid interpretation and explain ethnonationalist movements insofar as they are both violent or non-violent. An ethnonationalist movement is defined as a movement by an ethnic group united behind a mythsymbol complex which informs the movement's conception of ethnicity. Ethnonationalist movements seek to access, control or form a state. An ethno-nationalist movement places itself in opposition to the state, motivated by fears about the core ethnic group's survival or political and economic prospects. The movement itself can be violent, non-violent, or both, and its efficacy will be tied to its underlying social bases, internal and external politics, and resource supply.

Defining ethno-nationalism and categorizing conflict is an important preliminary step in coming to this definition. In particular it is important to clarify what kinds of actions count as being perpetrated by what kinds of groups. An excellent starting point comes from Gurr $(2017,34)$, who defines 'ethno-political conflict' as “political contestation in which one or more parties mobilizes support based on appeals to communal identity and aims to protect or improve the group's status vis a vis the state or 
other groups". Two important concepts contained therein are 'ethnicity' and 'conflict'. Gurr sees ethnicity as a construct, founded on "appeals to community identity" (2017, 34). Gurr narrows the concept of conflict to "observable kinds of action: usually physical contestation" $(2017,34)$. This is particularly important in contrast with definitions which focus on overt physical violence.

For example Byman defines ethnic terrorism as "deliberate violence by a subnational ethnic group to advance its cause [which] usually focuses either on the creation of a separate state or on the elevation of the status of one communal group over others" $(1998,151)$. Of course the distinct difference comes from Byman's (1998) focus on terrorism rather than conflict more broadly. Nonetheless from Byman's emphasis on the "subnational" we can see an understanding of ethnic identity in tandem with national identity $(1998,152)$. Relating this understanding back to Gurr's (2017) definition, we can understand how ethnicity can itself be an amorphous and ambiguous concept, while noting that a core aim of these groups is to seek either better representation at the state level or a separate state. Defining the nature of the relevant conflict is also important in determining what kinds of actions count as being perpetrated by what kinds of groups. Building on the work of Paul Brass, Brubaker and Laitin argue that "violence is regularly accompanied by social struggles to define its meaning and specify its causes, the outcome of which — for example, the labeling of an event as a pogrom, a riot, or a rebellion —-may have important consequences" $(1998,427-8)$. In this way we can understand that the way violence or conflict is characterized by any given group shapes its subsequent meaning for an ethno-nationalist movement and for broader society. Brubaker and Laitin warn that ethnic biases in framing may lead us to conflate various 
forms of violence with ethnic conflict $(1998,428)$. Brubaker and Laitin define ethnic violence as

"violence perpetrated across ethnic lines, in which at least one party is not a state (or a representative of a state) and in which the putative ethnic difference is coded — by perpetrators, targets, influential third parties of analysts—as having been integral rather than incidental to the violence, that is, in which the violence is coded as having been meaningfully oriented in some way to the different ethnicity of the target.” (Brubaker and Laitin 1998, 428)

Not all violent or non-violent conflict that occurs between people who might comprise different ethnic groups should be termed as ethnic conflict. Rather the very issue of ethnicity must be tied to the motivation behind the action or the specific selection of the target. The understanding of ethnic conflict becomes more specific by noting that the ethnic difference must be integral rather than incidental to the violence. In a similar vein, Kaufman finds that most scholars studying ethno-nationalist violence define a war as ethnic if "the contending actors or parties identify themselves or one another using ethnic criteria" $(2006,46)$.

It is important to note Brubaker and Laitin's emphasis that one party is "not a state (or a representative of a state)" $(2008,428)$. In Brubaker and Laitin (2008), Kaufman (2006), Byman (1998), and Gurr's (2017) works, an integral distinction seems to be applicable between ethnic and nationalist violence taken by non-state actors rather than state actors. Ethno-nationalist separatist movements seek "to protect or improve the group's status vis a vis the state or other groups" (Gurr 2017,34), meaning they either seek better representation at the state level or to create their own state. Thus an ethno- 
nationalist movement may or may not be separatist, and cleavages within an ethnonationalist movement may exist on the issue of whether the ultimate goal is a separate state or simply more representation at the state level.

Understanding the individual's motivation to identify as a part of an ethnic group, and more importantly to mobilize or take potentially violent action as part of an ethnonationalist movement is complicated. Rational choice models understand ethnic labels as a tool "used by individuals, groups, or elites to obtain some larger, typically material end" (Kaufman 2006, 49). From Kaufman this project draws a critique of rational choice models for presenting ethnic identity as particularly elite-led or the result of "individuals' rational pursuit of universal interests" $(2006,49)$.

Kaufman's (2006) symbolist approach to understanding ethnicity employs a less instrumentalist approach to understanding individuals motivations in regards to ethnonationalist conflict than rational choice models. "Each ethnic group is defined by a 'myth-symbol complex' that identifies which elements of shared culture and what interpretation of history bind the group together and distinguish it from others. These definitions are always subjective" (Kaufman 2006, 50). In this sense elites can manipulate ethnic identity but they do not create it in a vacuum. Instead their "ability to use ethnicity instrumentally is...limited by the cultural context in which they operate" (Kaufman 2006, 50-1). This 'myth-symbol' approach to understanding ethnicity is what this project operates with. It allows flexibility in understanding what constitutes ethnicity while still identifying its key components which are at play during ethno-nationalist conflict. This model also suggests how ethnicity can be used to motivate ethno-nationalist conflict. 
The symbolist model is built on neuroscience which shows that "emotions, not rational calculations, motivate people to act" (Kaufman 2006, 51). The model suggests that "ordinary people choose emotionally among competing values and leaders by responding to the most evocative symbol presented to them" (Kaufman 2006, 52). These symbols which are tied to identity through this lens of ethnicity are in a sense 'there for the taking' by savvy elites. "A group mythology that justifies hostility is a precondition for violent ethnic conflict; it must exist before a politician can manipulate it. Such myths are not, however, a sufficient explanation for violence: hostile myths are common, but ethnic violence is rare" (Kaufman 2006, 52-3).

Kaufman (2006) argues that two other preconditions must exist for ethnonationalist violence. The first is that appeals to ethnicity motivate extreme violence only if a group "fears that its existence is threatened" (Kaufman 2006, 53). This fear need not be rationally justified, but it could be. Instead what is important is evoking a visceral reaction that strikes fear into the individual about the continued existence of their ethnic group.

The second precondition concerns the more technical elements of political opportunity. "There must be enough political space...to mobilize without facing effective repression" as well as a "territorial base" (Kaufman 2006, 53). Ethno-nationalist movements cannot mobilize effectively without both a political and physical space to operate. Thus the mere presence of a 'myth-symbol complex' that can be understood as ethnicity must be tied in both with fear about the groups survival or existence as well as political opportunity. Kaufman's malleable understanding of ethnicity also allows us to 
understand how ethnicity can at once seem homogenous and pre-determined from afar yet have internal fissures that splinter and undermine the broader movement.

Particularly important for an insurgency are "the government's police and military capabilities and the reach of government institutions into rural areas" (Fearon and Laitin $2003,80)$. Insurgents prosper when the governments they oppose are weak, specifically "badly financed, organizationally inept, corrupt, politically divided, and poorly informed about goings-on at the local level" (Fearon and Laitin 2003, 80). Members of ethnic insurgencies are not necessarily of one mind in terms of either their ultimate ends or the means to achieve those ends. Instead insurgencies may be more focused on short term concerns about out-maneuvering the government as their primary opposition, choosing to use local resources as they are available (Fearon and Laitin 2003, 80).

Ethno-nationalist movements have internal dynamics of conflict and power struggles which affect how they operate. "Internal rivalry can be based purely on struggles over power and profit but can also reflect differing views over the interethnic conflict" such as deciding what the ultimate goals of the movement should be and what means are best to achieve those goals (Casperson 2008, 239). Beyond affecting the broader goals of an ethno-nationalist movement, divisions within an ethno-nationalist movement can disrupt the movement's unity and effectiveness. Ethnic and nationalist projects are "based on a belief in unity; a belief in a common destiny, common interests, and common needs" (Casperson 2008, 240). However the practical realities of mobilizing a potentially disparate group of people under a single collective banner can work in tandem with rival politics to undermine an ethno-nationalist movements internal cohesiveness. 
Ethnic leaders rival each other to appeal to audiences within the ethnic group, driving intraethnic rivalry. With regard to ethno-nationalist conflict, these audiences are "unlikely to shift their allegiances across the ethnic divide" but may instead support "rivaling leaders within the same group or decide to withdraw their active support and supply of resources" (Casperson 2008, 242). These audiences include the general population, political parties, political movements, military or paramilitary bodies as well as external actors or groups (Casperson 2008, 242). From this perspective, we can understand that analysing intraethnic divisions allows us to assess elite interests and elite politics in tandem with popular attitudes, "without having to rely on overly simplified, static categories" (Casperson 2008, 242).

This depth of analysis into the intraethnic or intragroup dynamics is important because it allows us to understand not only how ethno-nationalist movements operate when functional or particularly violent, but also how they splinter, dissolve, or weaken even without significant interference by external actors. From Casperson we can understand the "fluidity of ethnic conflict, the changing driving forces, and the lack of intragroup homogeneity" (Casperson 2008, 243). So while an ethno-nationalist movement utilizes a community identity built on a 'myth-symbol complex', this communal identity should not be understood as a particularly certain or invariable element within the movement, nor should the capacity to rule or the regime of any elite within said movement be considered to be a source of stability.

In the context of ethno-nationalist movements and with an understanding that ethnicity is itself a fluid and constructed concept, Staniland's (2012) idea of pre-existing social bases is particularly relevant. While these pre-existing social networks may not be 
wholly determinative, they weigh into how elites and their audiences within an ethnonationalist movement relate to, support, or splinter from each other. Staniland draws an important distinction between "overlapping and divided social bases" $(2012,150)$. "Overlapping social bases are pre-existing networks that combine strong horizontal links that pull together organizers across localities with vertical ties that embed them in local communities" (Staniland 2012, 150). Conversely "divided social bases are characterized by weak horizontal ties across organizers...weak vertical embeddedness within communities...or both" (Staniland 2012, 150-1).

Where a social group identifies itself as part of a broad ethno-nationalist movement, it may nonetheless find itself at odds with other social groups within that broader movement. While these differences may or may not be understood in strictly ethnic terms, divisions that exist within an ethno-nationalist movement's social base will affect the movement's organization.

In the case of Baloch ethnicity, the idea of a broad Baloch ethnic group is considered to be a collection of tribes. These tribes have their own elites, their own organizational structures, and their own social bases that must be incorporated into any broadly termed "Baloch" ethno-nationalist movement. Some tribes may have stronger connections than other and tribal leaders may be at odds with each other over power- or resource-sharing and the goals of their movements.

Staniland finds that "organizations built around divided networks struggle to forge integrated institutions because of the social fissures and gaps in collective action within the organization" $(2012,151)$. Weak horizontal linkages between these divided social bases results in a lack of centralized control, elite feuding, and fissures within the 
movement (Staniland 2012, 151). Thus a cohesive communal identity for an ethnonationalist movement that is subdivided, for example by tribes, is not merely a social construct, but also an institutional one that is affected by pre-existing linkages between these tribes.

Cunningham's definition of a 'self-determination movement' required the making of demands related to self-determination $(2011,280)$. This is a particularly relevant understanding of self-determination for this project's focus on ethno-nationalist movements and the demands regarding some level of increased group autonomy as regard cultural, political or economic rights.

Considering Staniland (2012) and Cunningham's (2011) approaches alongside the symbolist approach to ethnicity articulated by Kaufman (2006), we can understand how ethnicity can seem to be determined by a group's shared history, yet function as a fluid subjective construct. Although at least partially subjective, ethnicity is not constructed in a vacuum. The pre-existing 'myth-symbol complex' of a group can be coupled with the pre-existing social bases of that group to give a full picture of what that ethnic group constitutes. Individuals, such as elites, can manipulate these symbols and social structures that form the ethnic group, tying in fears about the group's status. However, they are bound to some extent by these structures, and this can undermine the cohesiveness of the movement itself.

Those members of an ethno-nationalist movement who seek power use "resources and symbols to ally with peripheral actors fighting local conflicts" (Kalyvas 2003, 476). The disjuncture between the center and the periphery of an ethnic group forms a "micro foundation of cleavage" which can undermine attempts to link together a broad 
movement (Kalyvas 2003, 476). Kalyvas finds that "local conflicts often trumped ideological ones" suggesting that opportunism and local cleavages, which may not be distinctly ethnic, can be understood as divisive factors within an ethno-nationalist movement with a divided social base $(2003,478)$. Tied in to the socially divisive factors and components of an ethno-nationalist movement are cleavages over resources.

Resource management is thus an important variable in understanding the internal dynamics of ethno-nationalist movements.

Organization structure determines the impact that resource endowments have on discipline and behaviour. When resources flow into cohesive organizations that are built around overlapping social bases, they will enhance the groups' fighting power, organizational capacity, and internal discipline...[However] resources that flow into fragmented organizations will not fundamentally change the organization's structure" (Staniland 2012, 151).

Thus a wealth of resources can hold a loose coalition together, but underlying social cleavages can lead to conflict over control of those same resources. Of particular note for the present project, "social innovation is constrained...by the group's socialorganizational underpinnings" such that "pathways of likely change are determined by the original structure of the organization" (Staniland 2012, 152). An ethno-nationalist movement will to a significant extent be constrained by its underlying social structure. "State sponsorship, diaspora mobilization, drug smuggling, and extortion are compatible with both disintegrative thuggishness and disciplined effectiveness" (Staniland 2012, 151-2). Thus resource flows can affect the ethno-nationalist movement's internal dynamics, but the way in which resources will affect the movement is over-determined 
by the movement's underlying social bases. Resource flows reflect two key ways that a movement can mobilize.

Economic viability and organization advantage are two broad categories of mobilization-supporting opportunities. Economic viability is supported by the presence of natural resources that can be exploited to help fund the movement as well as outside actors that may have a vested interest in either the movement, the region, or disrupting the state against which the movement collides (Surendra 2009, 254). For Surendra, the Baloch movement is bolstered by the presence of conflict-specific capital such as arms and munitions brought into the region over the course of several wars and most recently the War on Terror $(2009,254)$. Organization advantage revolves around geographic and demographic factors such as favourable terrain and social cohesion. The uniquely arid and tough nature of Baloch territory coupled with sparse varied population and tribal social traditions support the development of social mobilization (Surendra 2009, 256).

As such Surendra (2009) pinpoints opportunity as a key element in the evolution of Baloch nationalism and the continuing conflict. Moving beyond approaches that simply allow for grievance-based explanations benefits the present projects theoretical framework. An opportunity-based explanation also supplies a valid critique to much of the literature on Balochistan which focuses on the history of conflict and overlooks periods of relative stability.

While these approaches help us understand what effects an ethno-nationalist movement's internal dynamics, external pressures from the state against which the movement is occurring require a different approach. If we understand that ethnicity is constructed as oppositional to either the state or other groups (whether ethnic or not) also 
vying for power, it is important to understand how the state responds to ethno-nationalist movements that are themselves heterogeneous.

"Internally divided [self-determination] movements have difficulty presenting a coherent, strong challenge to the state" often making differing demands which compete with each other (Cunningham 2011, 275). The issue is that neither the state nor the factions within the movement know what concessions by the state could even resolve the conflict (Cunningham 2011, 275). States then prefer to capitalize on the internal divisions within such movements. This can be achieved through a 'divide and conquer' strategy by fostering conflict and furthering divisions, or by "coopting factions through side payments unrelated to their collective demands" (Cunningham 2011, 276).

Expanding on the more traditional 'divide and conquer' model, Cunningham (2011) argues that concessions themselves can be part of a 'divide and concede' strategy by states. The concessions to factions within the movement can allow for the splintering of the larger movement base (Cunningham 2011, 291). This works in tandem with Cunningham's finding that "internally divided movements are more likely to get concessions from their host states" $(2011,276)$. The result of concessions to divided movements is "continued, potentially violent contestation because concessions will not be designed to satisfy the entire group" (Cunningham 2011, 294).

The divide and concede approach should not be seen as the sole approach the state will use, as under Cunningham's model states will use a variety of approaches at different moments and in responding to different factions and movements $(2011,295)$. Nor should the state be assumed to choose tactics that turn out effective or desired results. 
As much as this project elaborates on divisions within an ethno-nationalist movement, it is important to acknowledge that the state, in this case the Pakistani state, is not a homogenous or uniform actor. Divisions within the state and various domestic and international political concerns for a state which has the kind of resource issues and political instability of Pakistan will invariably affect how the state responds to any given ethno-nationalist movement or political faction. Furthermore state actors may have ties to actors within an ethno-nationalist movement, or have previous personal relationships that influence how the broader relationship between the state and the ethno-nationalist movement play out. External actors further complicate this relationship.

Third-party actors, especially those who share an oppositional position to the same state that the ethno-nationalist movement structures itself against may contribute resources to the ethno-nationalist movement. "External resource flows from states and diasporas" are particularly helpful for insurgents in undermining attempts by the counterinsurgent state to cut off or starve resource flows (Staniland 2012, 146). External support via resource flows thus may bolster an ethno-nationalist movement. Yet increased resource flows have been found to be as disruptive to a movement's cohesion as they are beneficial. In particular increased resources can lead individuals in a movement to "become increasingly depoliticized" (Staniland 2012, 147). So while external resource support is an important variable and asset to an ethno-nationalist movement, it does not always guarantee increased efficiency or cohesion for the movement.

This project operates on a complex understanding of ethno-nationalist movements that is based on a symbolist approach to explaining how ethnicity is constructed. The internally heterogenous ethnic group places itself in opposition to an oppressive state 
figure. Internal divisions both within the state and the ethno-nationalist movement make cohesion difficult and can undermine strategies by other side to achieve their goals. Balancing the importance of external resource support, social cleavages, elite manipulation, state responses and strategies, this project puts forward a dynamic approach to assessing factors that affect ethno-nationalist movements' evolution.

\subsection{Methods}

This project proceeds by following secondary data review and content analysis methodologies. The complications and dangers of doing primary research in Balochistan for this project as well as an abundance of historical research have guided this project to this methodological approach.

Secondary review is generally understood as a research method that uses preexisting data that has already been compiled, often by a variety of other authors (Heaton $2011,3)$. Secondary review for this project will pertain to both quantitative and qualitative pre-existing data and research. Quantitative data will include census data conducted by the Pakistani state as well as demographic and economic data collected and compiled by previous researchers. Qualitative studies will be used as well though much of it will be drawn from the same sources as the quantitative data. This is in part because extensive qualitative research into Baloch history and culture is particularly lacking.

The quality and veracity of some of the more quantitative sources, such as the Pakistani Census, are sometimes contested. Nonetheless, census and survey data have been used to build a picture of both historical and present-day Balochistan. By using a variety of sources and cross-referencing them as well their sources, this project has 
compiled a substantial portion of reliable data through secondary review, though the picture may not be particularly precise in certain areas. While secondary review comprises the predominant methodology for the historical analysis, content analysis of news sources and journal articles forms the core of the analysis of more recent events in Balochistan.

Content analysis is a broad research method that can be adapted in a wide variety of ways to suit the unique needs of a researcher (White and Marsh 2006, 23-7). A useful definition of content analysis is "a research technique for making replicable and valid inferences from texts to the contexts of their use" (White and Marsh 2006, 23). The inferences will be made along the lines of the theoretical framework outlined above. "Qualitative content analysis is similar to textual analysis in that it is primarily interpretive in nature, and often does not utilise statistics for data analysis" (Kim and Kuljis 2010, 370). Conversely quantitative content analysis is "used to make valid and reliable inferences from the data to their context" (Kim and Kuljis 2010, 370).

This paper uses an approach Ahuvia terms ‘interpretive content analysis’ (2001, 145). For Ahuvia (2001) traditional content analysis of a magazine clipping would focus on the particular parts of the text the coder is looking for. Interpretive content analysis instead looks more holistically at the entire document rather than isolating the coded text (Ahuvia 2001, 145-6). By looking at the documents within the relevant context, the researcher can go deeper into the source material, while still benefitting from balancing findings from multiple sources. While the researcher's understanding of source materials will form the primary narrative that runs through this paper, interpretive content analysis 
also allows the researcher to interpret what the original author and their audience's understandings of the source material are as well (Ahuvia 2001, 151-3).

The quality of interpretive content analysis can be assessed by its 'public justifiability', a process which requires researchers to include the coded content along with their interpretation of said content (Ahuvia 2001, 146). This resolves issues associated with transparency, forcing researchers to better explain and justify interpretations of coded texts that go beyond a plain meaning understanding of the terms. This projects used a qualitative content analysis approach to news clippings and journal articles in order to understand how the independence movement in Balochistan has evolved in recent years.

Research on the recent conflict began by tracing secondary sources for a rough timeline of events. There are few extensive accounts of the recent conflict in Balochistan which could form a foundation upon which to build this project's narrative, resulting in a sparse and inadequate account of the recent conflict. Accordingly news media sources were used as primary sources to first construct a coherent narrative and then to provide more detailed accounts of events.

News aggregators Factiva and News Bank were used to search for articles publications via search strings. These search strings were built using words selected to reflect the key variables in order to locate texts with relevant information. For example, a broad search string used was "(baluchistan or balochistan) and (violence or tribe or tribal or economy or gas or gwadar or election or war or sardar or mengal or marri or bugti)". The results of a search were sorted chronologically and each article was individually read to determine what organization the article was published by and whether the article 
contained any relevant information or reporting on the recent conflict. More targeted search strings would be used to find additional information if there was limited reporting or sources for an event or issue.

If an article did contain relevant information, that article was downloaded and then sorted into folders based on the contents of the article and the date of its reporting. Articles with information relevant to multiple issues would be copied into multiple folders appropriately. For example an article with information pertaining to a bombing on a gas pipeline with commentary from a Baloch politician might be coded into a folder for the year and month of the event reported, a separate folder for bombings, a separate folder for gas pipelines, and a separate folder for political commentary. This method of sorting articles allowed articles about the same events to be easily located, and allowed assessment of how multiple sources reported an event or occurrence.

This method of sorting also enabled the project to corroborate the accuracy of reported information by comparing and contrasting reports from other sources. The interpretation of the data collected through this methodology was informed by this process of corroboration through varied sources. Media sources are interpreted as occurring either at 'local', 'national', or 'international' levels, with that level being partly indicative of the perspective that media source represents. By exploring content from all three levels, precise information can be bolstered while still casting a wide net to allow for different perspectives on an issue. National and editorial affiliations are also considered when interpreting data from the primary sources. An alphabetical list of the primary media sources consulted, with level and brief notes on ownership and editorial affiliation, can be found at Appendix A. 
National level media relates to media found at the state level, distributed across Pakistan to a national audience. At the national level most media outlets are generally based out of Punjab or Sindh. While the Pakistani state can exercise some control over media, many Pakistani news sources are seen as aligning with particular political interests or are tied directly to particular politicians. News sources such as Dawn and The Express Tribune are amongst the most widely read news sources in Pakistan and offer consistent reporting, whereas journals like the Pakistan Gulf Economist offer more in-depth articles.

At the local level are media and news sources internal to Balochistan such as the Balochistan Times and the Balochistan Express. They offer a more local Baloch perspective than national level sources, though they are not necessarily representative of those within the Baloch ethno-nationalist movement. While local level sources may not clearly reflect the perspectives of the Baloch, they do offer more localized stories and interviews with local actors who are largely overlooked by national level sources.

To balance these national and local sources, this project also incorporates international sources. International level sources from Asia included the Hindustan Times, ANI (Asian News International), and Xinhua News Agency. Outlets like ANI or Indian Express are privately owned and may reflect particular private interests, whereas Xinhua News Agency is a state-run media source which will reflect the interests of the Chinese state. Using various Asian news sources allows an assessment of regional perspectives on events and issues. In a similar vein sources such as The New York Times or $\mathrm{BBC}$ News provide more Western perspectives and focusing on longer narratives rather than local or individual actors. International sources tend to report on stories from 
a broad perspective, looking at the events on a larger scale than national and local sources.

All news sources have their own biases that influence what information makes it into a story, or how the story is reported. By cross-referencing multiple sources from various perspectives and countries, this content analysis method can ascertain how much weight to give the information contained within. As with most things in Pakistan looking at a multitude of sources for any given event gives the best picture of what can reliably be said to actually have occurred, as political motivations undermine the credibility of news sources to varying extents.

Data on Pakistan is not easy to come by or always reliable. Balochistan in particular, given its disparately spread population and the ongoing conflict, is a difficult region to accurately survey. The main data resources used came from the Pakistani government's Census and from the Pak Institute for Peace Studies, which itself relied significantly on the Census. Data on Pakistan from other sources such as the World Bank or the UN was somewhat helpful as well, but generally did not provide information that helped to explain and understand the Baloch ethno-nationalist movement. While there is some quantitative data available from some secondary news sources, much of this also relies on the Census or UN sources.

The content analysis and secondary review methodology this project employs is not without its downsides. It does not give the same depth of insight as primary data collection, for example via surveying, would have accomplished. Unfortunately such an engaged method is beyond the capabilities of this project. Yet a combined approach of secondary review and interpretive content analysis still allow this project to undertake a 
broad yet nuanced investigation of the Baloch ethno-nationalist movement(s). By looking at reliable sources on events and identifying patterns of behaviour within and without the ethno-nationalist movement, we can understand how the Baloch ethno-nationalist movement(s) have evolved over a long period of time noting the impact of internal and external factors in an overarching sense. 


\section{Chapter: An Overview of Balochistan}

Before exploring the Baloch ethno-nationalist movement it is important to have an overview of the region. Many of the grievances and frustrations that continue to fuel conflict in Balochistan are tied to its unique geographic location, wealth of natural resources, social demographics and economic impoverishment. In order to understand how Baloch identity, politics, resources, the colonial legacy and international actors intersected and impacted the movement's evolution, this chapter lays out a picture of Balochistan.

\subsection{The Baloch People}

The term 'Baloch' generally refers to "the people comprising a confederation of around five hundred tribes and clans" (Malik 2013, 58). Geographically the Baloch people historically resided in regions of modern-day Iran, Pakistan and Afghanistan (Malik 2013, 61). The Balochi language remains one of the distinguishing characteristics of Baloch ethnicity with Pashtun being the second most common spoken language in the modern Pakistani province of Balochistan (Malik 2013, 60). Similarly most Baloch people are Sunni Muslims who share an ancestral history of nomadic and pastoral practices which vary depending on the tribe (Malik 2013, 61).

The deep-rooted tribal traditions of Baloch people still persist today and an understanding of some basic features of this tribal system are important in order to understand how tribal politics have affected Baloch ethno-nationalist movements. The Baloch tribe is a hierarchical political entity composed of units of various origins. These tribes are head by a chieftain known as a Sardar or Tumandar. From there various powers 
and responsibilities are assigned to the Muqaddams, Naibs, and Maliks. The Muqaddams and the heads of the clans act as council during war and peace, mobilizing resources and men during wartime operations Malik 2013, 62-3).

The Jirga is an important facet of Baloch tribal traditions. The Jirga is an assembly that settles private and public business which dates back to at least the mideighteenth century (Malik 2013, 63). The general form of the Jirga is informal and varies greatly depending on the tribe. "In some tribes only the tribal chiefs and elders or grey beards take part while in others every adult male participates" (Malik 2013, 63). The Jirga regulates tribal life by taking up and settling disputes and by mobilizing the community in regard to certain issues. The Jirga is also a forum of communication which passes the opinions and decisions of the tribe to the government and passes the government's decisions down to the tribe (Malik 2013, 63). Despite their ancient roots, the Jirga and the tribal system still dominate public life for modern Baloch peoples and have had much impact on the creation and development of Baloch nationalism.

\subsection{Geography}

The province of Balochistan comprises about forty-three percent of Pakistan's land mass (PIPS 2012,13). More than fifty percent of the province is covered by mountains and hills while the rest is made up of desert and plains (PBS 1998, Provincial Studies: Balochistan). Although the geographically large province has a variety of climates ranging from tropical to temperate, most of the province experiences a low amount of rainfall resulting in limited natural vegetation (PBS 1998, Provincial Studies: Balochistan). More significant in Balochistan are the presence of high volumes of natural 
gas and coal deposits as well as minerals including copper, iron, gold and silver (PBS 1998, Provincial Studies: Balochistan). These mineral and gas deposits are of key interest for major domestic and international industry. The prevalence of bomb attacks on gas pipelines in the region demonstrates how gas has become a major point of tension in the Baloch-Pakistan relationship.

Balochistan's geographical location also factors into its historical and present-day geopolitical relevance. It is located on the northern tip of the Strait of Hormuz, "which marks the entry point into the Persian Gulf through which much of the world's oil supply passes" (PIPS 2012, 13-4). The province also holds the longest section of coastline in Pakistan which opens up onto the Arabian Sea and sits at a geographic crossroads between the Middle East and South and Central Asia (PIPS 2012, 13). This unique geographical position is what makes the Gwadar Port Project so important. In the context of the US-led War on Terror it is also worth noting that the large shared border with Afghanistan, which boasts much mountainous terrain, has provided an influx of refugees as well hard to penetrate hiding locations for militant forces (PIPS 2012, 15).

\subsection{Population, Ethnicity \& The Census}

The population of Balochistan has grown very quickly since Pakistan's inception but still only comprises about six percent of the country's total population. The major spoken languages include Balochi, Brahvi, Pashto, Urdu, Sindhi, Siraiki, Punjabi, Persian and Hindko with most inhabitants of the province capable of speaking more than one language (PBS 1998, Provincial Studies: Balochistan). 
While this data is somewhat dated, it is worth noting that the languages dominant in the rural areas reflect the tribes and cultures that traditionally coexisted in this region of South Asia. Conversely the presence of Urdu and Punjabi in urban settings suggests that immigration from other provinces into Balochistan has significantly shifted the ethnic makeup of the province. Sources vary in their estimates but most suggest that somewhere between forty to sixty percent of Balochistan's population is made up of ethnically Baloch peoples, whereas Pashtun peoples are said to make up anywhere between twenty-eight to fifty percent (PIPS 2012, 32).

Table 1: Pakistan versus Balochistan Population (PBS 1998, and PBS 2017)

\begin{tabular}{|l|l|l|l|l|l|l|}
\hline Year & $\mathbf{1 9 5 1}$ & $\mathbf{1 9 6 1}$ & $\mathbf{1 9 7 2}$ & $\mathbf{1 9 8 1}$ & $\mathbf{1 9 9 8}$ & $\mathbf{2 0 1 7}$ \\
\hline $\begin{array}{l}\text { Pakistan } \\
\text { Population } \\
\text { (in millions) }\end{array}$ & 33.8 & 43.0 & 65.3 & 84.3 & 132.4 & 207.8 \\
\hline $\begin{array}{l}\text { Balochistan } \\
\text { Population } \\
\text { (in millions) }\end{array}$ & 1.2 & 1.4 & 2.4 & 4.3 & 6.6 & 12.3 \\
\hline
\end{tabular}

Table 2: Percentage of Households by Language Spoken and Areas: 1981 (PBS 1998, Provincial Studies: Balochistan)

\begin{tabular}{|l|l|l|l|l|l|l|l|l|l|}
\hline \multicolumn{2}{|l}{ Language usually spoken } \\
\hline Area & Urdu & Punjabi & Pushto & Sindhi & Balochi & Brahvi & Hindko & Siraiki & Others \\
\hline $\begin{array}{l}\text { All } \\
\text { areas }\end{array}$ & 1.37 & 2.24 & 25.07 & 8.29 & 36.31 & 20.68 & 0.13 & 3.08 & 2.82 \\
\hline Rural & 0.30 & 0.39 & 25.15 & 8.74 & 38.28 & 22.02 & 0.01 & 3.03 & 2.07 \\
\hline Urban & 7.42 & 12.67 & 24.64 & 5.73 & 25.20 & 13.05 & 0.84 & 3.34 & 7.10 \\
\hline
\end{tabular}

The alleged increase in population from 6.6 to 12.3 million raises important questions about the true ethnic makeup of contemporary Balochistan. While the 1998 Census itself calls out historical statistical manipulation in previous Pakistan Censuses, 
representatives of the Pakhtunkhwa Milli Awami Party (PkMAP) Balochistan chapter have argued that the Pashtun population is higher than the most studies suggest (PBS 1998; PIPS 2012, 33). They claim that the statistics have been deliberately miscalculated in order for Baloch peoples to benefit from a greater share of provincial power (PIPS 2012, 33). If their claims are true, it is likely that the Pashtun population mirrors the numbers of the Baloch population. There is evidence that more than a million Afghan refugees have entered Pakistan but the numbers are uncertain (Ahmed 2016). Despite the provisional results being released August 25 $5^{\text {th }}, 2017$, the full 2017 Census results have yet to be released. As such there is no substantive information on the ethnic makeup of the population of Balochistan which has nearly doubled in the 19 years between the censuses (PBS 2017). As with previous studies, the 2017 Census is also mired in controversy.

Originally scheduled to be completed in 2008 , this most recent census has been plagued by accusations of politically motivated statistical manipulation alongside underfunding and general inaccuracies (Zaman 2017). The manner in which the 2017 census was being carried out has also been contested by some Baloch tribal leaders. They fear that the census statistics will include a massive influx of predominantly ethnically Pashtun refugees from Afghanistan which could make the Baloch tribes minorities in their own districts (Aamir 2017; Baloch 2017; Shahid 2017). Despite an order by the Balochistan High Court not to include Afghan refugees in the census, the census agents asserted that there was little they could do if an Afghan presented them with a Computerized National Identity Card (CNIC) (Zaman 2017). The Baloch representatives worry that fake CNICs in predominantly Pashtun areas will tilt the 
statistics on the provinces ethnic makeup, essentially codifying the false existence of many Pashtun citizens (Kashani 2017).

Baloch concerns about falsified Pakistani identifications documents are wellfounded. In a 2015 report, over 88,000 CNIC cards in Balochistan were rejected as fake by the National Database and Registration Authority (NADRA) of Pakistan (Express Tribune 2017). Similarly when Taliban leader Mullah Akhtar Muhammad Mansour was killed in 2016, he was found to be carrying a fake Pakistani passport under another name (Gall and Khapalwak 2017). While concerns about the veracity of the census process were high in Baloch circles early in 2017, the results of the provisional census have been met largely with silence (Zaman 2017).

It has been noted that the provisional statistics suggest that there have been no significant shifts in the ethnic makeup of Balochistan despite the massive population increase. Some sources, particularly those from within the Baloch community, argue that this is worthy evidence that supports the continuing majority presence of ethnically Baloch peoples in the province (Aamir 2017; Aamir 2018). Conversely, other Pakistani sources have suggested that the lack of shift in ethnic makeup since the 1998 census despite the population increases belies collusion on the part of provincial and state authorities in manipulating the statistics (Zaman 2017; Notezai 2017). At the same time there have been reports in the last few years that thousands of people have fled the province in search of more secure areas with better educational and economic prospects (Hindustan Times 2014; Khan 2014). Whatever the true nature of Balochistan's ethnic makeup today, there is no denying that the increasing presence of ethnically Pashtun people added another dimension to conflicts in the region. 
The rapid increase of the Pakistani population to 208 million gives the picture of a country that will continue to struggle to manage and distribute resources adequately (United News of India 2017). For the Baloch peoples, their control over the already weak provincial authorities is at risk. As far as political representation within the federalist system of Pakistan goes, their prospects for increased representation and oversight over the province dwindles as their province continues to populate with non-Baloch peoples. This adds fuel to the grievance-fire that Baloch nationalists continue to stoke. At the same time an increased non-Baloch population makes Baloch representation at local and state level seats of power more precarious.

\subsection{Economy \& Energy}

Balochistan continues to be the poorest and least developed province in Pakistan with approximately 58 percent of its population living below the poverty line (PIPS 2012, 23). The literacy rate sits somewhere around 30-36 percent, with males generally having almost twice as high a literacy rate as females (PIPS 2012, 23; Dawn 2008).

In 2009, Balochistan supplied 45 percent of Pakistan's total natural gas requirements, which constituted a substantial drop from 70 percent from a decade before (Mezzera and Aftab 2009, 20). Balochistan's coal reserves are also considered to be sufficient to cover much of Pakistan's future energy needs, with more than 350 different companies engaged in coal mining in Balochistan by 2006 (Mezzera and Aftab 2009, 20).

Mezzera and Aftab summarize Balochistan's grievances regarding the revenue sharing from natural resources. 
Balochistan's long-standing complaints towards the federal government centre primarily around the revenue sharing formula determined by the National Finance Commission (NFC). According to this mechanism, a divisible pool of resources is created at the federal level through the contribution of the four provinces. The proportion of each tax that flows into the pool is supposed to be determined every five years. The resources collected within the divisible pool are then redistributed to the provinces in accordance with the awards assigned by the same NFC. While the divisible pool shows an increasing trend (for the NFC 2006, it was estimated to be around $45-50$ percent of the total federal tax revenues), the central government at the same time has regularly showed a lack of willingness to further share tax revenues with the provinces. (Mezzera and Aftab 2009, 20) Baloch nationalists, separatists and moderates alike take issue with the distribution formula which focuses on the size of each province's population without much account for territorial size, development and poverty (Mezzera and Aftab 2009, 20). A related source of contention is that the government buys gas at significantly different rates from the provinces: compare the government buying rate in 2009 of Rs. 60 per million cubic feet from Sindh to the Baloch rate of Rs. 27 for the same quantity of gas (Mezzera and Aftab 2009, 20). There is no apparent justification for this disparity. The limited natural gas network in the province has seen limited expansion under strict central state control since the 1970s (Mezzera and Aftab 2009, 20). Although often tied to the security situation in Balochistan, historically periods of relative peace saw little investment and expansion of the network, with some Baloch sources suggesting that this 
is a deliberate move by the center state to undermine their development (Mezzera and Aftab 2009, 20).

Beyond the gas supply, Balochistan's horticulture, livestock and fishery industries remain on the sidelines, seeing little investment and interest (Fazl-e-Haider 2012). Furthermore many people across the province currently lack access to basic amenities (Frontier Star 2015a; Fazl-e-Haider 2015).

Perhaps the most significant, and certainly the most visible area where policy and the economy overlap in Balochistan is the Gwadar Port Project (Gwadar). After a decade of construction, Gwadar opened in March 2007 under the operating control of a consortium led by Port of Singapore Authority International (PSA International). The deal was to last 40 years, during which time PSA International would benefit from corporate tax and duty exemptions and. That deal included the potential of $\$ 3$ billion USD in investment, $\$ 550$ million of which was to be invested into the project in the first five years (Reuters 2007). Gwadar is a deep-sea port located in the Arabian Sea next to the Strait of Hormuz, one of the most significant oil shipping corridors in the world (Kazmi 2012). Gwadar is also a significant project because of its geographical position not only amongst several oil and resource rich countries in the Middle East and Central Asia, but because it offers a shorter route, dubbed the China-Pakistan Economic Corridor (CPEC), for China to access oil it needs to meet its ever-expanding energy needs (Kazmi 2012; Abbot 2013). 


\subsection{Conclusion}

The province of Balochistan tells the story of a region rich with valuable resources but impoverished at a social level. International stakeholders exert significant pressure through their interest in the region's mineral and gas reserves. Pakistan and China have particular interests in the Gwadar Port and CPEC. The influx of non-Baloch into the region dilutes Baloch representation at the state level and increasingly at the local level. For the Baloch people, the economic value of the land tied to Baloch ethnicity means non-Baloch powers exert significant pressure through the region. Any contemporary Baloch movement will have to openly contend with China and Iran, among other international actors, while harnessing a disparately located and factious population whose hold on political power remains tenuous. While this could bolster the idea that the Baloch peoples need a Baloch movement to protect their interests, it also means that the days of being able to posture solely against the Pakistani state are long-gone. 


\section{Chapter: A History of Conflict}

\subsection{The Birth of Balochistan: The Khanate of Kalat}

Although there are varying theories about their origins, the roots of Baloch identity before the seventeenth century are not well-known (Malik 2013, 59). The history of the Baloch nation has been traced back to Mir Jalal Han Rind in the fourteenth century whose attempts at forming a kind of confederacy were undermined by the nomadic nature of the Baloch people. His descendants are said to be the founders of five great tribes of Baloch: the Rinds, Lasharis, Korais, Hoats, and Jatois (Malik 2013, 66). Through the fifteenth century tribal war drove several Baloch tribes to create a more stable confederacy of tribes known as the Baloch confederacy of Derajat (Malik 2013, 66). The confederacy of Derajat was not stable enough, however, to withstand the conquering forces of nearby empires such as the Mughals under Aurangzeb. Nor was the Derajat confederacy able to effectively eliminate the intra-tribal conflict that spurred its creation (Malik 2013, 67). Where these other attempts to form a confederacy or broad unified nation out of the Baloch identity failed, the Khanate of Kalat served to form the foundation of modern Balochistan.

The Khanate of Kalat was established in 1666 by Mir Ahmad. The ruler of the Khanate was known as the Khan of Kalat and would rule over the tribes in their region in tandem with the Sardars (chieftains) from each tribe (Akhtar 2011, 124; Siddiqi 2012, 53). At the time of its inception the princely state only covered Sarawan and Jhalawan (Malik 2013, 69; Siddiqi 2012, 53). Mir Ahmad was killed and replaced by his younger brother Mir Abdullah Khan who expanded the borders of Kalat further by bringing more 
regions into the 'porous confederacy' of tribes (Malik 2013, 69-70). During the subsequent reign of Mir Muhabat, Mir Abdullah Khan's son, Persian ruler Nader Shah invaded portions of Balochistan, expanding the Persian empire into regions of what is present-day Afghanistan. Nader Sha forced Mir Muhabat as Khan of Kalat to surrender to Nader Shah's rule establishing a tributary relationship between Kalat and the rulers in the Afghan region (Malik 2012, 70).

Just as the Derajat confederacy was unable to maintain its independence from the dominance of the Mughal empire to its east, the Khanate of Kalat was forced to establish its subservience to the Persian empire in the West. This recurring battle against external conquerors and rulers has shaped the tribal relationships of the Baloch people, amplifying the effects of divisive internal conflicts which undermine the effectiveness of any panBaloch confederacy.

Mir Nasir Khan succeeded Mir Muhabat and ruled as Khan of Kalat from 17491795 , uniting many of the more disparate Baloch tribes. He expanded the Khanate into what would ultimately be its largest and most powerful peak in history (Siddiqi 2012, 53). Nasir Khan codified the centralization of power from the tribes by nominating Sardars from each tribes council and putting them into either the Majlis-e-Masahibeen or the Majlis-e-Mashawarat, essentially two houses that would advise the Khan on policy (Siddiqi 2012, 53). Thus under Nasir Khan's rule was an army of 25,000 men and 1,000 camels governed through a vaguely democratic two house structure Khan 2005, 111). The borders of Nasir Khan's Khanate reached as far east as Punjab, north into the Helmland River in Afghanistan, west into Sistan, Kirman, and Bandar Abbas in Iran and south into the Arabian Sea from Karachi to Bandar Abbas (Siddiqi 2012, 54). 
Nasir Khan used the assassination of Nader Shah in 1747 as an opportunity to expand his own empire soon after he came to power in 1749. As the Persian empire began to crumble following Nader Shah's death, Ahmad Shah Abdali took over as the ruler of Afghanistan and established the foundations of what would become modern day Afghanistan. Nasir Khan maintained a stable relationship with the Afghan leader while expanding the Khanate of Kalat to the south and the east, but never truly accepted the tributary relationship established by Nader Shah (Malik 2013, 70).

Eventually Nasir Khan's strengthened Khanate declared independence from its Afghan neighbours, a move that sparked the Afghan-Baloch war in 1758 (Siddiqi 2012, 53). Although Ahmad Shah Abdali's Afghan forces were able to invade Kalat and apprehend Nasir Khan, the two struck a treaty of non-interference known as the Kalat Treaty. The annual tribute that Nasir Khan had previously been paying to Ahmad Shah was revoked alongside an agreement of non-interference in internal Baloch affairs, although the Khan was to provide Shah with military support in the case of war with external enemies (Siddiqi 2012, 53).

This would go on to be a historic moment that codified an aspect of respect if not comradery in Afghan-Baloch relationships. Where in the past external powers invaded and disrupted the rule of the Khan, the Afghan-Baloch relationship granted the Kalat Khanate a measure of regional stability in the west. This relationship was also important due to the blend of Afghani Pashtun that have often lived in Baloch territory throughout history. More significantly the strong Afghan-Baloch relationship would shape the actions of the Khan of Kalat during the colonial rule of the British. 
After Nasir Khan, the Khanate of Kalat steadily declined in its reach and strength, meanwhile Russia began expanding into Afghanistan and the British started expanding into South Asia in a budding rivalry that would come to be known as the Great Game.

\subsection{The Colonial Era}

The First Afghan War (1839-42) would bring a major change to Balochistan. The British sought the help of the Khanate of Kalat in the war, and the Khan's refusal ultimately ended in his own defeat. On November $13^{\text {th }}, 1839$ the British invaded the Khanate and killed the Khan. The British sought to bring the region under their control for the sake of a trade route through the Bolan Pass as well as a buffer zone against Russian troops invading through Afghanistan (Malik 2013, 73). However, killing the Khan only served to disunite the tribes and create warring amongst them. This would prove to be of major consequence for the British whose trade route was often disrupted by the warring tribes, despite a Rs. 50,000 subsidy being paid to the new Khan (Siddiqi 2012, 54).

British Captain Robert Sandeman managed to coordinate an agreement between the Khan and the dissident tribes in 1876 . As Siddiqi observes, the Sandeman Treaty was significant for two reasons:

In the first instance, the treaty called upon the Khan and the Sardars that if a dispute arose between them 'they were to refer it to the British officer appointed to see the agreement in question carried out, and they would have to abide by his decision.' Second, Captain Sandeman preserved and strengthened the status quo by according more powers to the Sardars over his subjects (Siddiqi 2012, 54). 
Beyond putting an end to the tribal wars in the region, the effects of Sandeman's treaty were that it disrupted the traditional tribal system by instilling a more hierarchical governance structure, while placing the British at the top of that hierarchy (Akhtar 2011, 124; Malik 2013, 75). The Sandeman system of administration also meant that the Sardars owed their newfound power to the British authorities, making them more pliant and agreeable to British demands (Siddiqi 2012, 55). The Shahi Jirga, the council of chiefs, was an arena of political representation for the tribal leaders, yet was ultimately under the guidance of the British chief commissioner whose decision on council matters was final (Khan 2005, 113). Where the Jirga was in essence a communal court for the tribes allowing tribe members of various status, the Shahi Jirga was open only to the Sardars and the aristocrats (Malik 2013, 76). This shifted power into the hands of the tribal elites, creating a more hierarchical tribal structure that persists to present day.

Another long term effect of this new arrangement was the re-division of the Baloch region. Dera Ghazi Khan was amalgamated into Punjab; Khangarh was renamed Jacobabad and amalgamated into Sindh; Marri, Bugti, Khetran and Chaghi were declared Tribal Areas; Lasbela and Kharan were declared Special Areas; while Sarawan, Khalawan, Kachhi, and Makran together formed the new Kalat (Siddiqi 2012, 55). The Goldsmid line in the west gave nearly a quarter of the Khanate's former region to Persia while the Durand line gave an area of land in the north to Afghanistan (Khan 2005, 112). This is particularly significant because most of these regional divisions today are still in effect, as the process of partition did little to disrupt or change the divisions and power structures put in place by the British Colonial Administration. 
What remained of Balochistan was effectively used by the British as an area of strategic access to Afghanistan. Though there was not a focused program of economic or social development in Balochistan under British rule, the landscape was slowly dotted with railways, roads, post offices, rest houses and cantonments for British troops. While other regions of the British Raj saw more targeted development, Balochistan did begin to shift into the industrialist capitalist system that was developing in the region. The railway was a boon to Balochistan's mining industry which saw an increase from 122 tons of extracted coal in 1886 to 47,300 tons of extracted coal in 1903 (Khan 2005, 113). The nomadic and semi-nomadic cattle breeding practices that dominated Baloch culture also shifted in the wake of these economic developments. In 1900 more than 95 percent of the population still lived rurally and relied on cattle breeding for their livelihood. By 1931, 62.7 percent of the population had settled into more urban areas (Khan 2005, 115).

Shifting economic and social demographics under the British Raj were not, however, particularly beneficial for the Baloch. At the time of partition in 1947 "Balochistan had no degree colleges and only six government high schools" (Siddiqi 2012, 55). High taxation, predominantly in the form of wheat collected for British soldiers, caused many peasant farmers to lose the land they previously worked and shifted them into tenant and labourer positions. "For instance between 1879-80 and 190203 there was an 82 percent tax increase in Sibi; Between 1882 and 1895 there was a 350 percent increase in Quetta region" (Khan 2005, 113). Pauperisation of the peasant farmers and cattle breeders was worsened by the import of factory-made articles into a region that had previously relied on artisanal crafting. Moreover the new mercantile class that benefitted from these economic shifts was almost entirely made up of Punjabis and 
Sindhis (Khan 2005, 114). These shifts, and particularly the increasing influence of nonBalochis in the power structures of the region sowed the seeds of modern Balochi nationalism.

\subsection{Pre-Partition Era: The Foundations of Modern Baloch Nationalism}

The nationalist movement in Balochistan was not a unique phenomenon in early twentieth century South Asia. Ethnic and nationalist lines were being drawn all over the British Raj. Nationalist sentiment in Balochistan grew throughout the British reign, but saw its first outright movement begin in 1920. The 'Young Baloch' movement was led by middle-class Baloch students educated in British institutions and often the children of Baloch Sardars and civil servants. In 1929 Mir Yusuf Ali Magsi, one of the leading members of the movement, wrote an article entitled 'Faryad-e-Balochistan' ('Plea of Balochistan') (Siddiqi 2012, 55). It articulated the need for Baloch tribes to cease their internal warring and unite as a single nation. Magsi was duly arrested the following year on the charge of inciting rebellion. This did little to suppress the Young Baloch who, with the help of the captive Magsi, formed the Anjuman-e-Ittehad-e-Balochistan (Organisation for the Unity of Balochistan) (Malik 2013, 85). The Anjuman aimed not only for a unified and independent Balochistan, but for a representative governance structure at odds with the long-standing Sardar system (Siddiqi 2012, 56).

At the time, the Prime Minister of Kalat was a Punjabi named Shams Shah. He was the Anjuman's first target in a November 1931 pamphlet entitled 'Shams Gardi' ('Tyranny of Shams'). Led by Magsi, the Anjuman successfully rallied against Shah in what has since been dubbed the 'Magsi Agitation.' Shah had sought to put his son in the 
central seat of power as Khan of Kalat, but the Anjuman instead helped Mohammad Azam Jan take power in December 1931. Azam Jan was a product of the Sardar system and as Khan of Kalat pushed the Anjuman away. The Anjuman sought representative power structures which would have diminished the power of both the Sardars and the Khan, a possibility that Azam Jan was unwilling to abide. Azam Jan's reign as Khan was short-lived as his son Mir Ahmad Yar Khan ascended to the position of Khan in 1933. Although Ahmad Yar Khan was much more sympathetic to the Anjuman's nationalist cause than his father, he was also conciliatory in his relationship with the British (Siddiqi 2012, 56-7; Malik 2013, 85-6).

With the onus of the nationalist movement back on them, the Anjuman established the Kalat State National Party (KSNP) in February 1937. While they originally sought to dislodge the non-Baloch elements in the Kalat government, they quickly pushed a programme calling for a constitutional government in the Kalat state, the reformation of the tribal Jirga system as established under the Sandeman treaty, the re-joining of Baloch territories to the Kalat state as well as social, economic and educational rights for Balochis (Siddiqi 2012, 56-7; Malik 2013, 85-6). Sensing the disturbances the KSNP were causing, the Prime Minister of Kalat declared the party illegal in 1939 (Siddiqi 2012, 57; Malik 2013, 86). Although the Khan had supported the KSNP at its inception, their growing power coupled with their emphasis on representative power structures threatened his own seat of power, leading to his capitulation to British demands to silence the nationalist movement. Although many of the KSNP members were exiled they continued to operate underground through the Second World War. Notably, by 1944 the KSNP moved closer to the All India States Peoples Conference, a 
sister organization of the All-India Congress, in a short-lived alliance aimed at securing Baloch independence from Pakistan (Siddiqi 2012, 57-8).

While the KSNP were unique in their middle-class Baloch makeup and emphasis on representative constitutional government, they were not the only voice for Baloch nationalism, nor were they the only significant political organization. The Khan and the Sardars themselves were invested in an independent Balochistan and sought to align themselves with any powers that might guarantee that outcome. The Anjuman-i-Watan was founded by a Pathan named Abdus Samad Achakzai and acted as the Balochistan wing of the All-India Congress (Malik 2013, 86). The All-India Congress seems to have made its first significant links in the Kalat state through its relationship with the Anjuman-i-Watan. However as Achakzai was Pashtun, this link did not tie the All-India Congress to the nationalist elements in the region. The Balochistan Muslim League, founded by a Pathan and Quetta-based lawyer Qazi Muhammad Isa in 1939, enjoyed much of the Khan's attention in the wake of the KSNP's exile (Siddiqi 2012, 58). This relationship between Ahmad Yar Khan and the Balochistan Muslim League, the regional wing of Mohammad Ali Jinnah's Muslim League, would have the most significant impact on Balochistan's bargaining through the process of partition and its eventual annexation to Pakistan.

\subsection{Accession to Pakistan: The Birth of Pakistan-Baloch conflict}

The relationship between the Khan of Kalat and the Muslim League flourished when the Khan procured the services of Jinnah as the Legal Adviser to Kalat. The reasons for this relationship seemed simple enough, Jinnah was to advise the Khan on the best 
legal avenue to secure independence for the state of Kalat. In return for his guidance and support, the Khan heavily funded and publicly supported the Balochistan Muslim League's activities in Kalat and even sent money to the central office of the Muslim League (Siddiqi 2012, 58). The ultimate irony of the Khan placing his trust in Jinnah would only come out at the moment of partition as Jinnah had seemed, by available accounts, to support the independence of Kalat Khan 2005, 114-5). Consider the following 1946 memorandum presented by Jinnah as acting Legal Adviser to the Khan of Kalat:

(a) That the Kalat State is an independent sovereign State whose relations with the British Government are governed by the Treaty of 1876; (b) that its Indian associations are merely due to its connections with the British Government; (c) that Kalat being an independent State, the Khan, his Government, and his people can never agree to Kalat being included in any form of Indian Union; and (d) that with the termination of the treaty with British Government, the Kalat State will revert to its pre-treaty position of complete independence and will be free to choose its own course for the future. (Siddiqi 2012, 58)

Beyond the language of Jinnah's memorandum, the August $4^{\text {th }} 1947$ Round Table Conference saw an agreement between Kalat, the British, and the newly formed Pakistani state (represented by Jinnah and Liaqat Ali Khan) that guaranteed the independence of the Kalat state as well as "friendly relations with its neighbours" (Siddiqi 2012, 59; Malik 2013, 91). Corollaries to the agreement outline an important point of contention that would ultimately be used for the annexation of Kalat into Pakistan. 
Article 1 states that "The Government of Pakistan agrees that Kalat is an independent State, being quite different in status from other States of India; and commits to its relations with the British Government as manifested in several agreements" (Siddiqi 2012, 59). Article IV of the agreement, which is often overlooked by Baloch Historians, effectively places Pakistan in the same seat of power over Kalat that the British enjoyed (Malik 2013, 91).

A standstill agreement will be made between Pakistan and Kalat by which Pakistan shall stand committed to all the responsibilities and agreements signed by Kalat and the British Government from 1839 to 1947 and by this, Pakistan shall be the legal, constitutional and political successor of the British. (Siddiqi 2012, 59)

While the Khan signed what he thought was a binding agreement to his state's independence, Jinnah and the Muslim league had already solidified Pakistan takeover of the other regions of Pakistan, including British Balochistan. Article V of the August $4^{\text {th }}$ agreement stated that negotiations on specific aspects of the relationship between Kalat and Pakistan would be discussed in Karachi at some period post-independence (Khan $2005,115)$. These discussions, which took place in the Fall of 1947, serve as a defining moment evincing how Pakistan's relationship with Balochistan would mimic the British relationship with Kalat (Akhtar 2011, 125).

On the $15^{\text {th }}$ of August 1947, Kalat was declared an independent state by Ahmad Yar Khan (Malik 2013, 91; Khan 2005, 115). Upon the advice of the UK High Commissioner in Pakistan, Pakistani officials acted against the establishment of Kalat as an independent state and demanded its integration into Pakistan. A series of subtly 
orchestrated events, particularly playing on tribal rivalries, helped Pakistan leach significant portions of Kalat's territory and tribes into accession to Pakistan eventually leading to the capitulation of the Kalat (Malik 2013, 92; Khan 2005, 115). Pakistan, again following the example of the British Raj before them, exploited ever-present tensions in the Sardari system in order to do this (Akhtar 2011, 125; Siddiqi 2012, 60).

The Marri, Bugti and Sanjrani regions were historically the most disruptive and independent members of the Kalat state and were responsible for much of the violence against British officers which had led to the Sandeman Treaty in the first place. Despite having been brought into the state of Kalat, they retained unique levels of independence and paid no taxes to the Khan. Thus their joining Pakistan as a means to further their distance from the Khan was a relatively simple arrangement (Jaffrelot 2014, 136; Siddiqi 2012, 60).

Pakistan placed pressure on the Sardars of Kharan, Lasbela, and Makran who joined the dominion on March $21^{\text {st }} 1948$ (Jaffrelot 2014, 137). Only six days later a strange broadcast by the All-India radio claimed that the Khan had asked to merge with the new Indian Government but had been rejected due to the territorial gulf between them. Nehru later apologised for the false claim, but the actions nonetheless lost the Khan what little control he had left. At a moment when violence over Kashmir was beginning to emerge, the Khan had been accused of collaborating with the enemy. On March $30^{\text {th }}$ 1948, before Pakistan would send in military forces to no doubt put a forcible end to his rule, Ahmad Yar Khan acceded to Pakistan's demands and Kalat was merged into Pakistan, creating the province of Balochistan (Akhtar 2011, 125; Jaffrelot 2014, 136). 
Although the Government of Pakistan elected to continue its rule over Kalat by following the British example, it was markedly more interventionist from the outset. Jinnah imposed his authority directly over the Khan effectively leaving the title of Khan as a merely symbolic position. An officer was appointed to report back to and carry out the decisions of the Governor General on matters in the region, the Khan being subordinate to said officer (Khan 2005, 115-6). Beyond that, the central government had the leaders of the KSNP arrested and the party itself outlawed (Siddiqi 2012, 61).

This heavy-handed about-face by the Pakistani government was predictably poorly received amongst the nationalist circles in the region. The Khan's younger brother Prince Abdul Karim led a 700 man revolt against Pakistan (Malik 2013, 93-4). They marched across the border into Afghanistan, abjured the Khan's accession to Pakistan and demanded new negotiations over Kalat (Akhtar 2011, 125; Malik 2013, 94). As Siddiqi observes, this revolt failed for two important reasons.

First, the Afghans could not assure them of the requisite resource support because Kabul favoured the inclusion of Balochistan in an Afghan-controlled 'Pashtunistan' and was opposed to an independent Balochistan. Second, the rebels had neither the organisation nor the wherewithal for sustained action against an army equipped for highland operations (Malik 2013, 94; Siddiqi 2012, 61).

While Abdul Karim's revolt was a failure, his efforts evince the shaky foundations of sovereignty in Balochistan. A letter he wrote to his brother, the Khan, during this time also reflect the regional and ethnic schisms that were already so present and significant at Pakistan's inception and would later supply the fuel for further nationalist movements: 
From whatever angle we look at the present Government of Pakistan, we will see nothing but Punjabi Fascism. The people have no say in it. It is the army and arms that rule...There is no place for any other community in this government, be it the Baloch, the Sindhis, the Afghans or the Bengalis, unless they make themselves equally powerful. (Siddiqi 2012, 61)

Pakistani federalism was showing significant cracks less than a year after its creation. The new government's decision to keep colonial administrative structures in place may have been pragmatic given the conflict-ridden process of partition, but it sowed distrust within the broader regions of the country. Coupling this with the powercentralizing actions of the new federal government, there emerged new conflicts between the provinces and the centre. The idea of a powerful central government gave nationalist and ethnic leaders across the new country a new enemy: the Pakistani state. Thus the modern Baloch movement, a movement oriented in opposition to the Pakistani state, was born.

The Baloch, however, were already politically divided at the local level by the Sandeman system. They lacked the resources necessary to support either armed conflict or diplomatic maneuvering and failed to defend against a forced accession, giving up even more control over the region at the state level. Interference from India, which likely was aimed at disrupting Pakistani federalism more than supporting Balochistan, and a lack of support from otherwise vocal Afghan allies undermined the Baloch nationalists. That limited international support brought the Baloch nationalists further into the crosshairs of the federal government. Ultimately, a fear of outside influences and a 
politically disunited country would inform the ways the new postcolonial state responded to and affected the modern Baloch movement.

\subsection{The One Unit Scheme and Baloch Rebellion}

Administrative changes from the central government continued to invoke the ire of nationalists as a non-Baloch was appointed Prime Minister of the Balochistan States Union in 1952 (Siddiqi 2012, 62). Mounting frustrations came to a head when the One Unit Scheme was introduced in 1955 under Ayub Khan's central government (Jaffrelot 2014, 137). The policy grouped all of Pakistan's Western provinces into a single province as a means to counterbalance the populous and politically powerful East Pakistan, which was viewed as a threat to those who were currently in power in the central government. The scheme's attempts to downplay ethnic and regional differences at the federal level sparked nationalist movements across the country.

In Balochistan this saw Abdul Karim launch a new party named Ustoman Gal (People's Party). Ustoman Gal directly opposed the One Unit Scheme and demanded a unified Balochistan province (Jaffrelot 2014, 137). The Khan too organized and supported demonstrations against the scheme and called for an independent Balochistan, despite having officially signed onto the One Unit Scheme (Siddiqi 2012, 62). Being the most pronounced area of dissent, Balochistan drew the central government's ire.

In 1958 Iskander Mirza, the President of Pakistan, contacted the Khan of Kalat, purporting to be able to help the Khan secure independence for Kalat. He told the Khan to fly to London in order to ascertain the legal advice of Lord MacNair regarding Kalat's withdrawal from the One Unit Scheme. It was during his time away that Mirza trumped 
up charges that the Khan had organized a revolt against the central government (Siddiqi 2012, 62). Upon the Khan's return, the Pakistani Army moved into Kalat, arrested the Khan, his close followers, and various Baloch leaders from other tribes and parts of the region.

The Khan and his followers, including Abdul Karim, were accused of working with Afghanistan to create a rebel force of 80,000 armed men. The Khan denied the charges, in turn accusing Ayub Khan and Mirza of manufacturing the scenario specifically to justify the imposition of martial law (Malik 2013, 95). The Government demanded that all arms in the region be turned over at police stations to be confiscated by the central authority. Upon the tribesmen's refusal to comply, the Army began a ground unit campaign using tanks and artillery to bomb villages (Khan 2005, 116).

The manner in which the central government duped the Khan and moved into Kalat in the first place is an important example of the heavy-handed and manipulative tactics that Pakistan's leaders have deployed time and again to maintain dominance over the regions outside of Punjab.

The Army's bombing campaign provoked an armed rebellion led by Nawab Nauroz Khan, the 90-year tribal chief of the Jhalawan region. The Nauroz-led guerilla campaign and the Army's bombing continued on for more than a year before peace negotiations occurred (Malik 2013, 96-7). Again the central government used deceptive tactics to remove Nauroz as a threat. An oath on the Quran by representatives of both sides was used to agree to negotiations and get Nauroz down from the mountains where he was hiding. Upon his arrival to the July 1960 negotiations he was arrested along with his followers. His son and his followers were hanged on treason charges while Nauroz 
was jailed, wherein he would die four years later (Jaffrelot 2014, 138; Malik 2013, 96; Siddiqi 2012, 63).

Dying as a martyr for the Balochi people, Mir Nauroz is another in a long line of Baloch leaders whose slightest inclinations of goodwill toward the Pakistani state were exploited as a means for the central government to maintain power. This trend of interference and deceptive tactics matured into a subtle unwritten yet seemingly codified modus operandi of the Pakistani state through the 1960s.

Nationalist mobilization in Balochistan had been focused in the Kalat state as the Khan's seat had been centered in the areas of Sarawan and Jhalawan. The Marris and the Bugtis while not previously particularly dedicated to the nationalist cause, were nonetheless powerful tribes. Fearing the power of the Bugtis, the government created a false murder charge to place Akbar Bugti in jail, causing him to lose his Chieftainship (Siddiqi 2012, 63). Whereas Akbar Bugti had not made any moves towards supporting a nationalist movement, Khair Bakhsh Marri and Ataullah Mengal made pronounced outcries against the central government when elected to the National Assembly of Pakistan in 1962. This effectively put them in the crosshairs of the central government. In 1963 Ataullah Mengal was replaced by his uncle as Sardar. Ten days later the new Sardar was killed and Ataullah Mengal and his father were arrested on murder charges (Siddiqi 2012, 63). Two years later, Khair Bakhsh Marri, leader of the Marri tribe, was removed from his seat by the government and replaced by his uncle. When his uncle was murdered a few weeks later by fellow tribesmen, the government put the tribe under the administration of a panel of non-Baloch government officials. A similar panel 
was put in place to rule over the Bugti tribe after Akbar Bugti's removal from power (Siddiqi 2012, 63).

By continuously disrupting the tenures of tribal leaders and the stability of Baloch politics, the government sought to disrupt any unified resistance from forming. The government panels looked to replace the power of the tribal elite in the Jirga extending the interventionist tendencies of the Pakistani state. Contrary to their efforts, by entrenching the central government's grasp deeper and deeper into Baloch affairs, the government was giving impetus to a growing nationalist movement.

\subsection{Build-up of Insurgency}

In the early 1960s Sher Mohammad Marri, an ally of Khair Bakhsh Marri, helped found and lead the Parari guerilla movement (Malik 2013, 97). A precursor to the Baloch People's Liberation Front, the Parari movement was predominantly made up of Balochis from the Marri and Mengal tribes (Jaffrelot 2014, 139). The Pararis used guerilla tactics in their complex home terrain to gain the upper hand on the Pakistani Army (Malik 2013, 98). Skirmishes between the government and the Pararis saw a crescendo in the mid1960s and were curtailed in 1967 by a government sanctioned amnesty that saw Ataullah Mengal and Akbar Bugti released from prison (Siddiqi 2012, 64).

Although Akbar Bugti harboured resentment and dissent for the central

government, he was never brought into the fold of the nationalist movement. At the 1947 Shahi Jirga, he had voted in favour of accession (Meer 2016). Thus his release was not a boon for the nationalist movement, despite organized resistance to government. For example, soon after his release, Akbar Bugti led his tribesmen in breaching an important 
feeder canal so as to disrupt the flow of water towards irrigated Baloch land granted to Punjabi Army officials. Although this action constitutes a Baloch-led resistance to the central government, it stood separate from the Parari resistance and represented more of a Bugti versus Government struggle than a Baloch versus Government struggle (Siddiqi 2012, 64).

Within the nationalist movement itself some major splits were beginning to show along class and ideological lines. Much of the nationalist leadership argued for a radical socio-economic restructuring of Baloch society (Jaffrelot 2014, 138). The most vocal of these radicals was a group of young and educated middle class known as the Baloch Students Organization (BSO). When the Marri, Bugti and Mengal Sardars were put back in power of their respective tribes, the BSO experienced a major split. Those who argued against the hereditary rights and privileges of the Sardars splintered into the BSO Awami. A predominantly socialist group aligned closely to the alleged ideals of Zulfiqar Ali Bhutto's Pakistan People's Party (PPP), many of the BSO Awami members would join the PPP upon its takeover following the 1970 federal elections (Siddiqi 2012, 67-8).

Bhutto's tactics with the Baloch would mirror the kind of relationship between the Federal government and East Pakistan that led to the Bangladesh Liberation War soon after the 1970 elections. The Bengali Mujibur Rahman's Awami League won 160 of 162 seats in East Pakistan and out of a total of 300 seats across the country in the 1970 elections (Jaffrelot 2014, 216-8). Unwilling to concede power, Bhutto and Yahya Khan, Ayub Khan's military successor, postponed the convocation of the federal assembly in the hopes of negotiating the Awami League out of the power it had won through the elections (Jaffrelot 2014, 218). When the military took action by arresting Mujibur 
Rahman in March 1971, his followers fled to India where they formed a government in exile and sparked the revolution and war that would lead to Bangladesh's independence later that year (Jaffrelot 2014, 218).

While there is evidence that India had long since supported Bengali cries for independence, it was ultimately the unwillingness of those in power in West Pakistan's civilian establishment alongside the heavy-handed and oppressive tactics of the Pakistan Army that sparked the conflict (Jaffrelot 2014, 219). As the timeline of the BalochPakistan conflict proceeds, we will see that while some foreign actors offer support for movements that threaten a unified Pakistan, it was more prevalently the actions by the federal government that spurred separatist and nationalist movements.

While Zulfiqar Ali Bhutto eventually grabbed power through the electoralprocess, the 1970 elections also brought significant change to Balochistan. The NAP and the Jamiat Ulema-e-Islam (JUI) formed a coalition which won ten of the twenty seats in Balochistan's Provincial Assembly (Jaffrelot 2014, 138; Malik 2013, 98). Five seats went to independents and five to the Pakistan Muslim League (led by Qayyum Khan) and other parties. Bhutto's Pakistan People's Party failed to win a single seat in Balochistan despite winning in the rest of the country. Bhutto appointed an independent to the seat of Balochistan Governor, but facing backlash from the NAP-JUI coalition he placed Mir Ghaus Bakhsh Bizenjo as Governor and Sardar Ataullah Mengal as the Chief Minister of Balochistan (Malik 2013, 99; Siddiqi 2012, 65).

Bhutto's capitulation to the demands of the NAP-JUI should not, however, be seen as a large departure from the previous relationship between the central government and Balochistan's leaders. Bhutto wanted to garner Baloch support in part to strengthen 
his own position in a government prone to military takeover (Malik 2013, 99).

Furthermore the NAP had won the majority of seats in two provinces, and Bhutto could not deny them some semblance of power without putting his own position at risk. A letter written by Bhutto to Bizenjo emphasized the SUI gas installations as a matter of national importance and demanded that Bizenjo crack down on the nationalist Baloch movements which would undermine the central government's project of a unified Pakistan (Khan 2005, 117-8).

On April 26 1972, in regards to the appointment of non-ruling party members, Bhutto explained that he was "making this experiment in good faith and in the quest to achieve national purpose and unity...The Governor will, of course, hold office during the pleasure of the President, as provided in the Constitution" (Siddiqi 2012, 65). Despite the change over from a military to a civilian government, Pakistan's central government was nonetheless unwilling to grant Balochistan any significant degree of independence, even in provincial matters and insisted on using what power it had to forcefully quell nationalist movements.

As far as Sardars go, Ataullah Mengal and Khair Bakhsh Marri were considered 'progressive' and inclined towards socialist ideals, similar at least on the surface towards the socialist rhetoric of the PPP. Mengal gave up nearly half of his inherited lands to his tenants while Marri abolished many of the taxes that previous Chiefs had imposed upon his fellow tribesmen (Siddiqi 2012, 68). Similarly inclined towards socialist ideals was Bizenjo, now sitting in the seat of Governor of Balochistan. In June of 1972 these three leaders passed a momentous resolution which called for the formal end to the Sardari system in Balochistan. Aimed at abolishing the system in favour of one that was "in the 
best interests of the poor and oppressed people of Balochistan," the resolution would never come to fruition due to subsequent events that destabilised Balochistan's provincial government (Siddiqi 2012, 68).

\subsection{The 1973-77 Baloch Rebellion}

Reports of a London Plan in September 1972 accused members of the opposition to Pakistan's ruling party of colluding with Shaikh Mujib-ur-Rahman in a concerted effort to overthrow the government. The alleged London Plan was in fact a fabrication used to destabilise the provincial government in Balochistan (Malik 2013, 100; Siddiqi 2012, 65). The accusations of the London Plan coincided with a repatriation scheme aimed at removing non-indigenous officials from seats of power in the provinces. This saw hundreds of non-Baloch officials removed from their positions and replaced by locals. Despite this scheme of indigenisation occurring throughout Pakistan and in accordance with a national directive, the schema was further applied to law enforcement agencies which drew ire from the central government (Siddiqi 2012, 66).

Farhan Siddiqi has identified four events which are pivotal at this point in Balochcenter relations.

1. A conflict in November 1972 between Kahloies, tenants of Punjabi settlers, and Marris was conflated by the government into an ethnically motivated attack on Punjabis by Marri tribesmen.

2. A move by the Mengal Ministry to oust 60 per cent of non-Baloch officers from their police force and replace them with Baloch officers. The Ministry also created their own unique police structure which they dubbed the "Balochistan 
Dehi Muhafiz". The government was dissatisfied with this move and also accused the Ministry of purposely appointing NAP supporters into the positions.

3. A skirmish broke out between the Jamotes of Lasbela and the provincial government, ultimately resulting in the Pakistan Army taking control over Lasbela on February 9 1973. Bizenjo argued that the skirmish was purposefully orchestrated by the Federal Government to destabilise the provincial government. He argued that Qayyum Khan's followers "paid the Jamote tribe money and provided weapons so that they could rise against the Baloch government and Governor Rule could be imposed in the province" (Siddiqi 2012, 66). Bizenjo argued that the provincial government was forced to call upon tribesmen to suppress the rebellion when their attempts to use the provincial military were blocked by the Federal Government. Conversely, the central government accused the Balochi tribe leaders of looting and killing Jamotes and forcing them to take refuge in the nearby hills. It was upon this basis that the Federal Army seized control of Lasbela.

4. The day after the Army stormed into Lasbela and seized control, the Federal Government announced that they had discovered a "large cache of arms and ammunition at the residence of Nasir al Saud, Iraqi Military Attaché in Islamabad, which the government maintained were destined for the secessionist forces in Balochistan" (Siddiqi 2012, 67). Despite their being no evidence to link the arms to Balochistan, the government insisted that this was in fact the case and used it as grounds to dissolve the NAP-JUI provincial government on 14 February 1973. (Siddiqi 2012, 66-8) 
The re-occurring interference of the Federal Government in Baloch affairs was in part effective as it did de-stabilise the provincial government. The dissolution of the NAP-JUI government, however, was anything but a subtle move and sparked the question of Balochistan's role as subservient to the whims of a predominantly Punjabi Federal Government. Where the Federal Government had, since Pakistan's inception, sought to appease Balochis on the surface and use covert tactics to disrupt their political unity, Bhutto's heavy-handed tactics sparked the most significant Balochi uprising in Pakistani history (Malik 2013, 100).

Like the rebellions and skirmishes before it, the 1973 conflict was motivated by nationalist sentiments, but largely provoked by a central authority and over-arching political structure that not only placed Baloch leaders on the fringe, but actively sought to disrupt and interfere in Balochistan. This rebellion was different because, as Siddiqi observes, "two powerful tribal Sardars were involved, mainly the Marris and Mengals, which was previously not the case" (Siddiqi 2012, 68).

Whereas the Khan was heavily involved in the previous conflicts, the changing structure of government in Balochistan had left the Sardars and the Parari leaders as the effective figureheads of Baloch nationalism. The Baloch movement was more united at the local level than in the past because of the escalated threat that Bhutto posed to Baloch peoples on a wide-scale. Moreover the Federal Government's recent loss of East Pakistan in the successful independence movement in Bangladesh had left the now demoralized and battle-weary Army as an easier opponent.

The modern Baloch movement hit a particular pinnacle here at both the state and local levels. They were as united behind a threatened Baloch identity as they had been 
since Partition. They opposed a state that had shown a willingness to try and stamp out a different ethnic group by military force. That state's military also faced a particular resource shortage due to its recent loss. These factors overlapping at the local and state levels meant that the Baloch movement had a unique opportunity here to strike out against the state. However, international actors would ultimately factor in to the movements defeat in this campaign.

Predominantly a guerrilla rebellion against the more organized Pakistani Army, the skirmishes began in earnest in April 1973 with Baloch guerilla units ambushing army convoys. Guerilla troops continuously ambushed army personnel, disrupting supply lines and robbing munitions. The following month Mengal guerrilla forces ambushed the Additional Deputy Commissioner of Kalat, forcing the Federal Government to step up its tactics. In August 1973, Mir Ghaus Bakhsh Bizenjo, Khair Bakhsh Marri and Ataullah Mengal were placed under arrest. The Air Force was called in around the same time to begin a bombing campaign on guerilla strongholds (Siddiqi 2012, 69).

A major boon to the Federal Government's efforts was Iran's concern that the Balochi rebellion would spread to Baloch territory in Iran (Jaffrelot 2014, 139). "In mid1974, Iran sent thirty US-supplied Huey Cobra helicopters, many of them manned by Iranian pilots" (Siddiqi 2012, 69). The subsequently launched Operation Chamalan in the Marri region had a devastating effect on Baloch efforts, limiting them to quick attacks and small-scale guerrilla tactics.

The effect of international actors on the Baloch movement was particularly direct here. Bolstered by Iran's support, the Pakistan Army was better organized and better armed and the Baloch were unable to claim any significant swathes of territory under its 
control (Jaffrelot 2014, 139; Siddiqi 2012, 70). It is worth noting that Pakistan had lost half of its navy, a third of its army and a quarter of its air-force in the Bangladesh Liberation War, pointing further to its reliance on foreign support to bolster a military that was still in recovery from a lost civil war (Jackson 1975).

Therein lies the importance of assessing international level actors in tempering the evolution of the Baloch movement. Iran had its own interests in opposing any broad Baloch movement. By supporting the Pakistan Army, Iran helped to put down the Baloch rebellion. Despite the Baloch movement's rare opportunity to effect change at the local and state level, the international level concerns of Iran overpower what resources the Baloch rebels had managed to piece together. While the end of the conflict was essentially decided on a military resource battle, it helped spell the end of that period of unification within the Baloch movement. It also only gave Bhutto a temporary boost of stability as Pakistan's worn out military would ultimately turn against him.

Zia al-Huq's military coup in 1977 saw the end of Bhutto's government and the opportunity for fresh relations with the provinces of Pakistan. His release of Bakhsh Marri, Ataullah Mengal and Bizenjo was seen as a grand gesture of good-will towards the Balochi movement and the three leaders effectively called off the rebellion (Malik 2013, 101). Zia al-Huq had effectively used a divide and concede approach to disrupt the movement. By conceding to some of the Baloch nationalists' demands, Zia al-Huq acknowledged that the actions of the previous government were heavy-handed. Furthermore he had opened up the possibility that some of those within the Baloch movement with more moderate goals might achieve those goals by working with his government. 
This effectively put an end to the unified myth-symbol complex of a threatened Baloch ethnicity that had bolstered support for the movement. It splintered the movement by dividing it at local level. While the Sardars Mengal and Marri went into exile, Bizenjo shifted away from his nationalist stance and began to argue for reconciliation with the state and "outright conformism with the status quo" (Siddiqi 2012, 70).

The effective abandonment of the nationalist movement by these three leaders disrupted the Baloch movement's momentum and unity. At the state level there was a noticeable power vacuum. At the local level, the exile of key leaders and a controversial shift in stance by Bizenjo, amongst other leaders, left the Baloch in a tribe versus tribe status akin to the dynamic in the colonial era. Whether or not there was continuing international support for the Pakistani state mattered less now that there was no unified Baloch movement for the state to take on.

\subsection{The 80s and 90s: a Period of Relative Stability}

Following the rise of General al-Huq to power came a period of relative stability in Balochistan. Credit is due to Zia al-Huq as the release of Baloch political prisoners was accompanied by promises for economic development in Balochistan (Jaffrelot 2014, 140). Nonetheless, much of the stability can be attributed to the exile of nationalist leaders, leaving more moderate Baloch leaders to step in to the political limelight and push for better integration of Balochistan into the Pakistani state.

Of the three major leaders of the nationalist movement, two chose exile and the continuation of their movement from abroad while one opted into federal politics in Pakistan. Khair Bakhsh Marri exiled himself to Afghanistan where he led the Balochistan 
Liberation Army (BLA). The BLA advocated for an independent Great Balochistan including Baloch territories from Iran, Afghanistan, and Pakistan (Jaffrelot 2014, 140). Ataullah Mengal chose exile in London and, alongside Mumtaz Bhutto, founded the Sindh Baloch Pashtun Front which pushed for armed struggle against the Pakistani state in hopes of attaining a confederate regime (Jaffrelot 2014, 140).

Ghous Bukhsh Bizenjo on the other hand chose a moderate path by creating the Pakistan National Party (PNP) with the aim of achieving better representation for Balochistan at a federal level. Alongside the enforcement of the Constitution of 1973 as a guide to such improvements, the PNP advocated redrawing Pakistani provincial boundaries to better reflect and unify areas where Baloch language and culture were strong (Jaffrelot 2014, 140). After Bizenjo's death in 1989 the PNP was merged into a new party, the Baloch National Party (BNP), which continued on the PNP's primary platform (Jaffrelot 2014, 140-1).

The 1988 elections saw more Baloch leaders brought into the fold of electoral politics. Despite the weakening of Baloch culture, Sardars retained power and channeled it through the Baloch National Alliance (BNA). The BNA was an amalgamation of the BNM and Akbar Bugti's Jamhoori Watan Party. As moderates saw more success in this period, the idea that the Pakistani state and Pakistani federalism posed a direct risk to Baloch ethnicity waned. The political integration of local level leaders into state level politics suggested to many that the idea of a Baloch nationalist movement, particularly with the aim of an autonomous state, was unnecessary. This resulted in a major split within any potentially broad or unified Baloch movement, dividing those who favoured 
moderate diplomatic integration from those who remained adamant that military force needed to be used to create a safe autonomous state for the Baloch.

Changing social demographics also provide an insight into this period of stability. While the redrawing of Pakistani provincial boundaries following the One-Unit Scheme continued to undermine cultural homogeneity, emigration of Balochis out of the province and non-Baloch into the province led to linguistic and demographic shifts as well. Lack of education also undermined the development of a Baloch middle class or intelligentsia as the literacy rate was 10.1 per cent in 1981 (Jaffrelot 2014, 141). While the new leaders of the central government chose paths less interventionist than their predecessors, they did not grant Baloch peoples pathways to socio-economic development. Perhaps that is why there was a burgeoning drug trade in the region, featuring opium production in the tribal regions in Balochistan (Le Vine 1991).

Despite the relative political stability in the post-Zulfiqar Ali Bhutto era, social and economic progress for Balochistan was not on the radar of the Pakistani state and nationalist violence still occurred, however now it was increasingly directed at moderate Baloch peoples. For example, in the course of the 1993 federal elections, Baloch nationalists attacked other Baloch tribes over their involvement in the elections (Iqbal 1993). The following year a tribal conflict between the Raisani's and Bugti's led to a violent confrontation at a funeral with fears of continuing violence between the tribes (UPI NewsTrack 1994). It was evidently a period marked more by internal tribal conflict than any kind of unified militant movement against the federal government, though such attacks did occur (Lyon 1995; Grant 1996). The tribes in the past had generally worked in groups but were not unified on a large scale. The exile of major leaders as well the loss in 
the previous rebellion seem to have further entrenched tribal social divisions as political boundaries, pitting tribe against tribe for control of the region.

Relevant here is Surendra's argument that grievance-based explanations of social mobilization can overemphasize the importance of social discontent as a sufficient cause for mobilization. There was still a marked lack of development and little voice for Baloch leaders in the federal establishment, so grievances abounded. An opportunity-based explanation suggests that there was a lack of external support and available resources to prop up Baloch militants. The nature of federal-provincial relations further meant that there was opportunity for Baloch moderates within the government. This helps to explain this period of relative stability.

There was no broadly unified Baloch movement, with Baloch divided along political and tribal lines. The federal government was in control by civilian authorities who had little interest in the region beyond its gas and mining industries, which were nonetheless on the back burner to similar projects in other regions. Notably, attacks targeting government posts prove conflict persisted through the 1990s (Grant 1996). While widespread mobilization was not a feature of the Baloch movement at this time, there was an enduring group of militant separatists who opposed the possibility of reconciliation with the state.

Changes at the federal level would have a large impact on the Baloch tribes focus on internal and local level politics. Benazir Bhutto's reign was cut short by a loss to Nawaz Sharif who lasted no more than two years before Pervez Musharraf came to power in a military coup (Cooper 1996, Washington Times 1997; Zia 1993). By 1998 it seemed that the Pakistani public had become disillusioned by the corruption that ran rampant 
through the civilian governments and favored a return to a military dictatorship

(Goldenberg 1997; Grant 1996). Under Sharif and then Musharraf the federal government began testing nuclear weapons, touting the need to defend themselves from an India with nuclear weapons (Courier Mail 1998, Tolson 1998).

Of concern to the Baloch was that the nuclear weapons were being tested in Balochistan (Tolson 1998). Even before the testing began, a group of militant Baloch protested the selection of Balochistan as a testing grounds by hijacking a plane (Iqbal 1998). The tests were met with jubilation as a sign of unity against India in the eastern provinces, but many Baloch peoples saw it as another sign of their lack of integration into the federation (Kifner 1998). Similarly in 1999 Pakistan opened the coast near the Gwadar township to US fishing companies. This action was met by Baloch in the area with outcries that this decision would leave the local fishing economy destitute (Galpin 1999).

Grievances with the federal government were not particularly different in this time frame. Yet the Baloch nationalists were pushed to the background and inter-tribal conflicts were commonplace in the region. A period of civilian rule meant that moderates had better opportunity to take power through state institutions. Those who were more inclined to armed conflict seemed to sit more on the fringes of the feudal structure with little support amongst the Baloch for their more violent form of inter-tribal conflict.

There was, since Zia al-Huq's reconciliatory actions in 1977, seemingly no broad or unified Baloch identity that was directly threatened by the Pakistani state. Those moderates who wished to advance the position of Baloch peoples still lacked resources though they were given more political say than in times past. State level politics and the 
international threat India posed to Pakistan further disrupted unity at the local level in Balochistan. It was hard to organize against a state that was itself so unstable and changing and Baloch militants lacked the resources and political support necessary to take on the state. These factors undermined the efficacy of any Baloch movement during this period.

The era of civilian rule was, however, mired in corruption and the country's return to military rule saw a more hardline approach by the federal government in its relations with the provinces. In the next chapter we will see that the return of conflict in the 2000s was sparked not only by the coupling of new and longstanding grievances, but by more unified nationalist groups with a larger pool of resources than had been available for a Baloch movement in the decades prior. 


\section{Chapter: The Recent Conflict}

This chapter begins by picking up the narrative of the third chapter. It traces the political history, paying particular attention to the pattern of internal tribal conflict between separatists, nationalists, and moderates alongside the broader conflict between Balochistan, the Baloch peoples and the federal government and its military arm. With an understanding of the region and the conflict's evolution, the chapter turns to assess the role of the Gwadar Port and Pakistan's economic relationship with China. The chapter closes with an exploration of foreign influence and support for the Baloch nationalists and separatists.

This chapter relies in particular on interpretive content analysis of news and journal articles in order to contextualize and assess available information on the region and the recent conflict. Built on a skeleton of the recent conflict through what limited secondary sources are available, this chapter predominantly uses multiple news sources and agencies to code and compile, then verify and assess information about the conflict. Balancing the information from various news sources, this chapter uses reliable information to build an account of the conflict and the variables at play in the Baloch movement's evolution.

\subsection{The Sparks of Conflict in the Early 00s}

Under Musharraf's military rule, violent confrontations beginning at the turn of the millennium resulted in the various Baloch tribes involved in multiple confrontations with the Pakistani state. The return to military rule under Musharraf and the Pakistani military's domination by Punjabis and Punjabi interests fueled increased distrust and 
disassociation from the Pakistani state. In particular, key Baloch leaders Nawab Khair Baksh Marri, Nawab Akbar Khan Bugti and Sardar Ataullah Mengal supported the action of groups like the BLA, BLF and BPLF, all of which engaged in guerilla warfare against the state (Malik 2013, 111). After the relatively tranquil '90s, a few major events involving key Baloch tribal leaders saw conflict in the region spark and expand into a protracted conflict that continues today.

One of the earliest events tied to the spark of this most recent conflict was the killing of Justice Nawaz Marri of the Balochistan High Court in January 2000 (Shah 2018). Nawab Khair Baksh Marri, as well as his sons, relatives and associates were arrested for the killing, prompting the re-emergence of the BLA in part as a response to the arrest of the Baloch leader (Malik 2013, 108). Even now, nearly twenty years later, the trial of Gazeen Marri for that murder is still underway and violence against court officials in the region continues (Shah 2018). As the BLA began to re-emerge, the Pakistani military deployed troops throughout the region, in particular in support of the development of the Gwadar deep-sea port (Gwadar) (Malik 2013, 108).

On May 4, 2004, a roadside car-bombing killed 3 Chinese engineers en route to work on Gwadar (BBC News 2004). The bombing has since been attributed to Baloch nationalists protesting the development of Gwadar on the grounds that associated economic benefits would be monopolized by the Punjab-dominated military-run Pakistani government (Malik 2013, 108; BBC News 2004). In 2004 alone the BLF took credit for nearly thirty bomb blasts in Quetta alone, claiming that these acts supported the ultimate realization of an independent Balochistan (Malik 2013, 108). 
The bombings can be understood as the result of the way disenfranchised moderates in Baloch politics were losing ground as Musharraf's centralized and Punjab oriented policies suggested there would be little benefit in cooperating with the Pakistani state. As political opportunity diminished, it seems that violent actions by Baloch groups grew. The more the state responded with increasing force, the more convincing a case could be made that Baloch peoples were under threat and needed to unite. Baloch grievances had not changed in any radical way. Instead diminished opportunity for Baloch in the political realm meant that direct confrontation with the state, whether violent or not, became a more viable option. Musharraf's government grew more willing to take up arms against Baloch peoples more broadly to respond to an increase in guerilla bombings. This occurred in tandem with Baloch militants increasing willingness to bomb and attack symbols of the state. This violence escalated further the next year.

On January $3^{\text {rd }}, 2005$ the rape of Dr. Shazia Khalid by a military officer was met by efforts of the Pakistani government to cover up the incident by questioning Dr. Khalid's mental state and her character, including forcibly moving her to a hospital under government control in Karachi (Dawn 2005a; Kristof 2005). In response to the incident, Nawab Akbar Bugti, chief of the Jamhoori Watan Party (JWP), pointed the finger at the Pakistani military which led to an escalating feud resulting in armed confrontations between Bugti tribesmen and state military (Rashid 2005). Supported by the Balochistan Liberation Army (BLA), on January $11^{\text {th }}$ the Bugtis stormed a major Sui Gas plant in Dera Bugti resulting in a five-day conflict in which at least eight people died (Rashid 2005; McKenna 2006). The fighting prompted the infamous warning from Musharraf that 
if the Baloch do not cease the violence that "they will not know what hit them" (Mazari 2005).

In response to the situation the Pakistani government tried to broker a peace deal with Baloch leaders by forming a Parliamentary Committee on Balochistan under the auspices of then Prime Minister Shujahat Hussain (Malik 2013, 109). The Committee was tasked with investigating how to improve state law and order institutions while improving interprovincial harmony. At the same time government officials met with Nawab Bugti to try and maintain a ceasefire (Malik 2013). Nonetheless violence sparked again in March 2005, causing the death of over 60 peoples, mostly civilians (Wasim and Khan 2005; Malik 2013, 110).

While there is a notably limited record of subsequent fights through the year, small-scale skirmishes, largely the result of Baloch guerilla tactics, maintaining their focus on key economic, government and military targets, continued until a full-scale military conflict was launched in Kohlu district of Balochistan (Malik 2013, 110).

Maria Malik pinpoints two particular events as leading to this larger outbreak of violence (Malik 2013, 110). The first was a rocket attack carried out by the BLA on December 14, 2005 in Kohlu district, just hours before Musharraf landed there to give a speech regarding the conflict (Dawn 2005b). During this brief four-hour visit to Kohlu, Musharraf gave a speech at a public gathering wherein he stated that the socio-economic development in the region was to be harnessed for the benefit of the locals. He warned the public not to "pay heed to the elements who indulge in utterly baseless propaganda" (Dawn 2005b). The military responded quickly and confiscated eight rockets being transported by donkeys later that day (Reddy 2005; Dawn 2005b). Two days later Baloch 
fighters attacked a helicopter carrying military officials with both rocket and assault rifle fire (Reddy 2005).

The military further stepped up its response and the subsequent months saw continued conflict. A stark lack of reporting on the conflict means that we have very little insight into what shape that fighting took beyond presumably small-scale targeted guerrilla attacks versus larger-scale military operations supported by aircraft and more sophisticated artillery (Swami 2006). An article in The Hindu points to Baloch moderate Sardar Sherbaz Khan Mazari's suggestion that the fighting resembled the conflict in 1970 leading up to the Bangladesh' separation (Swami 2006). That same article notes that Najam Sethi, a prominent Pakistani journalist, blamed the crisis on Musharraf rigging the previous elections and sidelining mainstream parties in favour of Islamist military groups, thus alienating the older tribal elements and the newer middle class elements in the province at the same time (Swami 2006). Whatever biases may inform that article, it does not contravene the general narrative raised by the Baloch separatists and tribal leaders from previous conflicts with Musharraf. Musharraf seemed to understand that he could influence the inter-tribal dynamics at play. With tribal support at the local level splintered, the Baloch movement would be more manageable. Musharraf could focus on confronting militant Baloch groups directly through the Army and putting compliant Baloch or non-Baloch in power at the provincial and federal levels.

\subsection{The Death of Nawab Akbar Bugti: Moderate turned Martyr}

The BLA, BLF and BPLF all ramped up their activity as Musharraf sent more and more troops to respond to the increasing violence in Balochistan. Though all three are 
separate organizations, they share similar motives. Nonetheless their true leadership and internal organization remained uncertain as Nawab Akbar Khan Bugti, Sardar Ataullah Mengal, and Nawab Khair Baksh Marri all maintained that these organizations were beyond their control (Malik 2013, 111).

This is a particularly important point for understanding how Baloch ethnicity was defined by something more than elite manipulation. Leaders could harness some level of loyalty to their particular group, but many of those "following" them were themselves parties to the Baloch myth-symbol complex and loyal to the "cause" of Baloch autonomy rather than to their leader's particular politics. The cell-like structure of the BLA, BLF and BPLF meant that individual cells would act against government targets and progovernment officials or leaders, but without the same overarching tactical oversight that a unified military or movement would have. Of course this helped Baloch militants evade the Pakistan Army more easily, while at the same time possibly undermining a more effective use of their munitions and resources. Similarly, the Pakistan army had little insight into who any specific militant group was made up of, making it harder to tactically choose targets. The result was that the Army targeted whoever they could track, without insight into the effects of what killing those targets might be.

On August 26, 2006, a military operation in the mountains of Kohlu district attacked a militia made up of Bugti tribesmen, killing Akbar Bugti (Shahid 2006a). Nawab Akbar Bugti had apparently taken to the mountains with a militia to continue to fight against the military in an area that had traditionally been easier for the Baloch to defend and then strike out from. Akbar Bugti's death resulted in protests and riots across Balochistan (Gall 2006). The military tried to impose a 1 am curfew in Quetta, which was 
ignored by protesters who targeted government buildings and buses. There were also reports of gunfire and sparks of violence across the region (Gall 2006).

Akbar Bugti's killing was a particularly significant event for the Baloch movement. He had been the leader of one of the major Baloch tribes and a staunch nationalist for over 50 years. Tracing the course of his life, it is evident that his hope that the Baloch peoples could find a place in the project of a Pakistani federation waned.

In the 1947 Shahi Jirga, Akbar Bugti voted in favour of accession (Meer 2016). He continued to work as a moderate seeking better and fairer integration for his peoples and his province throughout the earlier conflicts. He was often at odds with the more nationalist counterparts and sometimes actively worked against the Marris and Mengals, yet saw himself forcibly removed from power, jailed, and exiled by the Pakistani state. Nonetheless, in 2004 Akbar Bugti unsuccessfully called for the various Baloch nationalist parties to unify and create a single party to represent the Baloch peoples collectively in the federal government (Dawn 2009; Meer 2016). His attempts at unifying local Baloch tribes into a broad and singular moderate movement that could exert influence at the state level failed. Then, in 2005, at 79 years-old he went headlong into battle alongside his tribesmen, seemingly happy to die fighting for his cause and apparently abandoning any hopes that non-violent action could see justice for Baloch peoples. It is unsurprising that he was widely regarded as a hero for the Baloch cause, nor should it have been surprising to the Pakistani state that his death could serve as a catalyst that would help unify otherwise rival Baloch tribes such as the Marris and Bugtis (BBC News 2006; Shahid 2006a; Hindustan Times 2006c). 
Akbar Bugti's death in battle against the Pakistani military suggested the legacy of a moderate who had given up on any hopes of diplomatically coming to terms with a hostile and autocratic state. Despite his continuing efforts to improve Balochistan's position in the federation, in death he was painted by many as a martyr for the Baloch nationalist cause, with people rioting and ramping up violence against symbols of the Pakistani state (Gall 2006; Meer 2016; Hindustan Times 2006c; Dow Jones International 2006a). A quote from Jamil Bugti, Nawab Akbar Bugti's son, is particularly telling: "This is where the establishment miscalculated. They though that once we get rid of Akbar Bugti that everything will die out, not realizing that it will spread to each and every corner of the Baloch land" (Al Jazeera 2012; Hindustan Times 2006b). The symbolic nature of Akbar Bugti's death helped push the narrative that the only option for protecting Baloch interests was through direct and violent confrontation with the state. The myth-symbol complex of an ancient Baloch ethnicity at risk of being obliterated by a brutal and oppressive state reached its highest peak since the 1973 rebellion.

Following the death of Akbar Bugti, the Baloch tribes gathered in Kalat and organized a grand jirga, in the style of their ancestors. Mir Suleman Dawood called the grand jirga on September 21, the first of its kind in over 100 years (Al Jazeera 2012; Shahid 2006b). In the jirga the Baloch agreed that they wanted to return to their at least semi-independent status before accession to Pakistan with a generally unified Balochistan under the sardar system (Al Jazeera 2012). The jirga declared that they "rejected the Sui tribal jirga's decision to abolish the Sardari system in the Bugti area and termed the action taken at the behest of the government an interference in tribal affairs and said that tribal matters should be resolved in accordance with customs and traditions" (Shahid 
2006b). The declaration of the jirga termed the Pakistani state's action as "state terrorism" (Shahid 2006b).

In his speech before the grand jirga, the Khan of Kalat Mir Suleman Dawood said that "the presence of so many sardars in the Baloch national jirga belied the claim of President Pervez Musharraf that 72 tribal chiefs were supporting his policy. He asserted that all Baloch people would abide the decision of the jirga" (Shahid 2006b). There were reportedly 85 tribal chiefs as well as over 300 elders at the jirga (Shahid 2006b). While the limited available reports of the event suggest that there was widespread consensus, it may well be that many sardars and chiefs at the Jirga followed suit with their Baloch comrades while holding out hopes for gaining individual favour with the federal government (Meer 2016).

Sardar Yar Muhammad Rind stated that the grand jirga's decision reflected only the views of some Baloch peoples, suggesting instead that there was much continuing support for the pro-government leaders like himself (Balochistan Times 2006). His sentiment was that the alleged consensus was a false one as the grand jirga only invited those sympathetic to their cause, purposely excluding those sardars and chieftains that were in favour of working with the government (Balochistan Times 2006). Whatever the true nature of the makeup of the grand jirga, the declaration that came out of it was a powerful statement from the nationalists.

The grand jirga saw the participating chiefs agree to raise an action before the International Court of Justice (ICJ). In particular they alleged that the 1948 accession agreement had been continually violated by the Pakistani state and as such demanded to be restored to their pre-accession status (Hindustan Times 2006a; Subramanian 2006). 
The declaration arising out of the grand jirga demanded that long overdue control of resources in the province and that Baloch territories in Sindh and Punjab be united with the Baloch territory to create a "purely Baloch unit" (Hindustan Times 2006a). Their declaration also rejected what they felt was a government backed Dera Bugti jirga which announced the end of the Sardar system (Hindustan Times 2006a; Subramanian 2006). It has been a noted strategy of Musharraf to end the sardar system as a way to put an end to the feudal structures that continued to dominate Baloch politics (Hindustan Times 2006a). Ending the sardar system would likely allow the federal government to put their own charges in seats of power in the province, disrupting the ethno-political cohesiveness that seemed to drive Baloch separatists and moderates alike.

In response to the grand jirga, Musharraf's government moved to plan a government-backed grand jirga on November $8^{\text {th }}$ (Alvi 2006). That jirga was boycotted by the sardars and chiefs at the September 21 grand jirga, as they felt it was an attempt by Musharraf to exercise control over the Baloch leaders (Alvi 2006). Of the roughly over 500 tribal leaders in the province, 85 leaders, including the Mengals and Marris, would boycott the jirga (Alvi 2006). Balochistan's Chief Minister Jam Muhammad Yusuf advocated the grand jirga as an opportunity for the pro-government Baloch leaders to have their voices heard by Musharraf (PPI 2006a).

Musharraf's divide and conquer strategies were likely ineffective because they were transparent attempts to exert more control that only fed into the narrative that the state was opposed to the Baloch peoples. Like Zulfiqar Ali Bhutto before him, Musharraf's attempts to dissuade the Baloch movement only seemed to fan the flames of discontent. Musharraf's clear disinterest in allowing more political power or resources for 
the Baloch helped push moderate elements further to the extreme. Furthermore the construction of the Gwadar Port meant that it was clear to anyone, including the Baloch, that the region held a unique strategic international value. Yet, there seemed little opportunity for Baloch peoples to reap any direct reward from the project. These factors renewed a unified Baloch movement.

\subsection{Continuing Violence \& the 2008 Federal Elections}

A steady stream of nationalist violence characterized the years that followed. Islamist militant attacks increased throughout the region, in part due to the influx of displaced fighters flowing across the border from Afghanistan (Jaffrelot 2014, 150). The War on Terror had pushed more and more Afghans over into Balochistan, especially Islamic militants fleeing the US presence in Afghanistan, and that made it harder to distinguish whether these attacks were perpetrated by nationalists or by sectarian militants (Xinhua News Agency 2006a; Yousafzai 2007). While it was often unclear what motivated any given attack, Baloch nationalist organizations steadily took ownership of attacks which targeted government installations, a feature which helped distinguish the nationalist violence from the sectarian (PPI 2006b; OANA 2006; Loudon 2007).

Rocket blasts and bombings at railway stations and Sui gas pipelines alongside less focused attacks throughout the region were a regular occurrence up to the elections in 2008 (Hindustan Times 2006d; Xinhua News Agency 2006b; Dow Jones International 2006b; BBC Monitoring 2007b). Bicycle and car bombs were a common tactic used by the nationalists especially in the city areas. Bicycle bombs were generally used to target 
police stations, courtrooms and government offices (Xinhua News Agency 2006a; IANS 2006; Mills 2006; Irish Examiner 2007; Kyodo News 2007).

The consequences of the continuing violence took their toll. Pakistan continued to face energy shortfalls, in large part due to the bombing of gas pipelines, while bombings at Gwadar port undermined the country's economic stability (BBC Monitoring 2007a; IANS 2007b). The conflict left thousands of people displaced, as many as 84,000 according to a UN agency in 2006 (Pennington 2006).

The Pakistani government, throughout this continuing violence, remained wary and alert to the possibility of influence and support for the Baloch nationalist cause by India, among other possible foreign interlopers (Varma 2006). Notably Brahmdag Bugti, Nawab Akbar Bugti's grandson and reported as his successor, fled the country and, as of November 2006, was hiding in Afghanistan with a militia (PTI 2006). The government pursued such nationalists by furthering military operations and holding the activists accountable for bombings through the judicial system (BBC Monitoring 2006a; OANA 2006). Despite the continuing violence that would follow, in May of 2007 Musharraf claimed victory over the separatists, suggesting that the military had all but wiped out their opposition leaving only a few struggling bases left to clean up (VOA 2007). It seems in retrospect as if Musharraf may have known he was overstating the situation, but by issuing a call to other militants to lay down their arms, he was likely trying to motivate the more moderate individuals to defect (BBC Monitoring 2007d).

This seemed to keep in line with a reports that found that Musharraf preferred a divide and conquer approach to dealing with insurgents (Business Recorder 2006). In particular the International Crisis Group found that Musharraf supported Pashtun Islamist 
parties such as the JUI-F, who were linked to the Afghan Taliban and often fought against the Baloch (PTI 2007c). The report suggested that not only were Musharraf's repressive policies feeding support for the Baloch nationalists, but that by alienating the Baloch, Musharraf was alienating potential allies in the War on Terror which he had tied so closely to his policy regime (PTI 2007c, Hussain 2007). International level politics could have informed more moderate policies that undermined the Baloch movement. Instead state level rivalries became Musharraf's focus, predictably unifying the Baloch movement.

Despite the unifying nature of Akbar Bugti's death, the Baloch movement was by no means a homogenous singular movement. Some leaders were staunchly progovernment or at least pro-Musharraf (PPI 2007f). The nationalist tribes emphasized the importance of their traditions and resisted attempts by the state to change them (Balochistan Times 2007). For their part Baloch leaders such as Ataullah Mengal suggested that they would welcome support from the US and India, although they claimed to not yet have received any such support (ANI 2006). The main nationalist militant groups were still divided largely by their tribal structures, though coordination seemed to have increased. Baloch militants preferred not to have a centralized organization or command centre, finding instead that it was easier to prevent being defeated by the army when they were small and flexible cells, coming out of hiding using guerilla tactics (Al Jazeera 2012). Despite growing insurgent networks, individuals within these groups that often mirrored their tribal structure did not always agree with the best way forward, leading to violence within the groups that disrupted the larger movement. 
In one instance Sardar Bangan Khan was killed in a bomb blast after turning over his weapons, surrendering to the government, and publicly expressing support for their policies (BBC Monitoring 2006b). Bangan Khan had been a close ally of Akbar Bugti before Akbar Bugti's death. Bangan Khan's killing was claimed by the BLA, who claimed that he had betrayed the movement (BBC Monitoring 2006b). Nor was this the only time that militants would seem to defect to the Pakistani state's side. In February 2007, 400 Marri tribesmen, alongside their commanders, surrendered to the government and promised their support for the government (IANS 2007a; Xinhua News Agency 2007). The next month a bomb targeting pro-government tribal elders killed 2 elders who had previously supported the late Akbar Bugti (PTI 2007b). Similar defections occurred throughout the conflict (BBC Monitoring 2007c). It seems evident that more militant nationalists were targeting their moderate counterparts, possibly considering them traitors to the Baloch cause and likely to influence others from defecting.

With elections coming up, it was important for civilian politicians to advocate for non-military solutions at the state level, as they sought to combat Musharraf and the military's control over the government (PPI 2007b). PPP Chairperson Benazir Bhutto was critical of Musharraf's handling of the situation and argued that her party would offer more diplomatic solutions for the problems in Balochistan (PPI 2007e). A similar call for acknowledging the grievances of the Baloch peoples and the offering of concessions to them was raised by the Jamaat Islami (JI) (PPI 2007a). It was to some extent in vogue to side with the Baloch nationalists against Musharraf as the would-be civilian rulers looked to garner as much public support as possible to secure the kind of decisive victory that could put an end to the military-dominated rule of Musharraf. 
In the fall of 2007 several politicians and leaders took issue with Musharraf's attempts to secure legitimacy by forcing presidential elections that were widely regarded as being heavily manipulated. Over 80 Members of Parliament (MP) resigned across the country in protest against Musharraf and continuing targeted violence (BBC Monitoring 2007e). The next month Balach Khan Marri, the head of the Balochistan Liberation Army (BLA) was shot dead in Afghanistan, dealing a major blow to the BLA and sparking condemnation of the government's policies from protestors, political parties and commentators (Al Jazeera 2007; PPI 2007c). Violence, particularly at polling stations, continued through the elections which eventually saw Musharraf's downfall (Zulfiqar 2008; PPI 2008a).

Baloch political parties saw some significant integration in the 2008 elections. Talal Akbar Bugti, son of the late Nawab Akbar Bugti, took his father's place as the head of the Jamhoori Watan Party (JWP) in May 2007 (PTI 2007a). Talal Bugti advocated following his father's path by fighting for complete autonomy for Balochistan through constitutional and diplomatic means (PTI 2007a). Only about a week before the February 18, 2008 general election, the Baloch National Front (BNF) put together a Baloch nationalist parties' alliance that united several nationalist and ethnic parties including the Jamoori Watan Party (JWP) (Brahamdagh) group, Baloch National Movement (BNM), Baloch Students Organization (BSO) (azad) group, Baloch Watan Movement (BWM), Baloch Unity Conference (BUC), Baloch Rights Council (BRC), Baloch Bar Association (BBA), and the Baloch Khawateen Panel (BKP) (BBC Monitoring 2008c). That collection promised to coordinate with the Baloch National Party (BNP) in order to best represent the Baloch people (BBC Monitoring 2008c). The moderate elements of the 
Baloch movement were unifying in hopes of exerting power in a new civilian government.

The 2008 general and presidential elections were a significant win for the civilian parties, but not for the Baloch movement. The February 2008 General Election saw the PPP take power (ECP 2008; PPI 2007d). The civilian regime pressured Musharraf eventually forcing his resignation which triggered a Presidential Election in September 2008 (PPI 2007d). The presidential election saw Asif Ali Zardari, the widowed husband of the late Benazir Bhutto, come to power with the PPP (ECP 2008).

In the Balochistan Assembly the BNP won only seven seats, while the National Party, a Baloch group which traced its routes back to the Kalat State, largely boycotted the election and only won a single seat (ECP 2008). In the national assembly the BNP won only a single seat. Instead the Muslim League had the biggest presence in Balochistan (ECP 2008). Nawab Zulfiqar Ali Magsi, a seasoned politician in the region, was named as Governor of Balochistan (PPI 2008c). Nawab Aslam Khan Raisani became the Chief Minister (PPI 2008b). As in the 2002 election, the people in Balochistan stayed away from the polls and so the province had a particularly low voter turnout (PPI 2008f).

The outcome of the elections paints the picture of a Baloch movement struggling to find its place in what would turn out to be a long overdue succession of civilian governments. Broader unity behind the idea of Baloch identity could only go so far. The militant elements of the Baloch movement did not have the capacity to defeat the Pakistan Army outright. The moderate elements could not garner enough votes to attain any significant power at the state level. For the Baloch movement grievances abounded, but opportunity to successfully attain power or autonomy was sparse. Ultimately a similar 
pattern of oppositional rhetoric mixed with calls for peace and dialogue alongside a sustained guerrilla conflict continued in the new civilian government era.

\subsection{Federal Government Changes but the Pattern Continues}

Violence continued after the elections despite the PPP's claims that they would answer the Baloch cries for increased control over resources and political autonomy (PPI 2008d; Yousafzai 2008). Much of the violence followed the same general narrative it did under Musharraf: Baloch cries for autonomy met with words that seem to support them but little substantive action, and targeted attacks by nationalists met by retaliatory military action by the federal government (BBC Monitoring 2008b; Bajpaee 2008; Trend News Agency 2008a). This period saw the Baloch movement expand into a protracted conflict against the Pakistani state.

As seen when Zulfiqar Ali Bhutto had come to power, Pakistan's civilian governments were far from immune from falling into patterns of conflict. In the case of the Zardari led federal government, the pattern took on a remarkably similar pattern of violence to Musharraf's government. Promises of reconciliation were followed by guerrilla attacks targeting key economic and government installations. Then, while things bubbled, the death of key Baloch nationalist leaders resulted in protests, a marked upswell in violence, and the ruination of hopes of reconciliation with the government.

The new civilian government initially began pulling troops out of the region but the continuing violence, particularly in the northwestern areas of Balochistan, meant that a significant troop presence remained which would continue the conflict (PTI 2008; Balochistan Times 2008). The military nonetheless took on a markedly more reserved or 
backseat role in the political sphere (ANI 2009). Furthermore, the new government faced the same resistance in integrating Bugti, Marri, and Mengal leaders into diplomatic talks and continuing the work of the Constitutional Reform Committee (Jamali 2008; Balochistan Times 2009e). In response they released Sardar Akhtar Mengal, who had been imprisoned in 2006, under Musharraf's reign, and invited Balochistan's representatives to join in key talks about the gas pipelines (Trend News Agency 2008b; Shahid 2008). The PML Balochistan chapter consistently positioned themselves against the separatists, nonetheless arguing that Balochistan needed better representation and inclusion at the federal level (PPI 2009b; Balochistan Times 2009c). The PPP led government took a harsh tone with sectarian militants who they labeled as terrorists (Shawl 2008). This was a markedly different tone than Musharraf had taken with Baloch leaders who he had also referred to as terrorists, yet it sat at odds with the new government's actions.

Targeted guerilla attacks by Baloch separatists continued alongside targeted killings by warring tribes, Islamic militants and Pakistani army (Balochistan Times 2009a; Balochistan Times 2010d). The civilian government allegedly had proof of Indian intelligence agency RAW's support of the Baloch resistance, complaining about the Baloch insurgents' continued attacks and even suggesting that RAW was setting up training camps in neighbouring portions of Afghanistan (Monitoring Desk 2008; Aziz 2009; IANS 2009). It is hard to say whether or not Baloch insurgents were as matter of fact supplied munitions or other resources by India. At the state level the civilian government was faltering in its ability to cope with the guerilla bombing campaign and pointing the finger at India may have been nothing more than a reflex. Yet, the Baloch 
insurgents seemed to be more capable than they had in the past. Given the influx of arms in neighbouring Afghanistan there was also the possibility that Baloch insurgents were better supplied by a more accessible illicit arms trade. In the end it likely mattered little whether the support was from a new arms market or from a foreign actor, the fact remained that Baloch insurgents were capably using what resources they had.

Baloch insurgents continued their bombing campaigns and continued to express their frustrations with Balochistan's oppression, arguing that the government was merely continuing Musharraf's policy of targeting Baloch leaders (BBC Monitoring 2008a; PPI 2008e; Balochistan Times 2009j). Still the key split in the movement remained as some Baloch leaders held out hopes that Zardari's election signaled the end of the military's reign and a new era for Baloch-Pakistan relations (ANI 2008; Business Recorder 2008). Sardar Yar Muhammad Rind, a pro-government Baloch who had been more critical of the Baloch separatists during his tenure in Musharraf's government, noted that the civilian government said they would change their policies to benefit the Baloch peoples but still bombed them all the same (PPI 2008g). State level federal and provincial politics divided even the moderates and politically powerful Baloch.

In April 2009, Ghulam Mohammed Baloch, the leader of the Baloch National Movement (BNM), was abducted along with two other nationalist leaders. Their bodies were found deceased and bullet-ridden days later (Yousafzai 2009b). While there was no consensus on who had actually killed them, the public nature of their deaths sparked a fire akin to that sparked by Akbar Bugti's death. Protests and riots by Baloch peoples were followed by attacks and an upswell of violence across the region (Balochistan Times 2009; Frontier Start 2009). 
Festering conflict and the apparent disinclination of the Pakistani state to offer substantial concessions to those in the Baloch movement further solidified the idea that Baloch identity and history was being threatened. As more of the Baloch movement began to see a separate independent state as the only viable option Baloch politics pushed further into the international. Where Akbar Bugti's death was followed by a historic grand jirga and a historic declaration of nationalist sentiment, Ghulam Baloch's death was followed by a historic declaration which announced the creation of a Council of Independent Balochistan (Baloch 2009a). On August 12 ${ }^{\text {th }}, 2009$, the Khan of Kalat Mir Suleman Dawood, from his exile in London, declared that this council would be open for all Baloch peoples, including those in Iran, to join in order to realize an independent state for their people (Baloch 2009a).

The economic value of Balochistan, particularly after Gwadar Port construction began, had pushed the Baloch movement somewhat into the international level in the late 1990s. Before that the possibility of instability in Pakistan or a border-breaching movement had drawn in actors like India and Iran. In the early 2000's foreign investors began to play a more integral role with regard to resources and politics. By 2009, however, the Baloch movement had shifted further onto the international level in a new way. Now Baloch leaders in exile far away were advocating that a separate state, a modern Baloch nation, was the only way to protect Baloch identity and tradition.

So the same pattern of violence played out over the next few years. Gas pipelines and government installations were bombed by guerillas, the federal government complained about Indian and foreign support for the conflict and Pakistan's security forces continued operations targeting Baloch nationalists all while people continued to go 
missing without explanation (Haider 2009; ANI 2012). Baloch leaders reiterated that the ongoing violence was a result of the Pakistani state's heavy-handed actions. Sardar Ataullah Mengal claimed that "The issue of Balochistan could have been resolved had the army and establishment not exceeded the limits" (Balochistan Times 2010c). While there seemed to be some degree of consensus that dialogue on both sides and political concessions by the state were as important as continued economic development of the region, the violence continued on (Balochistan Times 2010a).

It is perhaps an oversimplification to say that the federal government simply needs to give up power to the provincial government of Balochistan or offer substantial concessions to key actors in the Baloch movement. At the same time that the conflict in Balochistan is happening, Pakistan is dealing with terrorist attacks by Islamic militants across the country, quelling the presence of the Taliban in the rural areas in the War on Terror, and the ever-present conflict in Kashmir with India. They also had to draw up deals with Iran to supplement their gas supply which was scarce due to the continuous targeting of gas pipelines by nationalist groups (Today.AZ 2010; Fazl-e-Haider 2011). These issues often take the spotlight in the public discourse because of their international nature, while also taking up more of state resources. These pressures were there before Musharraf and they were thereafter.

Concessions to Balochistan could potentially create stronger allies in the Baloch peoples, but giving up control can understandably be a risky prospect for a country where civilian governments were often overthrown by the military in moments of, at the very least perceived, weakness. The PPP did make some forms of concessions such as increasing the job quota of the Balochistan province in federal posts, investing more 
funds directly into the province's development and promising to acknowledge the rights of the provinces (Siyal 2009; Balochistan Times 2009d).

The major effort of the PPP government from 2008-2013 was the Aghaz-eHaqooq-e-Balochistan Package (Package). That Package recommended the release of all political prisoners, initiation of dialogue with estranged Balochistan Nationalist leaders, return of political exiles, stoppage of all operations by the security forces except those related to fighting terrorism, withdrawal of the Army from Sui, ceasing the plan to construct cantonments in Sui and Kohlu, a judicial inquiry into the murder of Baloch leaders and a commission to inquire into the circumstances leading to the death of Nawab Akbar Bugti (Balochistan Times 2009g). The Package also included changes to the constitution that would improve provincial autonomy (Balochistan Times 2011). While that package would never be fully realized, it was a step in the broad scheme of Pakistani history that suggested that the government had evolved to at least recognize that a power imbalance existed and was part of the reason why the Baloch movement had as much staying power as it did.

The schisms that exist amongst the Baloch tribes nonetheless made it difficult for the federal government to chart a path that would broadly resolve the conflict. Government officials blamed the Sardar system, particularly its feudal structures and the violent tendencies of certain tribes, for the provinces continuing disparities (PPI 2009a). Although suggestions that the Sardar system was the major reason for conflict overstate its significance, the tribal structures certainly made it more difficult to determine what concessions and actions would be necessary to realize peace. It also bears remembering that it was the British Raj that had supplanted pre-colonial tribal practices featuring 
diffuse horizontal power sharing with British-style hierarchical structures that concentrated more power in less hands. It is hard now to determine how much of the modern Sardar system remains true to any potentially purely Baloch ethnic tradition. What is clear is that the federal government's open disdain for the Sardar system feeds the idea that Baloch ethnicity is being targeted by a power-hungry non-Baloch state. Thus the Sardar system remains invariably tied to the Baloch movement at every level.

Within the movement various Baloch leaders and people continued to have different tactics. The outspoken nationalist Mengals, Marris and Bugtis were often at odds with the goals of their more moderate counterparts, such as those in the Baloch National Party (BNP) who denounced the continuing violence (Balochistan Times 2009b). Moderates like the BNP, Baloch Republican Party (BRP), Baloch National Movement (BNM), and Baloch Students Organization (BSO-Azad) preferred tactics more within the confines of the traditional democracy, such as peaceful shut-downs of highways and malls alongside peaceful protests (Daily Balochistan 2010). Some separatist nationalists, such as Baloch Republican Party (BRP) spokesperson Sher Mohammed Bugti, argued that the Package was not only unfair but a deliberate tactic by the government to split the Baloch nationalist movement by pandering to the moderates (Yousafzai 2009a). Brahamdagh Bugti, BRP leader, called on the Baloch to attain independence through whatever means, whether through armed resistance or through political office, yet the BRP advocated against negotiating with the federal government (Butt 2012). On the other hand, many provincial politicians, including Pashtun and Baloch, saw the package as a much needed step forward (Balochistan Times 2009h). Sardar Ataullah Mengal complained that despite their efforts to find peace, that the 
Baloch leaders themselves could not quell the anger of the Baloch peoples, as the government's continuing policy of target killings only further incensed both young and old Baloch alike (Balochistan Times 2009b).

Conflict between and among the tribes continued to disrupt unity within the Baloch movement as each group made their efforts to realize whatever goal they had. There was a pattern of violence amongst the Baloch where targeted killings were followed by uncertainty and finger-pointing amongst the tribes claiming that one or the other was behind the killing (Baloch 2011; PPI 2012). It was often hard to determine which separatist group was behind attacks, in large part a decided defensive tactic of some militant groups was to target anyone who might reveal information about them PPI 2010a).

A complicating factor was the ongoing sectarian violence which often targeted schools and hospitals (Gishkori 2012). Some Baloch leaders felt that the government's inability to resolve the sectarian violence was being used to prolong the power imbalance between the state and the provinces (Balochistan Times 2010b). While the influx of Pashtun was also a source of conflict, there was some dialogue that suggested that both ethnicities could find some peace in the region (PPI 2010b; BBC Monitoring 2012). The Pashtun, while not deemed Baloch allies, were not seen as the enemy that the movement oriented itself against. Violence between Baloch and Pashtun is thus hard to characterize as central to the movement, though it was likely often a result of it.

Despite all the differences, the calls for greater provincial autonomy, better education, better economy for the locals and an end to the violence were widespread. In a 2012 interview with Al Jazeera, Jamil Bugti both airs the typical grievances of the Baloch 
while pointing out how working with the federal government has done little to benefit pro-government sardars. Jamil Bugti is in particular responding to claims that Balochistan has not seen development because of the significant presence of "anti-development" sardars such as himself.

What about all those sardars who are not anti-development? I have not seen any development in their areas. Let's start from Karachi. We go to Lasbela, Jam's area [Jam Kamal Khan of Las Bela]. Jam has been pro establishment since day one. Let's go to the Jamalis, they have always been in the government. Let's go to the Magsis, the Zehris, you name it. Except for Marri, Bugti, Mengal, these three bad Sardars, what about all the good sardars? Show me one college, show me one clinic, show me one hospital show me one library, show me one school where they will send their own children. (Al Jazeera 2012).

For Jamil Bugti, like so many other Baloch, the Zardari government had proved that it had no intention to develop the region for the benefit of the Baloch. The federal policies at the state level meant that Baloch peoples continued to have unanswered grievances. The broad instability across Pakistan as well as the influx of arms and insurgents in the region made armed conflict increasingly commonplace. Even those in the Baloch movement that sought the realization of an autonomous state or at least province through democratic means stood staunchly in opposition to the federal government. Weighing these factors together, it was clear that there was no simple solution for those within the Baloch movement, nor was there any singular course of action that Pakistan could take to put a certain end to the conflict. The conflict was to continue in its disjointed but steady pattern. 


\subsection{Elections \& a Decline in Violence}

The year leading up to the election was plagued by the same violence as the years preceding, but now political parties were ramping up their calls for peace and diplomatic concessions as the election approached (Balochistan Times 2012). Nawaz Sharif and his PML-N had steadily been building up his relationship with the Baloch provincial and nationalist leaders in the years prior to the election (Saleem 2010). A notable offer in September 2012 by the PML-N to Ataullah Mengal to be interim PM in the run up to the 2013 elections was rejected by Ataullah Mengal who felt he would not have been in a position to enact any real change (Zafar 2012).

During that time moderate Baloch leaders called for concessions and change on the part of the government. In October 2012, Sardar Akhtar Mengal returned from his self-imposed exile for a few days to outline a six-point plan that largely focused on stopping the military action by the government, the recovery of missing persons and for the government to support the integration of Balochistan's political parties (Inayatullah 2012). National Party President Dr. Abdul Malik Baloch argued that the biggest failure was occurring at the provincial level and called for Baloch peoples to support only the nationalist parties (Pur 2012). The BNP on the other hand continued to meet with PML-N representatives hoping to secure a better voice for the Baloch peoples through a coordinated relationship with a party that reached across the country (Dawn 2012). Some local parties even joined the PML-N (Business Recorder 2013b). This was a time where the moderate elements of the Baloch movement saw opportunity via the electoral process. 
The lead up to the election saw devastating violence across the country but in particular across Balochistan and Khyber-Pakhtunkwa (Free Press Journal 2013; BBC Monitoring 2013a). Of particular note was the dismissal of Balochistan's provincial administration after protests by Hazara Shi' ite Muslims who had endured prolonged sectarian targeting (Thai News Service 2013). Some Baloch leaders alleged that the dismissal was more politically centered around the Reko Dik Project's administration (Baloch 2013). For these leaders, framing these actions in this way promotes the idea of a threatened Baloch identity.

PTI Chairman Imran Khan called for elections to be held sooner rather than later due to the ongoing violence and in particular the dismissal of Balochistan's administration (Balochistan Times 2013b). Nonetheless many Baloch leaders did not feel it necessary to aggressively fight against the actions of a government so close to the end of its tenure (Baloch 2013). Tactically, resources and energy would be better spent preparing for the elections. Moreover seemed to be a growing consensus amongst both state and Baloch actors that peaceful and successful elections could offer better solutions than sustained conflict. As a measure to quell or at least reduce the violence, the temporary provincial administration offered separatist militants a 10,000 Rupee stipend if they turned over their guns and promised to cease their militancy (National Herald Tribune 2013). This measure was met with some modest success and likely helped keep the overall level of violence through the elections down at least a little bit (PPI 2013a).

The May 2013 elections saw Nawaz Sharif come back to power with the PML-N, while Zardari's PPP and Imran Khan's Pakistan Tehreek-i-Insaf (PTI) made up the major opposition (Express Tribune 2013b). A pre-election survey found that 47 percent of the 
Baloch peoples polled said they would vote for the BNP-Mengal (Kohari 2013). In the end the BNP-Mengal won only one seat in the national assembly (Daily Messenger 2013). Within the Balochistan provincial assembly the Pakhtunkhwa Milli Awami Party, a Pashtun party, won 10 of the 51 seats, the PML-N took 8 seats, various independents claimed 7 seats, while the two major Baloch parties, the National Party (Pakistan) and the Baloch National Party, claimed only 6 and 2 seats respectively (Daily Messenger 2013). The presidential election that followed on June 30 was boycotted by every major party except the PML-N and the PTI, resulting in the PML-N easily taking the election (UrRahman 2013).

A major issue for Baloch representation in the state and provincial governments is the continuous boycotting of the elections by key leaders alongside low voter turnout by the Baloch in particular. For the Baloch movement, participation in the political process is itself a divisive decision. The BNP continued to express their lack of interest in the elections while the Election Commission of Pakistan stressed the importance of Baloch participation in order to secure better representation (Business Recorder 2013a). BNP-M President Akhtar Mengal had returned from his self-imposed exile in March and was still undecided as to whether the party would run in the election until later that month (Chandia 2013). Baloch separatists saw BNP-M's participation in the elections as compromising principals by joining forces in the same establishment that was hurting the Baloch (Ahmad 2013). Dr. Allah Nazar, a commander in the BLF, stated that "If Akhtar Mengal takes part in this sham of an election, he will have compromised with the very same security establishment that has been responsible for the deaths of hundreds if not thousands of Baloch (Ahmad 2013). A BLA spokesperson claimed "we will not let 
Pakistan hold elections in Balochistan", taking the position that the elections were illegitimate (Ahmad 2013).

Threats and attacks made by militant Baloch nationalists stated that they would come after BNP-M if they ran (Pakistan Observer 2013a). Accordingly, BNP continued to flip-flop on the issue of participating. Even after participating it was not until August 2013 Akhtar Mengal finally took his oath to join the provincial assembly (Pakistan Observer 2013b; Balochistan Times 2013a). The JI and JUI electoral offices were targeted, as were various politicians and candidates (Frontier Post 2013a). The former Chief Minister of Balochistan Nawab Aslam Raisani also boycotted the polls, despite his significant history in the assembly (Frontier Post 2013c). Fear of attack was a likely reason why some Baloch leaders called for the EU and UN to monitor the elections both for security and ensure proper elections (BBC Monitoring 2013b). Protests against alleged riggings, a common occurrence across Pakistan, were predictably prevalent in the days that followed the election (Express Tribune 2013a). Federal and provincial politics undermined unity in the Baloch movement even when it offered power and opportunity. Nawaz Sharif and the PML-N started their tenure with a soft tone, distinct from Nawaz Sharif's previous reigns in power (Pakistan Today 2013). It was likely this tone that helped bring independent politicians in Balochistan into the fold of the PML-N and to create the coalition between the PML-N, the Pakhtunkhwa Milli Awami Party (PkMAP) and National Party (NP) (Daily Balochistan Express 2013). Nonetheless the divisions within the provincial administration were already apparent when the BNP-M boycotted the first sitting of the provincial assembly in protest against the new government (Shahid 2013a). 
Dr. Abdul Malik Baloch, a moderate from the National Party, was elected Chief Minister of Balochistan (Frontier Post 2013b). Soon after his victory, Abdul Malik Baloch stated "we are keen to bring the militants to the negotiating table with the help of the federal government" (Express Tribune 2013c). While he stands for better representation for Baloch peoples, the more separatist Baloch felt that he was too weak to stand up to the military (Dawn 2013c). Within days of Abdul Malik Baloch's appointment, and just a day after agreeing to join the provincial assembly, the BNP shut down highways and businesses in a fierce protest against the military 'death squads', the election results and the general political situation in the province (2013b). The challenge for the state was to bring the diverse Baloch into the fold of a government that could offer better representation, especially within the context of the $18^{\text {th }}$ Constitutional Amendment to the federal constitution which promised a 50 per cent share of oil and gas revenues for producing provinces (Express Tribune 2013).

The pattern of targeted violence on both sides, calls for dialogue, and unkept promises continued through the early part of PML-N government's reign. The military claimed that there was not a military operation while its forces nonetheless engaged in targeted killings on Baloch nationalists (Dawn 2013a). The government continued to promote its dialogue with the Baloch leaders while falling short on those promises (Pakistan Observer 2013c). Militant Baloch separatists continued to target moderates who worked within the government structure (Philip 2013; Shahid 2013c). Local elections yielded somewhat positive results in terms of increased civility but the low presence of Baloch representatives continued to be an issue (Shahid 2013b). Protests against the political situation and the continuing disappeared and dumped bodies were still a regular 
if somewhat less frequent occurrence (Balochistan Times 2014b). Gas shortages and pipeline bombings were less frequent though common nonetheless (Kashmir Monitor 2014; Patriot 2014).

Conciliatory attitudes by state actors towards Baloch moderates, more effective targeting of militant Baloch separatists by security forces, fissures amongst the Baloch along political and tribal lines, and an uptick of peaceful protests and work stoppages affected the Baloch movement and the conflict in turn. By late 2015 a marked downturn in violence was reported and there was a noticeable downturn in the frequency of violence (News International 2015; Rizwan 2016). The situation seemed to be favouring the moderates who were finding more room to operate alongside the PML-N. In a sixmonth period ranging from August 2015 through January 2016 over 600 insurgents in Balochistan surrendered to the provincial government (Express Tribune 2016). The Balochistan government was successfully implementing a plan whereby any insurgent who surrendered would be compensated for their guns and given 500,000 Rupees in installments, alongside potentially being given government work and identity cards to ultimately rehabilitate the fighters (Express Tribune 2016). In a December 2015 interview, the staunchly separatist BRP leader Brahamdagh Bugti, explained that while the Baloch peoples broadly should be wary of any pro-government sentiment, that he would welcome genuine negotiations with the Pakistani state (Asif 2015). This period of relative calm under Nawaz Sharif's government, more so a period of diminished conflict rather than a peace or ceasefire, saw a number of economic development projects, in particular Gwadar, in Balochistan make significant headway. 


\subsection{Revenue-Sharing, Energy Crisis \& the Pak-Iran Pipeline}

The National Finance Commission (NFC) revenue sharing formula has developed alongside the shifts in the economy and in local politics. The period stretching from the end of Musharraf's military dominated government to what is now the longest continuous period of civilian rule in Pakistan's history has seen significant economic development in the region (Upstream 2011). The PPP government elected in 2008 gradually brought a more flexible approach to the revenue sharing issue and for perhaps the first time in Pakistan's federal government's history was able to acknowledge that Sindh and Balochistan were not receiving their fair dues in the gas industry (Balochistan Times 2009k).

In December 2009 a historic NFC shift saw the provinces set to receive 56 per cent of the revenue under the new sharing formula, while the federal government would receive the rest. Balochistan was to be awarded 9 per cent of the total resource pool (Baloch 2009b). The Aghaz-e-Haqooq-e-Balochistan Package (Package) in 2010 also bolstered the prospects of economic development alongside the modified NFC revenue sharing structure (Nation 2010). Nonetheless, Baloch separatists and nationalists remained unsatisfied and continued bombing campaigns and protests that resulted in widespread gas shortages and an unstable gas supply chain throughout the country (Pakistan Today 2014; Saeedi 2010).

The unstable gas supply repeatedly hindered industrial development and the country's economy, while still leaving regular consumers on the hook for increased prices accompanied by widespread load-shedding (Saeedi 2010). In 2011 the load- 
shedding in Balochistan saw consumers and industry alike without public power supply for 18 hours on a daily basis (Daily Balochistan Express 2011).

By 2013 the Pak-Iran Gas pipeline project formally began and sought to bolster Pakistan's energy supply (Daily Messenger 2014). The pipeline would run over $700 \mathrm{~km}$ and help Pakistan generate 2000 megawatts of electricity (PPI 2013c). The BNP-M however saw the pipeline as another sign of Pakistan's federal government prioritizing federal government and foreign interests above attaining justice for Baloch peoples (Dawn 2013b). As early as 2009 Eni, an Italian energy technology firm that has operated in Pakistan since 2000, looked at investing more than 50 million USD a year in gas exploration and development (Oil Daily 2009). Firms from across Europe maintained an interest in the region. The ongoing conflict, however, meant that investment offers often failed to come to fruition as the security of any project could not be guaranteed, largely due to targeting by militant separatists (Fazl-e-Haider 2014; Ali 2015).

Despite increased gas purchasing through the Iran-Pakistan pipeline, in late 2014 a gas crisis across the country that saw many regions hard-hit, saw Quetta with no gas supply for over a week while other parts of Balochistan saw no gas for over 3 months (Ali 2014). Baloch commentators saw Punjab's more continuous supply of power as a remaining marker of where the government's true loyalties lay (Daily Balochistan Express 2011; Frontier Star 2014). A report in 2015 showed that while Punjab saw over 400,000 new gas connections for consumers in the previous two years, Balochistan saw less than 20,000 such connections (Patriot 2015). As much as recent civilian governments were willing to concede more with regard to gas, the lack of investment in the broader economy, education, and provision of basic necessities suggests that concessions were 
likely an effort to stabilize gas supply to stabilize the economy (Fazl-e-Haider 2012; Hindustan Times 2012; Frontier Star 2014).

At the same time the federal government is courting foreign investment, the Baloch nationalists see little evidence that their interests will be served by these investments. Yet the continued violence seemed to force the federal government to continue to offer concessions on gas projects.

For example in 2014 the $18^{\text {th }}$ Constitutional Amendment brought about a shared ownership structure whereby the provincial government would be equal part owners of oil and gas (Soofi 2014). Previously the federal government had been complete owner of any oil and gas. A key issue for investors and the Baloch alike was that the amendment did not specifically apply to already existing projects, meaning that already existing oil and gas projects would likely continue be owned under whatever ownership structure the federal government and the investors had previously agreed to (Soofi 2014). For investors there was some uncertainty but for the Baloch this meant that for many projects the amendment was too little too late to see them gain any real benefit. International investors seemed to offer little opportunity for the Baloch who had no substantial control over resources or land that investors were seeking. This only further disincentivized moderate elements within the Baloch movement and reinforced the need for a separate Baloch state.

Due both to the continuing violence in the region as well as the failure of various ventures, the province remains in an energy crisis. In 2016 the electricity demand in Balochistan sat around 1,650 megawatts while the province was able only to supply about 400 megawatts to a grid that was setup only to output a maximum 650 megawatts (Nasir 
2016). A 100 million USD loan from the world bank was cancelled late in 2016 citing continuous disruptions to the project as well as illegal connections that were siphoning gas and undermining the reliability of the existing network (PTI 2016b). As of early 2018 the province was able to only supply roughly 400 to 500 megawatts of power to a still ailing supply network, while estimates suggest that facilities in the province were nonetheless supplying 2000 megawatts of power to Punjab (Daily Balochistan Express 2018a).

The ailing power supply in the province continues to hamper the economy despite the repeated calls from the government that they are committed to development of the region (Pakistan Today 2018b). From the Baloch perspective it was Punjab and the state that were siphoning resources that should have been under the control or at least discretion of Baloch politicians and leaders. Moreover the state was directly undermining industrial progress in the region, feeding further into the idea that Pakistan was simply another outsider government threatening the Baloch peoples in order to obtain the resources from Baloch lands.

In May 2018, in response to a decision of the Sindh High Court, the federal government acknowledged that the national gas companies had overcharged consumers in Balochistan and Sindh, promising to pay back the overages to consumers over a 5 year span (Pakistan Today 2018a). While violence continues to have its place in affecting Balochistan's economy, there is a clear need for better policy and enforcement by government bodies in order to resolve the energy shortage and to better prioritize the needs of Balochistan. Actions like promising to pay back overcharges did not settle Baloch grievances. For the Baloch movement this reinforced beliefs that opportunity for 
the Baloch would come either by having exclusive provincial control over resource development or exclusive control via a separate Baloch state.

\subsection{Gwadar Port \& the China-Pakistan Economic Corridor}

Dubbed the China-Pakistan Economic Corridor (CPEC), CPEC's development has had a major impact by bringing the Baloch movement into the international focus. Pakistan's support of foreign control over much of the project has shifted a project that could have been used to offer opportunity to integrate into a divisive symbol of Baloch oppression.

CPEC offers China a unique resource route to the Arabian Sea through Gwadar which can significantly bolster its energy supply (Business Recorder 2009). The economic corridor runs from Kashghar, China through northern Pakistan down to the coastline where it will connect to Gwadar (Balochistan Times 2014a). Tied into CPEC as well is the Pak-Iran gas pipeline. Together these projects likely hold the key to not just Balochistan but Pakistan's economic future. China even offered significant investment along the corridor which runs through the country (Logistic China 2009). There is a clear confluence of interests by actors at the local, the state and international levels. Much of the conflict that has surrounded both projects comes down to the issues of who controls and who benefits from the projects.

As early as 2009, the PPP led federal government proposed a handover of control to the Balochistan provincial assembly (Business Recorder 2009). Particularly at issue with such a proposal was that the ports in Sindh were under federal control, largely due to the constitutional allotment of powers in the country (Business Recorder 2009). Instead 
of a smooth handover of power suggesting a new relationship between the province and the federation, Gwadar city became a desolate symbol of the Baloch-Pakistan conflict.

As violence raged on, there was a good deal of sympathy for the Baloch position. Resource starved for so long, some felt the locals desperately needed real opportunity and a genuine stake in the project, even if complete control by Balochistan was not always seen as the best path (Shahryar 2009). On the other hand, the federal government was desperate to see the project yield genuine results instead of being continuously waylaid by the violence. In 2009 they declared Gwadar a tax-free zone for ten years, exempting construction, sales, imports and exports in the region (Kazmi 2012). Despite their efforts the sustained conflict that had surged after Akbar Bugti's death hampered real progress in the projects development and Pakistan failed to develop an adequate road network to link the port to the rest of the country (Abbot 2013). By 2012 the PSA International led consortium was ready to sell and China entered the stage to purchase control (Free Press Journal 2012). It bears noting that China was an active investor in the project throughout its construction due to the importance of the project for its own economy (Kazmi 2012). As early as 1998 international interest in the project emphasized to state actors and those within the Baloch movement that Gwadar was a vital job and revenue generating opportunity.

Ultimately China purchased its share in the project through China Overseas Port Holdings Limited, a company owned by the Chinese government (Abbot 2013). By the time China was purchasing its stake in the project, the Port was operating at only 15 per cent capacity and Pakistan had only completed 60 per cent of the roads necessary for Gwadar to be functional. More than that, the continuing violence meant that the road was 
far from a secure route once it would be completed (Abbot 2013). Handing Gwadar over to Chinese control was contentious as many Baloch nationalists felt it was the surest sign that they were being stripped of the resources and land that was rightfully theirs (ANI 2013). Leaders within the Baloch movement, whether separatists or not, were outraged at the complete lack of consultation with even those Baloch leaders who had a positive relationship with the federal government (ANI 2013). After the takeover, Baloch militants continued to target Gwadar as a symbol of the conflict (Khan, 2013). The pattern with Gwadar matched the pattern through much of the region. Development promised by the federal government is met with cries for more autonomy for the province and important roles for the Baloch. While the government offered concessions to the Baloch, most of the separatists felt these concessions were meant only to divide them from the moderate Baloch rather than genuine attempts at reconciliation. This continued through the PML-Ns reign as well.

The PML-N government's first priority, when it took over in 2013, was to link Gwadar to the road network so they could increase the port's productivity (Pakistan Engineering Review). China continued investing heavily in the project, despite the setbacks to the roadwork. It was not until 2015 that Balochistan was able to properly establish Gwadar as a free trade zone in line with China's demands (Express Tribune 2014; Rind 2015). Despite the investment, the continued attacks along the CPEC route caused the government to consider switching the route to run through Islamabad, Lahore and Karachi (mostly through Punjab and Sindh rather than Balochistan) to make it safer (Khalid 2015). When this potential decision was made public, BNP leader Akhtar Mengal and PPP Balochistan leader Mohammed Sadiq Umrani both responded by saying that 
Balochistan had once again been left out of the dialogue in changing the route (Daily Messenger 2015). To them this was a continuation of the same policies that Baloch movement leaders had complained of since Balochistan acceded to Pakistan. They did not trust that the government had any genuine interest in stabilizing the region and making peace with the Baloch beyond securing Pakistan's economic future more broadly (Daily Messenger 2015). It seemed that state actors were happier to exclude the Baloch entirely than make concessions. Within the Baloch movement, this meant that there were divisions oriented around how to respond to the Gwadar project. For militants, this emphasized a continuing need for guerilla tactics. For moderates, this would make it harder to sell the idea that the Baloch movement could effectively proceed through diplomacy.

BRP leader Brahamdagh Bugti, while in exile in Germany, expressed such concerns and argued that before Gwadar and CPEC go through, Balochistan should have a UN supported referendum regarding Balochistan's independence (Shaukat 2015). While not going so far as to explicitly demand Balochistan's complete independence, BNP-M argued that Gwadar should remain under provincial control (Frontier Star 2015b; Daily Balochistan Express 2016). In late 2015 the Chief Minister of Balochistan adamantly argued that while a free economic zone could be in the Baloch interests, the Balochistan provincial assembly would resist any sale of land to outsiders (Zia 2015). Despite these concerns and the Chief Minister's resistance, over 280 hectares of land were sold to China in early 2016 (Flare 2015; ANI 2016b).

An important part of the Baloch concerns arises from the continuing lack of basic services for locals of the Gwadar township. While the federal government continued to 
assure the public that they were investing in those necessities, the reality has been many promises with little action (Express Tribune 2015). What complicated all these factors was a marked lack of transparency and coordination between the different levels of government (Dawn 2016). Alongside those concerns are a fear that development, particularly by foreigners, will make the Baloch peoples a minority in their own homeland, further stripping them of what little power they have (Pakistan Observer 2015). A fear of foreigners ousting Baloch out of their own territory feeds into the mythsymbol complex of an ancient Baloch peoples constantly defending their land from outsiders.

In the wake of ambiguous policies at the state level in Pakistan, China's justified concerns over the continued targeting of Chinese workers in Gwadar meant that the federal government handed increasingly more authority over to the Chinese (Dawn 2016; Kohli 2016). This also meant an increased military presence in the area, particularly by the Pakistan Navy and Chinese security forces (ANI 2017). This increased militarization has only further fanned the flames in the region. The BNM argued that not only were Baloch locals continuously displaced and left behind, but they were being explicitly targeted in a military campaign meant to undermine the nationalists but that also took out civilians as collateral (ANI 2016a). Hyrbyair Marri, of the Free Balochistan Movement (FBM) argues that Gwadar is another step in the further colonization of Balochistan, with China and Pakistan using it as a permanent military base while exploiting the region's resources for their own economic profit and providing nothing for the locals (M2 Presswire; ANI 2018b). While Pakistan denies FBM's claims regarding a Chinese 
military base (Indian Express 2018), there is little doubt that Gwadar thus far has done little to benefit local Baloch peoples.

At the time of writing, Gwadar is still not fully operational and the road network has yet to be completed (Fazl-e-Haider 2018). The Gwadar township and the towns along CPEC are still deprived of basic amenities such as power, water or education and without real economic opportunity (Phullan 2018; ANI 2018a). Baloch nationalists remain opposed to the Chinese control and Baloch party leaders maintain their dissatisfaction with the project, arguing that even now Baloch peoples are looked over for jobs, while outsiders are brought in to work (Daily Balochistan Express 2018c). For the Baloch movement this makes Gwadar a powerful symbol of state oppression tied to foreign interests. An inability to obtain resource control through political means due to foreign interests coupled with a power-centralizing state has pushed the Baloch movement further into violent confrontation through guerilla bombing campaigns.

On the other hand, some pro-government Baloch leaders continue to argue that the nationalists and separatists are the real problem, fueling insurgency for their own ends rather than for the good of the Baloch people (Balochistan Times 2018). For them the Baloch movement is little more than a political vehicle for certain elites to grab power. From their perspective it is the meddling of foreign governments and actors that is supporting the sustained conflict. Thus while international interests have undermined the Baloch movement's ability to take control over Gwadar, other international actors may be actively supporting the Baloch movement. 


\subsection{India: A Phantom Menace or an Easy Scapegoat?}

Looking through the history of Pakistan, blaming internal conflict on conspiratorial acts by the Indian government has essentially been standard practice for whoever is ruling the country. That is not to say that India has not had any active role in destabilizing Pakistan. The Pakistan-India relationship itself is much too complex to go into here. Yet in order to understand how the Baloch movement has sustained a conflict for so long, it merits assessing what role India has in supporting the ongoing conflict.

Since the most recent conflict sparked in the early 2000s, militant elements within the Baloch movement have managed to steadily sustain attacks on government installations. As discussed earlier in the chapter, the federal government has repeatedly accused Indian and Afghan elements of supporting the Baloch by providing them resources, in particular firearms and military training. In 2009 federal minister Rehman Malik stated that the "BLA was raised and funded by Russia during the Soviet-Afghan war when Pakistan was supporting Afghanis and now India is backing its activities" (IANS 2009). For the Pakistani state, fomenting regional violence was a steady tactic of their international rivals.

The ability of the Baloch movement to sustain these levels violence has likely been possible due to strategic bombing predominantly using improvised explosive devices. For the Baloch movement a pragmatic and tactical use of resources is fundamental to sustaining the conflict over a long period. The Baloch militants have never been able to grapple with the size and dominance of the Pakistan Army, which is why most of the fighting was targeted attacks by both sides rather than direct conflict. At the same time, external support has likely been an important source of support for 
militants and for India and Iran, the Chabahar Port project can be seen as rivaling Gwadar.

In May 2015, Iran and India signed an agreement wherein India would invest heavily into Iran's Chabahar Port project (Chabahar) (Vayu Aerospace \& Defence Review 2015). Gwadar remains a markedly bigger project in large part due to its geographical location and water depth, plus Iran has multiple agreements with Pakistan to provide energy to Gwadar and other regions (Siddiqui 2017; Pakistan Today 2015). Nonetheless Chabahar would be of particular importance to India as it would give them sea-to-land access route to Afghanistan, which they have been unable to access due to the troubled Pakistan-India relationship (Siddiqui 2017; Vayu Aerospace \& Defence Review 2015). However, for Iran, Pakistan remains an important ally due not only to their shared border but their trade relationship. At the same time, the prospect of a large port with heavy investment from India would greatly bolster Iran's economy. As such Iran has adamantly maintained that Gwadar and Chabahar are to be 'sister ports' rather than economic rivals (Zafar 2016; Siddiqui 2017).

At the international level, India could openly support the Baloch movement and oppose Pakistan, but India also needs to maintain a stable relationship with Iran. For Iran's part there is a clear benefit to maintaining regional stability alongside functioning relationships with both Pakistan and India. There is a complex relationship playing out between Iran, Pakistan and India in which the Baloch have little power. For the Baloch movement, the creation of an autonomous Baloch state would entail control over the Gwadar port and an important seat at the international table. For India, an independent Baloch nation could turn Gwadar into another access point into the region for commerce 
and trade. Without Baloch control over Gwadar, India's prospects of using the port will rely on mending a broken relationship with its major political antagonist. For the Baloch movement, control over Gwadar port is therefore key to attaining power at the international level as well as the local and state levels.

The Baloch movement is not, however, united in accepting support from actors like India. Alongside members of the federal government and pro-Pakistan voices, many Baloch moderates argue that India, particularly through their foreign intelligence agency Research and Analysis Wing (RAW), are supporting militant nationalists and separatists (Shaukat 2015). The Indian government has a history of criticizing Pakistan for its treatment of the Baloch, and Indian Prime Minister Narendra Modi is no exception (Chatterji 2016). On Indian independence day in 2016, notably held the day after Pakistan's independence day, Modi openly criticized Pakistan's treatment of the Baloch and Balochistan generally (Chatterji 2016). While this was clearly a response to Islamabad's criticism of India's violent actions in Kashmir, Baloch separatists such as the BNM leader Khalil Baloch and BRP leader Brahamdagh Bugti welcomed the comments (Sharma 2016; Pakistan Observer 2016a). Brahamdagh even went so far as to approach India for asylum while in exile (PTI 2016a). This mirrors the sentiments of Ataullah Mengal who stated that while India is not actively supporting Baloch nationalists, they would welcome any and all support from India (A1 Jazeera 2012). For the Baloch movement it is hard to pinpoint key examples of external support, but it is clear that such support would be welcomed to a movement with scarce resource supplies and a weak political voice. 
Modi's comments were met with protests and anti-India commentary throughout Balochistan and Pakistan (Frontier Star 2016). Chief Minister of Balochistan Sanaullah Khan Zehri argued that India was openly supporting insurgents like Brahamdagh Bugti by sending money (Frontier Star 2016; Pakistan Observer 2016a). Some Baloch leaders registered cases against Brahamdagh Bugti and other separatists who welcomed Modi's criticisms, arguing that they were traitors both to the Baloch and to Pakistan (Pakistan Observer 2016b). Such Baloch leaders, like now PTI Balochistan leader Sardar Yar Mohammad Rind, have also argued that India, through funding, is working alongside Afghanistan, where militant Baloch are given sanctuary (Khaama Press 2017). BNP-M leader Akhtar Mengal has mirrored these complaints, pointing out that "shadowy" organizations and networks are promoting extremism to undermine the democratic process in the region (Statesman 2015).

While accusations of shadowy organizations mirror the same conspiratorial arguments that largely characterize the India-Pakistan relationship, there is clearly evidence that India has some interest in promoting the Baloch separatist cause beyond mere political rivalry and that Baloch militants will clearly welcome support from wherever they can get it. While Iran has a larger stake in a positive relationship with Pakistan, India is nonetheless a significant ally. Afghanistan may offer sanctuary for Baloch militants, but that may also be more of a consequence of geographical proximity and the mountain ranges than one of particular benefit for Afghanistan. This nexus of interwoven rivalries, at the same time economic, military and political, make it hard to discern where the truth lies in terms of any explicit supply of munitions and moneys. 
Within the Baloch movement, there are two mutually exclusive goals with their own routes to success. The first is better integration into the Pakistani state structures to put Baloch leaders at seats of power in the government. The other is outright separatism achieved through armed conflict and diplomatic calls for independence in tandem. This is the key division within the Baloch movement today, and it shapes how the actors at all levels interact and engage with Baloch peoples.

The region is already a hot-bed of arms due to the influx of militants from Afghanistan fleeing the US-led War on Terror. This further complicates determining where international support is coming from. What is more certain is that the presence of foreign influences, particularly out of economic interest has complicated the situation and increased its scale to an ever-more international conflict. That same escalation of the conflict has further entrenched divisions within the Baloch movement. Baloch identity is not the most influential variable here. Instead economically valuable resources, political disputes over control of those resources, a state that continues to operate using colonial and power-centralizing tactics, and the interests of powerful international actors have disrupted the tactics, unity and efficacy of the Baloch movement.

\subsection{Elections: Prolonged Civilian Rule and a Prolonged Conflict}

Imran Khan and the PTI's success in Pakistan's 2018 federal election is at the very least a marker of a more stable era of civilian rule. For the first time in the country's history three successive civilian governments have completed their rule and directly handed power over to the next civilian rulers. Stability at the state level alongside increasingly receptive state officials should in theory provide moderate leaders from 
various ethnic groups across the country more opportunity to pursue their goals through diplomacy. Yet targeted violence and cries of electoral corruption and manipulation remained staples of election day across the country and throughout Balochistan (Nation 2018c; Kindred 2018). The inherently disruptive nature of elections in in the Pakistani context results in predictable yet chaotic violence.

In the wake of the violence BNP-M leaders found it hard to celebrate their hard fought victory for only two seats in the federal assembly (Pakistan Observer 2018). On the provincial side the Balochistan Awami Party (BAP) formed a coalition to take charge of the provincial government, with Jam Kamal Khan elected as Chief Minister of Balochistan (Nation 2018a; Daily Messenger 2018). The inability of Baloch movement leaders to effectively penetrate political seats mean that moderate Baloch leaders will have to request action by state officials, while separatists and militants will look to direct confrontation and international support for independence.

Official records show that Balochistan has seen over 1,860 incidents of gun, bomb and suicide attacks over the past seven years, with official estimates estimating over 2,000 people have been killed in the violence (Gishkori 2018). It is hard to pin down how accurate these numbers are given the complaints around how state forces are handling Baloch peoples. It is then no surprise that many Baloch leaders continue to call on the state to address missing persons in Balochistan, provincial control over natural resources and control over Gwadar and CPEC (Dawn 2018; News International 2018).

BNP-M's decision to sign an alliance with the PTI over a deal which outlines how the government should work to improve the province is a major step forward for integrating a largely nationalist but moderate section of the Baloch movement into the 
federation (Nation 2018b). According to BNP-M party leader Akhtar Mengal, this is the first government in twenty years that has accepted the six-point plan he has advocated for so long (Zafar 2018). The six points cover the issue of missing persons, census and demographic issues about the Baloch becoming minorities in their own region, increased provincial control and share of mineral resources, the construction of dams to mitigate drought, a six percent quota for Baloch peoples in federal positions, and the repatriation of all Afghan refugees to Afghanistan (Zafar 2018).

While tensions continue between the new government and the Baloch leaders, it seems that Imran Khan's government is, at least on the surface, willing to go a step further toward mending the broken relationship between Balochistan and the federal government (Daily Balochistan Express 2018b). If the government is able to follow up on its rhetoric with real action taken to reconcile the ailing federation, there may be positive results in the integration of many of the more nationalist Baloch leaders into the federation. However, militant separatists will likely continue their fight, seeking instead a separate state for Balochistan. In effect the state has been using a divide and concede approach, albeit alongside a continued campaign of violence. This approach has kept the militant factions within the Baloch movement justified in maintaining a prolonged guerilla campaign. At the same time it has opened up some, albeit very limited, paths for diplomatic resolution to Baloch grievances.

Any end to the recent conflict will require the state to approach the factions within the Baloch movement in at least two different ways. However a more unified and transparent strategy might help to quell fears of a threatened Baloch identity. Key to meeting widely-accepted demands of the Baloch movement will be managing the 
Gwadar Port and Balochistan's resources effectively. The recent conflict is not a novel phenomenon. For the Baloch, the divisions within the movement might hamper a clean or singular solution, but those same divisions also prevent the Baloch movement from being taken down by a singular coordinated armed assault. For the state, the present goal is to satisfy enough of the movement and cut off munitions supply chains such that key economic projects can proceed. In turn, to keep the Baloch satisfied, the state will have to invest in Balochistan's people through jobs and educations. Ever-evolving international dynamics, resource politics in a state with a continuing colonial legacy and the factious political nature within both the Baloch movement and the Pakistani state remain the key variables that make paths to resolution murky. 


\section{Chapter: Conclusion}

The evolution of the Baloch movement has ebbed and flowed as a result of key variables. Legitimate grievances of an economically and socially destitute province bolstered claims for independence that existed before Pakistan was even a thought. There has never been a completely unified Baloch ethno-nationalist movement, but certain moments such as the death of widely respected leader can serve to unify the movement if only temporarily. Foreign support by funding and supply of arms has aided the more militant factions within the movement. Meanwhile concessions by the government have brought more moderate factions into the fold of the federation but made them targets of the separatists within the movement. In tandem these factors have propelled the Baloch movement forward while at the same time preventing those within the movement from achieving their goals, however modest they may be. The recent influx of international interests has further complicated the conflict, making it more certain than before that a long-standing peace will require broad, extensive and far-reaching policy changes by many actors.

\subsection{Policies \& Prospects: A Separate State or a Seat at the Table}

Future prospects for the Baloch movement will increasingly depend on actors that are beyond the ability of the Baloch to exert significant influence over. Those within the Baloch movement are right to be skeptical of a state that has failed time and again to honor its own promises. Pakistan has been unable to share power in a way that would ensure the goals of even the moderates in the movement. The process of creation of a separate Baloch state would likely require a violent armed struggle for independence, and 
might not even ensure Baloch autonomy. It is hard to imagine Balochistan having any kind of a clean break from Pakistan. Given Pakistan's economic reliance on Balochistan's resources and the Gwadar project there is little possibility that the state will let Balochistan separate without using force. A violent conflict would also open up the region to nearby sectarian militants like the so-called Islamic State. Violence within the region, and in particular related to the Baloch-Pakistan conflict has diminished in recent years, but still flares up on a regular basis. The region has also seen increased investment alongside the construction of universities and schools, but still lags so far behind even a basic standard that suggesting that social and economy prospects have clearly improved at all for the Baloch would be overstating what has been accomplished.

If Pakistan's federal government wants to see a stable federation with a prosperous economy and cooperative provincial governments, it will have to concede significant power to the provinces that make up its federation. Sustaining foreign interest and investment in the country will require a stable Balochistan, but this remains an unlikely outcome in the near future. Balochistan is key for the country's economic future and Pakistan will do well to keep the province in the country. From a state perspective, security forces have been ineffective at putting a definitive end to guerilla bombing campaigns, and changes through the democratic structures in the country have been more effective at disrupting the movement by dividing moderates from militants.

Zardari, the Bhuttos, and Nawaz Sharif were career politicians with multiple reigns in various seats of power. Part of the narrative around Imran Khan's campaign has been that he is a different breed of politician and represents a new wave in Pakistani politics. In particular he has called out the corruption that has plagued past regimes. So 
far Imran Khan has at least acknowledged the concerns of the Baloch, but so did most of his predecessors. For the sake of a stable Pakistan, Imran Khan would be wise to act quickly to shift powers in the federal structure while good faith remains in his relationship with key Baloch leaders. Yet it remains unlikely that the new government will be capable of granting enough control to the Baloch to ensure stability in the region.

To see a Balochistan that is entirely without militant separatists seems altogether unlikely. The Baloch tribes have held on to their tribal traditions, language and culture in a way that many ethnic groups across Pakistan have not. Many Baloch never wanted to be part of Pakistan and many of their successors seem to carry on those sentiments. Some will never be happy with any share of the resources or government control short of an autonomous independent Baloch state. It is likely that the fiercely separatist tribal elements will remain a mainstay of the Baloch peoples. For the militant Baloch, nothing short of powerfully armed foreign allies or a suddenly depleted Pakistan Army will allow them to take the region by force. For the moderates, Imran Khan's election may present a new opportunity for fresh power-sharing negotiations with the state, but their inability to mobilize local support means they will likely remain estranged from seats of power.

It bears reiterating that the presence of a strong Baloch ethnic identity does not itself guarantee the existence of a broad ethno-nationalist movement, whether militant or not. However the institutions of the Pakistani state remain pointed against giving up power. There is little in the new government's actions which suggest that Pakistan will break from its colonial legacy and satisfy the grievances of the Baloch with regard to resource and political control. Convincing the Baloch that their interests are best protected within the federation remains a herculean task beyond the capacity of the 
Pakistani state. The same pattern of conflict and violence that has existed since Pakistan's inception seems doomed to continue.

This project recommends broad courses of policy change directed toward a longstanding peace in the region, however notes that these are practically unachievable. The Pakistani state must wind down its military campaign against Baloch militants, pulling out its military presence and instead focusing solely on defending government structures and agents. Because ethnicity is constructed through a myth-symbol complex, military action by the Pakistani state needs to take on a visibly less anti-Baloch posture. Defeating the movement in military combat is essentially impossible without completely wiping out the Baloch population. At the same time Pakistan's military is a vital extension of the government, in particular because an inactive military always poses the threat of a coup over elected civilian rulers. As such a winding down of Pakistan's military campaign is very unlikely.

Tackling the underlying grievances of the Baloch is the most significant step the Pakistani state can take to alleviate the conflict. Visibly and publicly acknowledging the educational and economic woes of the province is only the first step. The major burden on the state is to invest significant amounts into education across the province. Education through the primary and secondary school system needs to be matched with better developed universities and practical and affordable training programs for Baloch to find gainful employment. At the same time Pakistan needs to set and uphold higher quotas for Baloch hiring and invest in the economy more broadly across Balochistan. Additionally alleviating the inequality in gas prices and supply will also undermine the popularity of militant Baloch targeting of gas installations and pipelines. Balochistan, however is not 
the only under-developed region in Pakistan. Considering what little political sway the Baloch hold over state level politics, Balochistan remains unlikely to see the kind of development that might help stabilize its relationship with the rest of the federation. Moreover, Baloch separatists continue to target what infrastructure the state tries to erect in the region, further disincentivizing the state from investing its limited funds into easily targeted projects.

Putting the province Balochistan in primary control of Gwadar Port might be a major step to decreasing violence in the region and surrounding the project and CPEC, however it remains a politically difficult prospect. Creating the opportunity for Baloch moderates to actually control and influence the development of key economic projects through legitimately attained elected positions might split them from militant Baloch elements as it has done before. However, Pakistan now has to maintain a happy relationship with China, and the state will want to maintain direct control over the port rather than handing it over to Baloch leaders who may have supported the targeting of Chinese workers.

From the Baloch perspective creating a unified political party is the most overwhelming challenge to attaining power through the state structures. Intraethnic rivalries continue to undermine Baloch participation in Pakistan's democracy. Moreover many of the long-standing grievances are widely supported throughout the Baloch movement. Creating one or two major Baloch parties that can appeal across tribal divides is necessary to see better outcomes through influence on government policy, but remains politically unlikely so long as the tribal structures keep internal Baloch rivalries strong. 
Given the economic value of Balochistan to Pakistan, achieving a separate state for Balochistan can only come at a military cost that the Baloch movement cannot afford. Militant Baloch have been effective at forcing the federal government to pay attention to Baloch grievances but the targeting of intraethnic rivals has undermined the movement more broadly. Unifying the militant elements with the moderates remains an unlikely possibility as separatist and pro-federation divides within the movement will remain.

International actors will likely see support for the Pakistani state and possibly some direct investment into Balochistan's economic and educational development as pathways to peace in the region. International actors remain interested in the region for their own benefits and Baloch movement leaders are quick to point that out, suggesting that investment projects will continue to be targeted by Baloch militants. While international actors hold a lot of possible power to benefit locals or influence the conflict, there is no indication that they will change their behaviour to act in the interests of the Baloch. Nor is there any indication that the Baloch are welcoming of any international voices besides those that support the Baloch position directly. As such international actors are unlikely to be able to effect peace in the region, though they will continue to have serious impacts on the movement's evolution.

\subsection{Conclusion}

By tracing the history of the modern Baloch movement and assessing the impact of Baloch identity, resources, politics, the postcolonial state, and international actors across local, state and international levels, this project has argued that the Baloch movement is a factious and amorphous movement, the evolution of which is often 
determined by factors external to local Baloch identity and politics. What is key to understanding the evolution of the movement is assessing how these factors intersect at the various levels. No single factor is wholly determinative. No particular tribe or leader is singularly representative.

This project adopts a unique approach to studying ethno-nationalist movements by arguing for a long-term approach that examines how key variables and actors at local, state and international levels converge and intersect to shape ethno-nationalist movements. This approach requires examining local and individual motivations and incentives within the ethno-nationalist movement as well as the social foundations particular to the ethnic group upon which the movement is built. State level variables include actors that represent the movement as well as those the movement orients itself in opposition to. Much of the field of study on ethno-nationalism focuses on the significance of state, and to a lesser extent local level actors, suggesting that these variables at these levels alone explain the evolution of ethno-nationalist movements at peak moments of violence. This project argues that integrating international factors and assessing how they affect state and local level variables, either directly or indirectly, is necessary to understand and fully explain how a movement evolves. In particular periods of relative stability or minimal violence are often overlooked in the study of ethno-nationalist conflict, while the support of international actors for either the state or the movement is taken to be of minimal effect. Through this project it is evident that assessing local, state, and international factors in tandem informs a more thorough understanding of an ethnonationalist movements by balancing the impact of a multitude of actors on a movement's evolution. 
From the beginning there was no clear consensus within any broad Baloch movement on ultimate goals or methods. What did exist was an idea that there was a group of people, the Baloch, who had historically inhabited a certain land, Balochistan. These people historically defended themselves from powerful neighbouring empires while maintaining a diffuse tribal power structure. Alongside other cultural practices, this is the fundamental myth-symbol complex that underlies the idea of Baloch ethnicity and in turn underlies the modern Baloch movement which continues to this day.

The recent conflict in Balochistan brings out the impact of a distinct colonial legacy on the Baloch peoples. Baloch tribes had been fighting for position and power in their region as far back into written history as there are mentions of 'Baloch' people. When the British Raj took power, particularly hierarchical structures within Balochistan and across South Asia resulted in a new political era, with regional governments established to maintain control over a large region from a singular central location. Partition shifted that central location from Britain to a new capital in Punjab, but many of the same power structures remained. There was less a sense that Baloch peoples could stand united with other South Asian ethnic groups against a powerful foreign nation. Now the powerful foreign entity was a Punjabi-dominated Pakistan. The Pakistani state became the antagonist and the modern Baloch ethno-nationalist movement began.

The Pakistani state's heavy-handed and power-centralizing tendencies have been fundamental in influencing the movement. In particular Pakistan was either unable or unwilling to integrate Baloch peoples into positions of power or representation, nor did the state create economic or educational opportunities for the Baloch. Thus the state fed the fear that Baloch peoples' existence and prosperity were directly threatened by 
Pakistan. This antagonistic relationship has yet to be resolved. State actors have been unable to concede enough to the moderates to satisfy them, let alone enough to quell the enduring distrust amongst the more separatist elements within the Baloch movement. The savvy guerilla tactics of the Baloch and the internationally supplied Pakistan Army have in turn made a clean military victory for either side an impossibility.

State actions, resource scarcity and political divisions keep the Baloch movement fuelled but divided to this day. However, international actors have more significantly impacted the movement in the past two decades. The Iran-Pakistan pipeline, Gwadar Port and CPEC are all major economic focuses for Pakistan and draws for international actors. The continued lack of representation of Baloch in local oversight or control of these projects has bolstered the case for a Baloch movement. International support also bolsters the movement particularly by supplying resources. Moreover as Baloch leaders have fled in exile from an oppressive state, the Baloch movement has pushed further into the international level, raising increased concerns of a spillover effect into Afghanistan and Iran where Baloch territory historically existed.

As these factors remain in flux and out of control of any single actor, be it the Pakistani state, a nexus of leaders within the Baloch movement, or a foreign actor like China, a clean resolution to the present conflict remains unlikely. The Baloch remain in a desperate socio-economic position. There remains a lack of reliable opportunity for the Baloch to rectify these grievances within Pakistan's federation. As a result the Baloch movement is as likely to continue on as it is to remain at least factionally militant.

This project has argued that assessing local, state and international variables is necessary to explain how an ethno-nationalist movement has evolved. In the case of the 
Baloch ethno-nationalist movement, looking at how these factors are presently entwined paints a picture of a conflict that remains far from being resolved. The most common cries from separatist, moderate and pro-government Baloch seem to call for many of the same things. Whether it is called modernizing or assimilation or anything else, it is evident what most Baloch peoples are after. They want fair economic and educational opportunity, as well as government structures that provide opportunity through employment and security rather than serving as symbols of a power-hungry non-Baloch elite. Baloch peoples will remain divided on whether the best means to such ends is through Pakistan or through a separate Baloch nation. Pakistan remains interested in the region for its economic value and will seek stability and peace insofar as it aids Pakistan's economic projects and keeps the Pakistani federation functioning. International actors will remain focused on what benefits their own interests, whether that is supporting the Baloch, Pakistan, or anyone else. Even if Pakistan's federal government concedes real power to Balochistan and manages to satisfy some of the major grievances of the Baloch, the conflict has evolved and sustained itself in such a way that it may only be a matter of time before Balochistan goes the way of Bangladesh. 


\section{Appendices}

\section{Appendix A}

Below is a list of primary media sources identified and interpreted through this project's qualitative content analysis methodology. 'Source' indicates the name of the media source. 'Level' indicates whether this project considers the media source to be a local, national, or international level media outlet. 'Notes' includes brief information on the ownership and origin of the media source.

\begin{tabular}{|l|l|l|}
\hline Source & Level & Notes \\
\hline Al Jazeera & International & $\begin{array}{l}\text { State-owned, independently operating news } \\
\text { agency from Qatar. }\end{array}$ \\
\hline $\begin{array}{l}\text { ANI (Asian News } \\
\text { International) }\end{array}$ & International & Privately owned news agency from India. \\
\hline Associated Press & International & $\begin{array}{l}\text { Non-profit cooperative news agency from } \\
\text { United States. }\end{array}$ \\
\hline Australian, The & International & $\begin{array}{l}\text { Privately owned news agency from Australia. } \\
\text { Owned by News Corp. }\end{array}$ \\
\hline $\begin{array}{l}\text { Balochistan Times, } \\
\text { The }\end{array}$ & Local & $\begin{array}{l}\text { Not-for-profit online magazine published from } \\
\text { Balochistan. }\end{array}$ \\
\hline Balochistan Voices & Local & $\begin{array}{l}\text { Not-for-profit, volunteer funded online } \\
\text { newspaper published from Balochistan. }\end{array}$ \\
\hline BBC Monitoring & International & $\begin{array}{l}\text { British Broadcasting Corporation (BBC) } \\
\text { division. Public corporation from United } \\
\text { Kingdom. }\end{array}$ \\
\hline BBC News & International & $\begin{array}{l}\text { British Broadcasting Corporation (BBC) } \\
\text { division. Public corporation from United } \\
\text { Kingdom. }\end{array}$ \\
\hline Business Recorder & National & $\begin{array}{l}\text { Privately owned Pakistani financial daily } \\
\text { newspaper. }\end{array}$ \\
\hline ExC News & International & $\begin{array}{l}\text { State-owned, independently operating public } \\
\text { broadcasting corporation from Canada. }\end{array}$ \\
\hline Daily Express & $\begin{array}{l}\text { Privately owned news agency from } \\
\text { Balochistan. }\end{array}$ \\
\hline
\end{tabular}




\begin{tabular}{|c|c|c|}
\hline Source & Level & Notes \\
\hline Daily Messenger & National & Privately owned news agency from Pakistan. \\
\hline Daily Times & National & $\begin{array}{l}\text { Privately owned news agency from Pakistan. } \\
\text { Owned by PPP member. }\end{array}$ \\
\hline Dawn & National & $\begin{array}{l}\text { Privately owned news agency from Karachi, } \\
\text { Pakistan. Started by Jinnah as Muslim League } \\
\text { newspaper. }\end{array}$ \\
\hline Diplomat, The & International & $\begin{array}{l}\text { Privately owned international news agency } \\
\text { from Tokyo, Japan. }\end{array}$ \\
\hline $\begin{array}{l}\text { Dow Jones } \\
\text { International }\end{array}$ & International & $\begin{array}{l}\text { American publishing firm owned by News } \\
\text { Corp. }\end{array}$ \\
\hline Energy Update & National & Privately owned news agency from Pakistan. \\
\hline Express Tribune, The & National & $\begin{array}{l}\text { Privately owned news agency from Karachi, } \\
\text { Pakistan. Internationally affiliated with The } \\
\text { New York Times. }\end{array}$ \\
\hline Financial Times & International & $\begin{array}{l}\text { Privately owned news agency from United } \\
\text { Kingdom. Owned by Nikkei, Inc. from Japan. }\end{array}$ \\
\hline Free Press Journal & International & $\begin{array}{l}\text { Privately owned news agency from Mumbai, } \\
\text { India. }\end{array}$ \\
\hline Frontier Post & National & $\begin{array}{l}\text { Privately owned news agency from Peshawar, } \\
\text { Pakistan. }\end{array}$ \\
\hline Frontier Star & National & Privately owned news agency from Pakistan. \\
\hline Guardian, The & International & $\begin{array}{l}\text { Privately owned news agency from United } \\
\text { Kingdom. }\end{array}$ \\
\hline $\begin{array}{l}\text { Global Insight Daily } \\
\text { Analysis }\end{array}$ & International & $\begin{array}{l}\text { Privately owned news agency from United } \\
\text { Kingdom. }\end{array}$ \\
\hline Hindu, The & International & Privately owned news agency from India. \\
\hline Hindustan Times & International & $\begin{array}{l}\text { Privately owned news agency from India. } \\
\text { Started by Mahatma Ghandi as Congress Party } \\
\text { newspaper. }\end{array}$ \\
\hline $\begin{array}{l}\text { IANS (Indo-Asian } \\
\text { News Service) }\end{array}$ & International & Privately owned news agency from India. \\
\hline Irish Examiner & International & Privately owned news agency from Ireland. \\
\hline Indian Express & International & Privately owned news agency from India. \\
\hline $\begin{array}{l}\text { India Today } \\
\text { Television }\end{array}$ & International & Privately owned news agency from Ireland. \\
\hline $\begin{array}{l}\text { Kashmir Monitor, } \\
\text { The }\end{array}$ & International & Privately owned news agency from Kashmir. \\
\hline Khaama Press & International & $\begin{array}{l}\text { Privately owned news agency from } \\
\text { Afghanistan. }\end{array}$ \\
\hline Kyodo News & International & $\begin{array}{l}\text { Non-profit cooperative news agency from } \\
\text { Japan. }\end{array}$ \\
\hline Logistic China & International & State-owned and run news agency from China. \\
\hline Meri News & International & $\begin{array}{l}\text { Privately owned public journalism news } \\
\text { agency from India. }\end{array}$ \\
\hline
\end{tabular}




\begin{tabular}{|c|c|c|}
\hline Source & Level & Notes \\
\hline Nation, The & National & Privately owned news agency from Pakistan. \\
\hline $\begin{array}{l}\text { National Herald } \\
\text { Tribune }\end{array}$ & National & Privately owned news agency from Pakistan. \\
\hline New York Times, The & International & $\begin{array}{l}\text { Privately owned news agency from United } \\
\text { States. }\end{array}$ \\
\hline $\begin{array}{l}\text { News International, } \\
\text { The }\end{array}$ & National & Privately owned news agency from Pakistan. \\
\hline $\begin{array}{l}\text { OANA (Organisation } \\
\text { of Asia-Pacific News } \\
\text { Agencies) }\end{array}$ & International & $\begin{array}{l}\text { Association of news agencies from Asia- } \\
\text { Pacific. Started as UNESCO initiative. }\end{array}$ \\
\hline $\begin{array}{l}\text { Pakistan \& Gulf } \\
\text { Economist }\end{array}$ & National & Privately owned news agency from Pakistan. \\
\hline $\begin{array}{l}\text { Pakistan Engineering } \\
\text { Review }\end{array}$ & National & Privately owned news agency from Pakistan. \\
\hline Pakistan Herald & National & $\begin{array}{l}\text { Privately owned news agency from Pakistan. } \\
\text { Part of Dawn Media Group, started by Jinnah. }\end{array}$ \\
\hline Plain Dealer, The & International & $\begin{array}{l}\text { Privately owned news agency from Cleveland, } \\
\text { United States. }\end{array}$ \\
\hline Pakistan Observer & National & Privately owned news agency from Pakistan. \\
\hline Pakistan Today & National & Privately owned news agency from Pakistan. \\
\hline Patriot, The & National & Privately owned news agency from Pakistan. \\
\hline $\begin{array}{l}\text { PPI (Pakistan Press } \\
\text { International) }\end{array}$ & National & Privately owned news agency from Pakistan. \\
\hline Press Trust of India & International & $\begin{array}{l}\text { Non-profit cooperative news agency from } \\
\text { India. }\end{array}$ \\
\hline Reuters News & International & $\begin{array}{l}\text { Privately owned international news agency. } \\
\text { Owned by Thomson Reuters from Canada. }\end{array}$ \\
\hline Statesmen, The & National & Privately owned news agency from Pakistan. \\
\hline Thai News Service & International & $\begin{array}{l}\text { Thai state-owned public broadcasting } \\
\text { organization. }\end{array}$ \\
\hline Times of India, The & International & Privately owned news agency from India. \\
\hline Today.AZ & International & Privately owned news agency from Azerbaijan. \\
\hline Toronto Star & International & Privately owned news agency from Canada. \\
\hline Trend News Agency & International & Privately owned news agency from Azerbaijan. \\
\hline United News of India & International & $\begin{array}{l}\text { Non-profit cooperative news agency from } \\
\text { India. }\end{array}$ \\
\hline UPI NewsTrack & International & $\begin{array}{l}\text { Privately owned news agency from United } \\
\text { States. }\end{array}$ \\
\hline $\begin{array}{l}\text { VOA (Voice of } \\
\text { America Press) }\end{array}$ & International & $\begin{array}{l}\text { State-owned and run news agency from United } \\
\text { States. }\end{array}$ \\
\hline $\begin{array}{l}\text { Washington Times, } \\
\text { The }\end{array}$ & International & $\begin{array}{l}\text { Privately owned news agency from United } \\
\text { States. }\end{array}$ \\
\hline Xinhua News Agency & International & State-owned and run news agency from China. \\
\hline
\end{tabular}




\section{Bibliography}

Aamir, Adnan. 2017. "No Major Change in Ethnic Balance of Balochistan: Census Data Analysis Proves." Balochistan Voices, September 2, 2017.

http://balochistanvoices.com/2017/09/no-major-change-ethnic-balance-balochistancensus-data-analysis-proves/.

Aamir, Adnan. 2018. "Balochistan Roundup 2017.” Daily Times, January 3, 2018. https://dailytimes.com.pk/172692/balochistan-roundup-2017/.

Abbot, Sebastian. 2013. "China poised to control Pakistani port vital for economic and perhaps military interests." Associated Press, February 1, 2013. Factiva.

Ahmad, Mahvish. 2013. "As Mengal lands, pressure builds to boycott elections." Dawn, March 25, 2013. Factiva.

Ahmed, Engr Mansoor. 2016. “Afghan Refugees.” The Express Tribune, May 30, 2016. Factiva.

Ahuvia, Aaron. 2001. "Traditional, Interpretive, and Reception Based Content Analyses: Improving the Ability of Content Analysis to Address Issues of Pragmatic and Theoretical Concern." Social Indicators Research 54, no. 2: 139-172. http://www.jstor.org/stable/27526933.

Akhtar, Nasreen. 2011. "Baluchistan Nationalist Movement and Unrest in Pakistan.' South Asian Survey 18, no. 1: 121-135. https://doi.org/10.1177/0971523112469528.

Al Jazeera. 2007. "Baluch leader killed in Afghanistan.” November 21, 2007. Factiva.

Al Jazeera. 2012. "Balochistan: Pakistan's other war.” January 9, 2012. Documentary, 47:28.

https://www.aljazeera.com/programmes/aljazeeraworld/2012/01/2012121372863878.htm $\underline{1 .}$

Ali, Asad. 2015. "Investment likely to trigger increased Baloch militant activity in Pakistan." Global Insight Daily Analysis, April 23, 2015. Factiva.

Ali, Muzaffar. 2014. "Gas crisis worsens in Punjab." Pakistan Observer, December 23, 2014. Factiva.

Alvi, Mumtaz. 2006. "PONM, Baloch Parties not to attend government-planned jirga." Business Recorder, October 28, 2006. Factiva.

ANI (Asian News International). 2006. "Baloch leader Mengal sees US, India-sponsored war for free Balochistan.” December 22, 2006. Factiva. 
ANI (Asian News International). 2008. "P Baloch leaders hope Zardari's election as Pak President will end their woes." September 7, 2009. Factiva.

ANI (Asian News International). 2009. "Pak Army chief's hands-off on politics creating new set of problems." March 29, 2009. Factiva.

ANI (Asian News International). 2012. "UN team probing missing persons issue says something is 'seriously wrong' in Balochistan." September 17, 2012. Factiva.

ANI (Asian News International). 2013. "Gwadar port handover to China breaches Pak Constitution, claim Baloch leaders.” March 4, 2013. Factiva.

ANI (Asian News International). 2016a. "China is Pakistan's strategic partner in killing Balochis: BNM.” September 22, 2016. Factiva.

ANI (Asian News International). 2016b. "CPEC'S western route to be accomplished by." January 6, 2016. Factiva.

ANI (Asian News International). 2017. “Concerns over CPEC security as violence spreads in Balochistan.” July 29, 2017. Factiva.

ANI (Asian News International). 2018a. "Baloch activists protest against CPEC." January 29, 2018. Factiva.

ANI (Asian News International). 2018b. "Exiled Baloch to protest Gwadar expansionist moves in London." January 24, 2018. Factiva.

Asif, Haseeb. 2015. "In conversation with Brahamdagh Bugti." Pakistan Herald, December 31, 2015. Factiva.

Aziz, Khalid. 2009. "India, Russia behind unrest in Balochistan.” The Nation, April 22, 2009. Factiva.

Bajpaee, Chietigj. 2008. "Gas Pipeline Bombed by Militants in South-West Pakistan." Global Insight Daily Analysis, April 28 2008. Factiva.

Baloch, Bari. 2009a. "Council of Independent Balochistan announced." The Nation, August 12, 2009. Factiva.

Baloch, Bari. 2009b. "Historic NFC Award inked.” The Nation, December 30, 2009. Factiva.

Baloch, Bari. 2011. "BNP-M leader shot dead.” The Nation, September 29, 2011. Factiva. 
Baloch, Bari. 2013. "Balochistan coalition parties threaten protest." The Nation, January 19, 2013. Factiva.

Baloch, Shezad. 2017. "Problems with census in Balochistan." The Express Tribune, March 30, 2017. https://tribune.com.pk/story/1370062/problems-census-balochistan/.

Balochistan Times, The. 2006. "Jirga Decisions Does Not Reflect Decision of Entire Balochistan.” September 26, 2006. Factiva.

Balochistan Times, The. 2007. "Balochistan Preserves Legacy of Tribal Traditions, Pirkani.” August 28, 2007. Factiva.

Balochistan Times, The. 2008. "Strike observed in Balochistan." September 10, 2008. Factiva.

Balochistan Times, The. 2009a. "210 persons killed in target killing in Quetta alone." March 18, 2009. Factiva.

Balochistan Times, The. 2009b. "Akhtar condemns killing of Mureed Bugti." June 20, 2009. Factiva.

Balochistan Times, The. 2009c. "Balochistan must be provided its due share of its resources: Raja.” November 12, 2009. Factiva.

Balochistan Times, The. 2009d. "FG implementing billions of rupees on public welfare projects." August 7, 2009. Factiva.

Balochistan Times, The. 2009e. "Jan Jamali Provincial autonomy matter be sorted out." July 10, 2009. Factiva.

Balochistan Times, The. 2009f. "Malik presents written evidence of interference of India, Russia and Afghanistan in Balochistan." April 23, 2009. Factiva.

Balochistan Times, The. 2009g. "Payment of Rs. 120 billion arrears on GDS, judicial inquiry into murder of Baloch leaders." November 24, 2009. Factiva.

Balochistan Times, The. 2009h. "Political leaders from Balochistan hail "Balochistan Package." December 10, 2009. Factiva.

Balochistan Times, The. 2009i. "Rallies held to condemn assassinations of three Baloch leaders." April 9, 2009. Factiva.

Balochistan Times, The. 2009j " Sardar Akhtar Balochs cannot be defeated." April 2, 2009. Factiva. 
Balochistan Times, The. 2009k. "Sindh backs Balochistan stance on NFC: Pir Mazhar." October 27, 2009. Factiva.

Balochistan Times, The. 2010a. "Proxy war being fought in Balochistan: Zehri." December 10, 2010. Factiva.

Balochistan Times, The. 2010b. "Lashkari terms bomb blast a link of great game of imperialism in Balochistan.” April 16, 2010. Factiva.

Balochistan Times, The. 2010c. "Sardar Attaullah says Establishment that deemed West Pakistan a burden busy in exacerbating Balochistan issue.” May 3, 2010. Factiva.

Balochistan Times, The. 2010d. "Target killing incidents an outcome of forced occupation of Balochistan: Hyrbiyar.” March 25, 2010. Factiva.

Balochistan Times, The. 2011. "NA body expresses concerns over non-implementation of Aaghaz-e-Haqooq-e-Balochistan.” January 10, 2011. Factiva.

Balochistan Times, The. 2012. "Quetta becomes most troubled district; 19 out of 30 Balochistan districts affected by violence.” June 9, 2012. Factiva.

Balochistan Times, The. 2013a. "Sardar Akhtar Mengal finally takes oath as Balochistan MPA." August 29, 2013. Factiva.

Balochistan Times, The. 2013b. "Zardari's resignation, immediate elections only way out.” January 17, 2013. Factiva.

Balochistan Times, The. 2014a. "Balochistan's development linked with Economic Corridor: Mamnoon.” December 27, 2014. Factiva.

Balochistan Times, The. 2014b. "Balochistan's protest against lawlessness, kidnappings." January 1, 2014. Factiva.

Balochistan Times, The. 2018. "Opponents of Gawadar port, CPEC enemies of Pakistan: Baloch leader.” April 7, 2018. Factiva.

BBC Monitoring. 2006a. "Pakistan court sentences Baluchistan activist to death for bomb blasts.” November 7, 2006. Factiva.

BBC Monitoring. 2006b. "Pro-Pakistan Baluch commander killed in bomb blast." December 21, 2006. Factiva.

BBC Monitoring. 2007a. "Gas pipeline blown up, security checkpost attacked in Pakistan's Baluchistan.” January 18, 2007. Factiva. 
BBC Monitoring. 2007b. "Pakistan: Railway service disrupted in a Baluchistan blast." March 10, 2007. Factiva.

BBC Monitoring. 2007c. "Pakistani militant commander surrenders along with 20 men." August 26, 2007. Factiva.

BBC Monitoring. 2007d. "Pakistani president in Baluchistan, asks militants to lay down arms.” May 10, 2007. Factiva.

BBC Monitoring. 2007e. "Pakistan provincial opposition MPs resign.” October 3, 2007. Factiva.

BBC Monitoring. 2008a. "Armed groups fighting for Pakistan's Baluchistan 'freedom"”. August 15, 2008. Factiva.

BBC Monitoring. 2008b. "Pakistan: Gas pipeline blown up in Baluchistan". February 25, 2008. Factiva.

BBC Monitoring. 2008c. "Newly formed Baluch nationalist parties' alliance announces poll boycott." February 14, 2008. Factiva.

BBC Monitoring. 2012. "Pakistan Pashtun party leaders condemn attacks in tribal area, Balochistan.” July 21, 2012. Factiva.

BBC Monitoring. 2013a. "Pakistan polling day marred by blasts, rigging charges." May 11, 2013. Factiva.

BBC Monitoring. 2013b. "Pakistan's Balochistan urges EU observers to monitor polls in province.” April 12, 2013. Factiva.

BBC News. 2004. "Pakistan car bomb kills Chinese." May 3, 2004. http://news.bbc.co.uk/2/hi/south asia/3679533.stm.

BBC News. 2006. "Lonely burial for Baloch leader.” September 1, 2006. http://news.bbc.co.uk/2/hi/5304594.stm.

Brubaker, Rogers and David Laitin. 1998. "Ethnic and Nationalist Violence." Annual Review of Sociology 24: 423-452. http://www.jstor.org/stable/223488.

Business Recorder. 2006. "The problem is the mindset.” December 18, 2006. Factiva.

Business Recorder. 2008. "Gazin Marri's meeting with Zardari.” September 19, 2008. Factiva.

Business Recorder. 2009. "Gwadar Port - a question of control.” April 5, 2009. Factiva. 
Business Recorder. 2013a. "CEC to persuade disgruntled Baloch to contest election." March 28, 2013. Factiva.

Business Recorder. 2013b. "Leaders of different parties from Loralai join.” March 16, 2013. Factiva.

Butt, Qaiser. 2012. "Balochistan crisis: We will never negotiate with govt, says BRP." The Express Tribune, October 21, 2012. Factiva.

Byman, Daniel. 1998. "The Logic of Ethnic Terrorism.” Studies in Conflict \& Terrorism 21, no. 2: 149-169. https://doi.org/10.1080/10576109808436060.

Casperson, Nina. 2008. "Intragroup Divisions in Ethnic Conflicts: From Popular Grievances to Power Struggles." Nationalism and Ethnic Politics 14, no. 2: 239-265. https://doi.org/10.1080/13537110801985070.

Chadda, Maya. 2009. "Imagining Alternative Ethnic Futures for Pakistan.” In Pakistan's Nuclear Future, edited by Henry Sokolski, 243-282. Carlisle: Strategic Studies Institute. https://www.jstor.org/stable/resrep12045

Chandio, Ramzan. 2013. "Mengal's BNP decides to go for polls." The Nation, March 27, 2013. Factiva.

Chatterji, Saubhadra. 2016. "Modi targets Pak rights abuse in Balochistan, PoK on Independence Day.” Hindustan Times, August 16, 2016. Factiva.

Cooper, Kenneth J. 1996. "Pakistan's Bhutto served long, not well." The Toronto Star, November 8, 1996. NewsBank.

Courier Mail, The. 1998. "Islamic Nuclear Age Dawns in Pakistan.” May 29, 1998. NewsBank.

Cunningham, Kathleen Gallagher. 2011. "Divide and Conquer or Divide and Concede: How Do States Respond to Internally Divided Separatists?" The American Political Science Review 105, no. 2: 275-297. https://www.jstor.org/stable/41495066.

Daily Balochistan Express. 2010. "Complete strike in major parts of Balochistan." November 21, 2010. Factiva.

Daily Balochistan Express. 2011. "Load shedding in Balochistan.” April 19, 2011. Factiva.

Daily Balochistan Express. 2013. "PML-N, PkMAP, NP to form coalition Govt in Balochistan.” May 19, 2013. Factiva. 
Daily Balochistan Express. 2016. "BNP never opposed development process, says Akhtar Mengal.” January 17, 2016. Factiva.

Daily Balochistan Express. 2018a. "Development without gas electricity." February 7, 2018. Factiva.

Daily Balochistan Express. 2018b. "Mengal not ready to budge an inch from 6 points." August 20, 2018. Factiva.

Daily Balochistan Express. 2018c. "People of Balocistan must be benefited from provincial resources: Akhtar Mengal.” July 12, 2018. Factiva.

Daily Messenger. 2013. "ECP announces results of 254 National Assembly seats." May 14, 2013. Factiva.

Daily Messenger. 2014. "Pakistan, Iran agree to give impetus to Pak-Iran Gas pipeline." May 11, 2014. Factiva.

Daily Messenger. 2015. "Balochistan not getting due rights; change in Gwadar-Kashgar rout not acceptable: Mengal." February 25, 2015. Factiva.

Daily Messenger. 2018. "BAP to form govt in Balochistan with coalition partners: Jam Kamal.” July 30, 2018. Factiva.

Dawn. 2005a. "Rape victim under pressure to keep mum." February 4, 2005. https://www.dawn.com/news/382104/rape-victim-under-pressure-to-keep-mum.

Dawn. 2005b. "Saboteurs will fail, says Musharraf: Rockets fired during president's Kohlu visit." December 15, 2005. https://www.dawn.com/news/170026.

Dawn. 2008. "Balochistan: Myth of development." November 2, 2008. https://www.dawn.com/news/845263.

Dawn. 2009. "Remembering Akbar Bugti.” August 26, 2009. https://www.dawn.com/news/841260.

Dawn. 2012. "BNP-M team meets Nawaz.” December 12, 2012. Factiva.

Dawn. 2013a. "A different reality: Kayani’s remarks on Balochistan." September 8, 2013. Factiva.

Dawn. 2013b. "BNP-M criticises Iran pipeline plan.” March 12, 2013. Factiva.

Dawn. 2013c. "Challenges faced by Dr Malik." June 15, 2013. Factiva. 
Dawn. 2016. "Govt making CPEC controversial by hiding things.” January 10, 2016. Factiva.

Dawn. 2018. "BNP chief criticises election results.” August 4, 2018. Factiva.

Dow Jones International. 2006a. "Thousand Protest In Pakistan Over Tribal Leader's Slaying." September 3, 2006. Factiva.

Dow Jones International. 2006b. "UPDATE: Bomb Kills 4 Near Bus Station In Pakistan Police." September 8, 2006. Factiva.

ECP (Election Commission of Pakistan). 2008. General Elections 2008 - Report. https://www.ecp.gov.pk/frmGenericPage.aspx?PageID=3054.

Express Tribune, The. 2013a. "Balochistan scene: Protests continue to rage against election results." May 15, 2013. Factiva.

Express Tribune, The. 2013b. “Challenges faced by Dr Malik.” July 1, 2013. Factiva.

Express Tribune, The. 2013c. "Exclusive interview: Dr Baloch speaks his mind on challenges." July 1, 2013. Factiva

Express Tribune, The. 2014. "Balochistan to receive big slice of Chinese funds." March 15, 2014. Factiva.

Express Tribune, The. 2015. "Gwadar's development: Rights of locals to be protected: Baloch." October 12, 2015. Factiva.

Express Tribune, The. 2016. "Balochistan reconciliation: 625 insurgents surrendered in six months." February 8, 2016. Factiva.

Express Tribune, The. 2017. "Illegal aliens: NADRA blocked 88,000 CNICs in Balochistan.” February 12, 2015. https://ribune.com.pk/story/836898/illegal-aliensnadra-blocked-88000-cnics-in-balochistan-national/.

Fazl-e-Haider, Syed. 2011. "Gas Production in Balochistan.” Pakistan \& Gulf Economist, January 16, 2011. Factiva.

Fazl-e-Haider, Syed. 2012. "Balochistan: The Investment-Starved Province." Pakistan \& Gulf Economist, June 3, 2012. Factiva.

Fazl-e-Haider, Syed. 2014. "Alluring Foreing Investment in Balochistan: Challenges and Issues." Pakistan \& Gulf Economist, February 16, 2014. Factiva.

Fazl-e-Haider, Syed. 2015. "Balochistan needs a Microfinance Development Strategy to Alleviate Poverty.” Pakistan \& Gulf Economist, September 27, 2015. Factiva. 
Fazl-e-Haider, Syed. 2018. "Gwadar Port Tie-Up Trade Facilities Across Balochistan." Pakistan \& Gulf Economist, July 8, 2018. Factiva.

Fearon, James D. and David D. Laitin. 2003. "Ethnicity, Insurgency, and Civil War." The American Political Science Review 97, no. 1: 75-90. http://www.jstor.org/stable/3118222.

Flare. 2015. "Another Good News Land handed over to China for economic zone in Gwadar.” December 31, 2015. Factiva.

Free Press Journal. 2012. "Gwadar port to be taken over by Chinese co.” August 30, 2012. Factiva.

Free Press Journal. 2013. "Fifteen more die in violence on poll eve.” May 11, 2013. Factiva.

Frontier Post. 2013a. “JI, JUI-F targeted in Balochistan.” April 28, 2013. Factiva.

Frontier Post. 2013b. "Malik elected CM Balochistan unopposed Says plan available for talks with disgruntled brothers." June 9, 2013. Factiva.

Frontier Post. 2013c. "Raisani decides to boycott polls.” April 7, 2013. Factiva.

Frontier Star. 2009. "Three more banks torched in Balochistan on second day of strike." April 10, 2009. Factiva.

Frontier Star. 2014. "Balochistan kept backward under a conspiracy: Siraj ul Haq." November 4, 2014. Factiva.

Frontier Star. 2015a. "Balochistan still seeking basic amentias: Mengal.” September 19, 2015. Factiva.

Frontier Star. 2015b. "BNP-M demands handing over Gwadar Port to provincial govt." September 7, 2015. Factiva.

Frontier Star. 2016. "Protest rallies held in Balochistan against Indian PM's statement-Participants chanted anti-India Slogans.” August 19, 2016. Factiva.

Gall, Carlotta. 2006. "Tribal Leader's Killing Incites Riots in Pakistan.” The New York Times, August 28, 2006.

https://www.nytimes.com/2006/08/28/world/asia/28pakistan.html.

Gall, Carlotta, and Ruhullah Khapalwak. 2017. "Taliban Leader Feared Pakistan Before He Was Killed.” The New York Times, August 9, 2017. 
https://www.nytimes.com/2017/08/09/world/asia/taliban-leader-feared-pakistan-beforehe-was-killed.html.

Galpin, Richard. 1999. "Fury at Pakistan Opening to US.” The Guardian, May 3, 1999. NewsBank.

Gishkori, Zahid. 2012. "Over 400 killed in Balochistan sectarian violence: Report." The Express Tribune, July 1, 2012. Factiva.

Gishkori, Zahid. 2018. "Balochistan witnesses over 1,860 terror incidents in seven years." The News International, July 16, 2018. Factiva.

Goldenberg, Suzanne. 1997. "50 years as free nation leave little to celebrate." The Washington Times, August 16, 1997. NewsBank.

Grant, Jeremy. 1996. "Pakistan: On the border of violence." Financial Times, April 9, 1996. NewsBank.

Gurr, Ted Robert. 2017. "Observations on the Study of Ethnic Conflict." Ethnopolitics 16, no. 1: 34-40. https://doi.org/10.1080/17449057.2016.1235345.

Haider, Zeeshan. 2009. "Pakistan accuses India, Afghans, of Baluch meddling." Reuters News, April 22, 2009.

Heaton, Janet. 2011. Reworking Qualitative Data. London: Sage Publications. http://doi.org/10.4135/9781849209878.

Hindustan Times, The. 2006a. "Baloch chiefs to approach International Court of Justice." September 22, 2006. Factiva.

Hindustan Times, The. 2006b. "Grand 'jirga' of tribal chiefs to discuss Balochistan." September 21, 2006. Factiva.

Hindustan Times, The. 2006c. "Pakistan has given Baluchs a hero." August 29, 2006. Factiva.

Hindustan Times, The. 2006d. "Rockets, explosions rock Balochistan province." September 14, 2006. Factiva.

Hindustan Times, The. 2012. “A case study of Balochistan.” June 8, 2012. Factiva.

Hindustan Times, The. 2014. "Thousands of people leave Balochistan." November 4, 2014. Factiva.

Hussain, Jam Sajjad. 2007. "Musharraf abrogated Constitution, derailed judiciary." The Nation, November 3, 2007. Factiva. 
IANS (Indo-Asian News Service). 2006. "Man killed in Pakistan bomb blast.” December 2, 2006. Factiva.

IANS (Indo-Asian News Service). 2007a. "400 armed tribesmen surrender in Pakistan." February 8, 2007. Factiva.

IANS (Indo-Asian News Service). 2007b. "Rocket attack blacks out Gwadar port city in Pakistan." February 3, 2007. Factiva.

IANS (Indo-Asian News Service). 2009. "Pakistan accuses India of backing Baloch terror group." April 22, 2009. Factiva.

Inayatullah. 2012. "Mengal mission what next?” The Nation, October 6, 2012. Factiva.

Indian Express. 2018. "Pakistan denies reports of Chinese military base near Gwadar port." January 4, 2018. Factiva.

Iqbal, Anwar. 1993. "Thirty-three die in Pakistan political, religious.” UPI NewsTrack, August 31, 1993. NewsBank.

Iqbal, Anwar. 1998. "Hijackers Want No Nuclear Explosion.” UPI NewsTrack, May 24, 1998. NewsBank.

Irish Examiner, The. 2007. "Pakistan: 13 killed in courtroom bombing." February 17, 2007. Factiva.

Jackson, Robert Victor. 1975. South Asia Crisis: India, Pakistan and Bangladesh: A political and historical analysis of the 1971 war. New York: Praeger.

Jaffrelot, Christophe. 2014. The Pakistan Paradox: Instability and Resilience. Translated by Cynthia Schoch. Oxford: Oxford University Press.

Jalal, Ayesha. 1995. Democracy and Authoritarianism in South Asia: a Comparative and Historical Perspective. Cambridge: Cambridge University Press.

Jalal, Ayesha. 2014. The Struggle for Pakistan: A Muslim Homeland and Global Politics. London: The Belknap Press of Harvard University Press.

Jamali, Dera Murad. 2008. "Taj Jamali unsatisfied with reconciliation committee.” PPI (Pakistan Press International), May 6, 2008. Factiva.

Kalyvas, Stathis N. 2003. "The Ontology of "Political Violence": Action and Identity in Civil Wars." Perspectives on Politics 1, no. 3: 475-494.

http://www.jstor.org/stable/3688707. 
Kashani, Hammal. 2017. "Pakistan's Census: A Baloch Perspective.” The Diplomat, February 3, 2017. https://thediplomat.com/2017/02/pakistans-census-a-balochperspective/.

Kashmir Monitor, The. 2014. "Militants blow up two gas pipelines.” January 13, 2014. Factiva.

Kaufman, Stuart J. 2006. "Symbolic Politics or Rational Choice? Testing Theories of Extreme Ethnic Violence.” International Security. 30, no. 4: 45-86.

https://muse.jhu.edu/article/196920.

Kazmi, S. Kamal Hayder. 2012. "Gwadar Port and its Infrastructure.” Pakistan \& Gulf Economist, November 4, 2012. Factiva.

Khalid, Sadia. 2015. “Economic corridor.” The Express Tribune, May 18, 2015. Factiva.

Khaama Press. 2017. "Imran Khan's PTI links anti-Pak campaign in Switzerland to Afghanistan, India." September 24, 2017. Factiva.

Khan, Adeel. 2005. Politics of Identity: Ethnic Nationalism and the State in Pakistan. London: Sage Publications.

Khan, Azam. 2014. "NA Proceedings: Balochistan exodus figures contested." The Express Tribune, December 4, 2014. Factiva.

Khan, Omer Farooq. 2013. "Militants raid Gwadar port in Pak, 10 killed." The Times of India, July 28, 2013. Factiva.

Kifner, John. 1998. "Pakistan Completes New Nuclear Bomb Test.” The Plain Dealer, May 31, 1998. NewsBank.

Kim, Inhwa, and Jasna Kuljis. 2010. "Applying Content Analysis to Web-based Content." Journal of Computing and Information Technology 18, no. 4: 369-375. http://doi.org/10.2498/cit.1001924.

Kindred, Alahna. 2018. "Pakistan election 2018 news: Bomb kills 29 in Quetta as 105MILLION voters head to polls.” Daily Express, July 25, 2018. Factiva.

Kohari, Alizeh. 2013. "Elections 2013: survey indicates close contest." Dawn, February 8, 2013. https://www.dawn.com/news/784655/elections-2013-survey-indicates-closecontest.

Kohli, S.C. 2016. "China concerned over security of its citizens working in Pakistan's Gwadar port city." Meri News, February 2, 2016. Factiva. 
Kristof, Nicholas D. 2005. “Another Face of Terror.” The New York Times, July 31, 2005. https://www.nytimes.com/2005/07/31/opinion/another-face-of-terror.html.

Kydd, Andrew and Barbara Walter. 2002. "The Politics of Extremist Violence." International Organization 56, no. 2: 263-296. http://www.jstor.org/stable/3078606.

Kyodo News. 2007. "11 including judge killed in explosion in Quetta." February 17, 2007. Factiva.

Le Vine, Steve. 1991. "Pakistan Opium Crop Booming.” The Washington Times, January 1, 1991. NewsBank.

Logistic China. 2009. "Pakistani president praises China support for port project." December 11, 2009. Factiva.

Loudon, Bruce. 2007. "Pakistan catches suicide bombers." The Australian, February 19, 2007. Factiva.

Lyon, Alistair. 1995. "Mohajirs blame crackdown for fomenting hatred." The Washington Times, October 7, 1995. NewsBank.

M2 Presswire. 2016. "China has stationed its People's Liberation Army in the Gwadar area and wants to permanently use our ports for military purposes, said Hyrbyair Marri." October 4, 2016. Factiva.

Malik, Maria. 2013. Balochistan Conundrum: The Real Perspective. Islamabad: Poorab Academy.

Mazari, Shehryar. 2005. "The world according to the Baloch." BBC News, February 8 , 2005. http://news.bbc.co.uk/2/hi/south asia/4243129.stm.

McKenna, Terence. 2006. "Land, Gold and Women Part 2: The case of Shazia Khalid." CBC News, February 28, 2006. https://www.cbc.ca/news2/background/pakistan/mckenna pakistan-pt2.html.

Meer, Shah. 2016. "Balochistan and the Killing of Akbar Bugti: 10 Years Later." The Diplomat, August 26, 2016. https://thediplomat.com/2016/08/balochistan-and-the-killingof-akbar-bugti-10-years-later/.

Mezzera, Marco, and Safiya Aftab. 2009. "Country Case Study: Pakistan: Pakistan StateSociety Analysis." Initiative for Peacebuilding / Clingendael. https://www.clingendael.org/sites/default/files/pdfs/20090300 cru pakistan mezzera.pdf

Mills, Elizabeth. 2006. "Restaurant Bomb Attack Injures 18 in South-West Pakistan." Global Insight Daily Analysis, September 11, 2006. Factiva. 
Monitoring Desk. 2008. "Proof about Raw involvement in tribal, Balochistan areas provided to US.” Business Recorder, August 2, 2008. Factiva.

Nasir, Ayesha Abdul. 2016. “Balochistan energy crisis.” Dawn, June 28, 2016. Factiva. Nation, The. 2010. "Balochistan Budget.” June 22, 2010. Factiva.

Nation, The. 2018a. "BAP to form govt in Balochistan: Kamal.” July 29, 2018. Factiva. Nation, The. 2018b. "PTI, BNP-Mengal sign six point agreement." August 10, 2018. Factiva.

Nation, The. 2018c. “Quetta bleeds on Election Day.” July 26, 2018. Factiva.

National Herald Tribune. 2013. "Balochistan govt announces stipend for those who would voluntarily quit rebellion.” January 30, 2013. Factiva.

News International, The. 2015. "Law and order situation improving in Balochistan." October 4, 2015. Factiva.

News International, The. 2018. "Alleged rigging in elections: Grand opposition stages protest outside ECP.” August 9, 2018. Factiva.

Notezai, Muhammad Akbar. 2017. "Disturbing Trends.” Dawn, September 21, 2017. https://www.dawn.com/news/1359077.

OANA (Organisation of Asia-Pacific News Agencies). 2006. "Two Baloch leaders named in bomb blast case." November 24, 2006. Factiva.

Oil Daily. 2009. “Eni Expands in Pakistan.” March 19, 2009. Factiva.

Pakistan Engineering Review. 2013. "Gwadar links get priority.” December 31, 2013. Factiva.

Pakistan Observer. 2013a. "Balochistan elections: Situation takes new turn." April 12, 2013. Factiva.

Pakistan Observer. 2013b. "BNP-M threatens boycotting elections." April 5, 2013. Factiva.

Pakistan Observer. 2013c. "Govt renews dialogue offer to end insurgency." October 23, 2013. Factiva.

Pakistan Observer. 2015. "Govt in Ambiguity Over Balochistan Dialogue: Mengal." November 28, 2015. Factiva. 
Pakistan Observer. 2016a. "Brahamdagh Bugti is a traitor: Zehri." August 19, 2016. Factiva.

Pakistan Observer. 2016b. "Brahamdagh, others booked for backing Modi comments." August 23, 2016. Factiva.

Pakistan Observer. 2018. "Imran's PTI gets 115 NA seats in final tally.” July 29, 2018. Factiva.

Pakistan Today. 2013. “The PML-N reconciliatory stance.” May 16, 2013. Factiva.

Pakistan Today. 2014. "CM says it again: Sit-ins causing huge loss to economy." November 24, 2014. Factiva.

Pakistan Today. 2015. "Iran to supply 2,000 MW power to Balochistan." Janury 13, 2015. Factiva.

Pakistan Today. 2018a. "Gas consumers in Sindh, Balochistan to receive Rs18bn from SSGCL in 5 years.” May 23, 2018. Factiva.

Pakistan Today. 2018b. "Govt committed to development and progress of Balochistan : PM Abbasi." March 8, 2018. Factiva.

Patriot, The. 2014. "Gas pipeline blown up in Dera Bugti." January 28, 2014. Factiva.

Patriot, The. 2015. "775,821 new gas connections given to domestic consumers in two years: Ministry.” November 28, 2015. Factiva.

PBS (Pakistan Bureau of Statistics). 1998. Population Census 1998. http://www.pbscensus.gov.pk/.

PBS (Pakistan Bureau of Statistics). 2017. 2017 Provisional Census Results. http://www.pbscensus.gov.pk/sites/default/files/DISTRICT WISE CENSUS RESULTS CENSUS 2017.pdf.

Pennington, Matthew. 2006. "Pakistan belatedly approves relief effort for children displaced by tribal conflict." Associated Press Newswires, December 22, 2006. Factiva.

Philip, Snehesh Alex. 2013. "Pro-government elder, 6 others gunned down in Pakistan." Press Trust of India, October 29, 2013. Factiva.

Phullan, Shakeel. 2018. "Gwadar's issues and CPEC." The Nation, August 22, 2018. Factiva. 
PIPS (Pakistan Institute for Peace Studies). 2012. Conflict and Insecurity in Balochistan. Lahore: Narratives.

PPI (Pakistan Press International). 2006a. “HUB-Jam speaks.” October 24, 2006. Factiva. PPI (Pakistan Press International). 2006b. "Secretary General BNM speaks." November 4, 2006. Factiva.

PPI (Pakistan Press International). 2007a. "Politics: PPP calls for stopping constitutional subversion.” January 28, 2007. Factiva.

PPI (Pakistan Press International). 2007b. "Politics: PPP calls for stopping constitutional subversion." January 28, 2007. Factiva.

PPI (Pakistan Press International). 2007c. "PPP (BB condemns murder of Balaach Marri)." November 22, 2007. Factiva.

PPI (Pakistan Press International). 2007d. "PPP not to vote for Musharraf re-election: Amin Fahim.” June 14, 2007. Factiva.

PPI (Pakistan Press International). 2007e. "PPP stands with people of Balochistan: BB." January 17, 2007. Factiva.

PPI (Pakistan Press International). 2007f. "Provisional Constitutional Order inevitable for countrys interest - Chief Minister Balochistan Jam.” November 4, 2007. Factiva.

PPI (Pakistan Press International). 2008a. "22, 000 FC troops deployed in Balochistan for elections." February 17, 2008. Factiva.

PPI (Pakistan Press International). 2008b. "Nawab Raisani only candidate for Chief Minister post in Balochistan.” April 10, 2008. Factiva.

PPI (Pakistan Press International). 2008c. "Political profile of new Governor Balochistan Nawab Zulfiqar Ali Magsi.” March 5, 2008. Factiva.

PPI (Pakistan Press International). 2008d. "PPP demands end to military operation in Balochistan, release of political prisoners." February 25, 2008. Factiva.

PPI (Pakistan Press International). 2008e. "Rulers continuing Musharraf policies in Balochistan.” August 24, 2008. Factiva.

PPI (Pakistan Press International). 2008f. "Very low turn out in Balochistan." February 19, 2008. Factiva.

PPI (Pakistan Press International). 2008g. "Yar Muhammad Rind speaks." October 3, 2008. Factiva. 
PPI (Pakistan Press International). 2009a. "Fauzia points out Sardari System as main reason for backwardness of Balochistan.” April 23, 2009. Factiva.

PPI (Pakistan Press International). 2009b. “Jam Yusuf elected President PML Balochistan unopposed.” July 9, 2009. Factiva.

PPI (Pakistan Press International). 2010a. "Baloch Armed Defence Army accepts responsibility." March 5, 2010. Factiva.

PPI (Pakistan Press International). 2010b. "Barech Tribal Jirga held.” June 20, 2010. Factiva.

PPI (Pakistan Press International). 2012. "Sardar's also involved in forced disappearances: Ansar Burney.” July 13, 2012. Factiva.

PPI (Pakistan Press International). 2013a. "70 Baloch fighters laid down arms: Balochistan.” February 18, 2013. Factiva.

PPI (Pakistan Press International). 2013b. "BNP announces demonstrations, shutter down.” June 30 2013. Factiva.

PPI (Pakistan Press International). 2013c. “Governor welcomes commencement of PakIran Gas pipeline project.” March 11, 2013. Factiva.

PTI (Press Trust of India). 2006. "Pak demands Afghan extradite Bugti's grandson." November 3, 2006. Factiva.

PTI (Press Trust of India). 2007a. “Akbar Bugti's son becomes new party chief.” May 14, 2007. Factiva.

PTI (Press Trust of India). 2007b. "Blast kills 2 tribal elders, 3 injured in Pakistan." March 7, 2007. Factiva.

PTI (Press Trust of India). 2007c. "Pak govt supporting Islamist groups to suppress Balochs." October 23, 2007. Factiva.

PTI (Press Trust of India). 2008. "Forces to remain in tribal areas till order is restored." May 5, 2008. Factiva.

PTI (Press Trust of India). 2016a. "Baloch leader Brahamdagh Bugti approaches India for asylum.” September 20, 2016. Factiva.

PTI (Press Trust of India). 2016b. "World Bank cancels USD 100 million loan for Pakistan.” December 8, 2016. Factiva. 
Pur, Manjhi. 2012. "Politics of corruption and commission will be defeated." The Balochistan Times, December 17, 2012. Factiva.

Rashid, Ahmed. 2005. "Explosive mix in Pakistan's gas province." BBC News, February 4, 2005. http://news.bbc.co.uk/2/hi/south asia/4195933.stm.

Reddy, B. Muralidhar. 2005. "Pakistan Army chopper fired at." The Hindu, December 16, 2005. Factiva.

Reuters. 2007. "New Pakistan Gwadar port to open in March.” February 3, 2007. Factiva.

Rind, Hina Mahgul. 2015. "Balochistan govt yet to make land available for free trade zone.” The News International, January 7, 2015. Factiva.

Rizwan, Tariq. 2016. "Peace Returns To Balochistan.” National Herald Tribune, March 18, 2016. Factiva.

Saeedi, Tariq Ahmed. 2010. "Energy - Industries To Face Gas Shortage." Pakistan \& Gulf Economist, October 31, 2010. Factiva.

Saleem, Muhammad. 2010. "Baloch leaders call on Nawaz." Business Recorder, April 1, 2010. Factiva.

Shah, Syed Ali. 2018. "Court indicts Gazeen Marri in Justice Nawaz Marri murder case." Dawn, February 28, 2018. https://www.dawn.com/news/1392292.

Shahid, Saleem. 2006a. "Bugti killed in operation: Six officers among 21 security personnel dead.” Dawn, August 27, 2006. https://www.dawn.com/news/207726.

Shahid, Saleem. 2006b. "Grand jirga in Kalat decides to move ICJ." Dawn, September 22, 2006. https://www.dawn.com/news/211514.

Shahid, Saleem. 2008. "Pakistan PM invites Baluchistan province to join gas pipeline as stakeholder." BBC Monitoring, May 13, 2008. Factiva.

Shahid, Saleem. 2013a. "BNP-M boycotts Balochistan PA's session.” Dawn, June 2, 2013. Factiva.

Shahid, Saleem. 2013b. "JUI-F bags highest number of seats; PkMAP, NP big winners." Dawn, December

Shahid, Saleem. 2013c. "Tribal feud claims seven lives in Balochistan." Dawn, November 27, 2013. Factiva.

Shahid, Saleem. 2017. "Balochistan Jirga wants foreigners out of census count." Dawn, February 19, 2017. Factiva. 
Shahryar, Bahawal. 2009. "Developing Gwadar Port." Pakistan Observer, September 7, 2009. Factiva.

Sharma, Smita. 2016. "Baloch Nation welcomes PM Modi's Balochistan comment, hopes US, Europe join to hold Pak Accountable." India Today Television, August 16, 2016.

Factiva.

Shaukat, Sajjad. 2015. "Why Baloch Leader Opposes CPEC?” National Herald Tribune, July 1, 2015. Factiva.

Shawl, Ishfaqullah. 2008. "Rehman rules out talks with 'extremists'." Business Recorder, June 4, 2008. Factiva.

Siddiqi, Farhan Hanif. 2012. The Politics of Ethnicity in Pakistan: The Baloch, Sindhi and Mohajir ethnic movements. London: Routledge.

Siddiqui, Sabena. 2017. "Comparing Gwadar and Chabahar Ports: rivals or 'sisters'?” Asia Times, December 7, 2017. http:/www.atimes.com/comparing-gwadar-chabaharport/.

Siyal, Nazir. 2009. "Provinces to get rights without fight: Zardari." The Nation, June 21, 2009. Factiva.

Soofi, Ahmer. 2014. "Ownership of Oil and Gas.” Energy Update, February 28, 2014. Factiva.

Staniland, Paul. 2012. "Organizing Insurgency: Networks, Resources, and Rebellion in South Asia.” International Security 37, no. 1: 142-177. https://muse.jhu.edu/article/480539.

Statesmen, The. 2010. "Balochistan killings.” August 31, 2010. Factiva.

Statesmen, The. 2015. "Extremism being promoted in Balochistan to weaken nationalists: Mengal.” January 16, 2015. Factiva.

Subramanian, Nirupama. 2006. "Baloch leaders for pre-1947 status." The Hindu, September 23, 2006. Factiva.

Surendra, Shanna Dietz. 2009. "Explaining Social Mobilization in Pakistan: A Comparative Case Study of Baluchistan and Azad Kashmir." Comparative Studies of South Asia, Africa and the Middle East 29, no. 2: 246-258. https://muse.jhu.edu/article/315169.

Swami, Praveen. 2006. "The war in Balochistan: a backgrounder." The Hindu, January 12, 2006. Factiva. 
Thai News Service. 2013. "Pakistan: Pakistani Government Yields to Quetta Protesters." January 15, 2013. Factiva.

Today.AZ. 2010. “Iran, Pakistan sign gas pipeline deal.” March 17, 2010. Factiva.

Tolson, Mike. 1998. "Pakistan Unsheathes its Nuclear Saber." Houston Chronicle, May 29, 1998. NewsBank.

Trend News Agency. 2008a. "Rebel leader released in Pakistan.” May 9, 2008. Factiva.

Trend News Agency. 2008b. "38 killed as Pakistani forces clamp down on rebels in Balochistan.” July 21, 2008. Factiva.

United News of India. 2017. "Pakistan population soars to 208-million.” August 26, 2017. Factiva.

UPI NewsTrack. 1994. “Tribal clash in Pakistan kills 9.” August 27, 1994. NewsBank.

Upstream. 2011. "OGDCL targets output expansion drive from five major projects." August 19, 2011. Factiva.

Ur-Rahman, Javaid. 2013. "PPP, allies boycott presidential vote.” The Nation, July 27, 2013. Factiva.

Varma, K. J. M. 2006. "Musharraf blames 'foreign hand' behind Balochistan crisis." OANA (Organisation of Asia-Pacific News Agencies), September 5, 2006. Factiva.

Vayu Aerospace \& Defence Review. 2015. "China's Gwadar and India's Chabahar port projects." May 31, 2015. Factiva.

VOA (Voice of America Press). 2007. "Pakistani President Claims Victory Over Baluch Separatists." May 10, 2007. Factiva.

Washington Times, The. 1997. "Sharif apparent winner in Pakistan." February 4, 1997. NewsBank.

Wasim, Amir and Sher Baz Khan. 2005. "Baluchistan situation alarming." The Tribune, March 23, 2005. https://www.tribuneindia.com/2005/20050325/index.htm.

White, Marilyn Domas, and Emily E. Marsh. 2006. "Content Analysis: A Flexible Methodology." Library Trends 55, no. 1: 22-45. https://doi.org/10.1353/lib.2006.0053.

Xinhua News Agency. 2006a. "1 killed, 12 injured in bomb blast in SW Pakistan." October 28, 2006. Factiva. 
Xinhua News Agency. 2006b. "Car bomb blast in Pakistan kills 3, injures 5: police." November 2, 2006. Factiva.

Xinhua News Agency. 2007. "Two commanders, 400 armed tribesmen surrender to Pakistani gov't.” February 8, 2007. Factiva.

Yousafzai, Gul. 2007. "Islamists suspected of Pakistan blast; toll to 16." Reuters News, February 18, 2007. Factiva.

Yousafzai, Gul. 2008. "Provincial govt reaches out to rebels in SW Pakistan." Reuters News, April 9, 2008. Factiva.

Yousafzai, Gul. 2009a. "Pakistan's reform package "peanuts" - Baluch rebels." Reuters News, November 25, 2009. Factiva.

Yousafzai, Gul. 2009b. "Two killed in protests in Pakistan's Baluchistan." Reuters News, April 9, 2009. Factiva.

Zafar, Mohammad. 2012. "Polite refusal: Mengal declines to become interim." The Express Tribune, September 15, 2012. Factiva.

Zafar, Mohammad. 2016. "Gwadar, Chabahar to be made 'sister port cities'." The Express Tribune, January 12, 2016. Factiva.

Zafar, Mohammad. 2018. "Province's welfare more important than ministries: Mengal." The Express Tribune, August 11 2018. Factiva.

Zaman, Fahim. 2017. "Census 2017: How can flawed results have any credibility." Dawn, September 19, 2017. https://www.dawn.com/news/1358516.

Zia, Amir. 1993. "Pakistanis Unfazed by Military Rule." Associated Press News Service, October 13, 1999. NewsBank.

Zia, Sajid. 2015. "Sale of Gwadar land to any country to be resisted." The Nation, November 24, 2015. Factiva.

Zulfiqar, Shahzada. 2008. "4 soldiers among 6 dead in Balochistan violence." The Nation, February 17, 2008. Factiva. 